\title{
ESTRATÉGIAS DE COMERCIALIZAÇÃO DE SOJA - FRENTE AO RISCO DE MERCADO
}

\author{
JOÃO BATISTA PADILHA JÚNIOR \\ Engenheiro Agrônomo
}

Orientador: Prof. Dr. José Vicente Caixeta Filho

Dissertação apresentada à Escola Superior de Agricultura "Luiz de Queiroz", da Universidade de São Paulo, para obtenção do título de Mestre em Ciências, Área de Concentração: Economia Aplicada.

P I R A C I C A B A

Estado de São Paulo - Brasil

Junho - 1997 
Dados Internacionais de Catalogação na Publicação (CIP)

DIVISÃO DE BIBLIOTECA E DOCUMENTAÇÃO - Campus "Luiz de Queiroz"/USP

Padilha Júnior, João Batista

Estratégias de comercializacão de soja frente ao risco de mercado / João Batista Padilha Júnior. - Piracicaba, 1997.

117 p. : il.

Dissertação (mestrado) - Escola Superior de Agricultura Luiz de Queiroz, 1997. Bibliografia.

1. Comercialização 2. Mercado 3. Risco economico 4. Soja I. Título

CDD 338.13334 


\title{
ESTRATÉGIAS DE COMERCIALIZAÇÃO DE SOJA FRENTE AO RISCO DE MERCADO
}

\author{
JOÃO BATISTA PADILHA JÚNIOR
}

Aprovada em: 01.09.1997

Comissão julgadora:

Prof. Dr. José Vicente Caixeta Filho

ESALQ/USP

Prof. Dr. Fernando Curi Peres

ESALQ/USP

Prof. Dr. Derli Dossa

EMBRAPA/CNPf

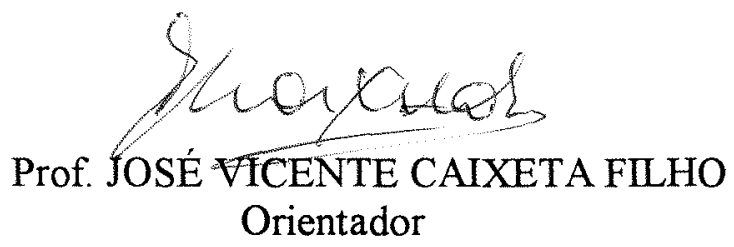


Ao meu pai em memória.

Para minha mãe, Larysa. 


\section{AGRADECIMENTOS}

Ao Professor Dr. José Vicente Caixeta Filho, pela sua valiosa orientação, paciência e dedicação oferecidas durante o desenvolvimento desta dissertação.

Ao Professor Dr. Judas Tadeu Grassi Mendes, pela sua amizade, orientação, apoio e encorajamento para a realização deste mestrado.

Ao Professor Dr. Pedro Valentim Marques, pela sua orientação inicial durante o desenvolvimento das disciplinas.

Ao Professor Dr. Fernando Curi Peres, pelos comentários e sugestões ao modelo teórico utilizado neste trabalho.

Ao Professor Dr. Derli Dossa, pelo apoio e comentários que ajudaram a engrandecer este trabalho.

Aos demais professores e funcionários do Departamento de Economia e Sociologia Rural da ESALQ pela amizade e apoio no transcorrer do curso.

Aos amigos do Departamento de Economia Rural e Extensão da Universidade Federal do Paraná, pelo apoio durante o desenvolvimento da dissertação.

Ao CNPq (Conselho Nacional de Desenvolvimento Científico e Tecnológico), pelo suporte financeiro, sem o qual este mestrado não teria ocorrido.

A minha mãe Larysa, pelo incansável apoio e encorajamento recebidos durante o transcorrer do mestrado.

A Helena, pela paciência, companhia e compreensão durante o desenvolvimento desta dissertação. 


\section{SUMÁRIO}

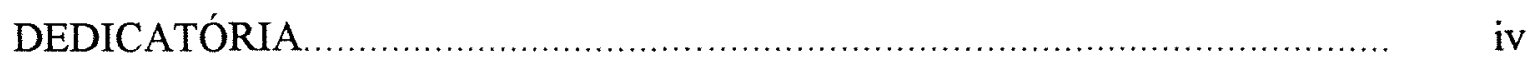

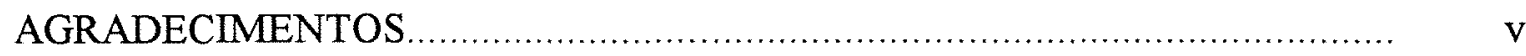

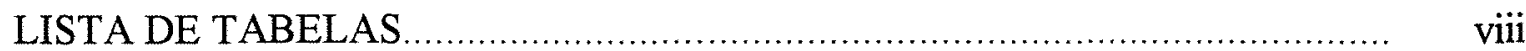

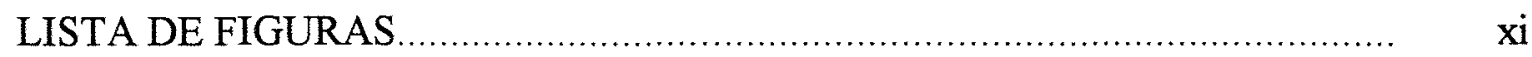

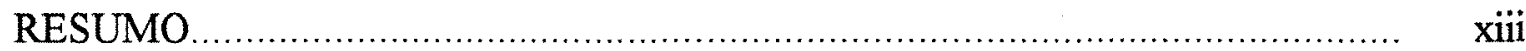

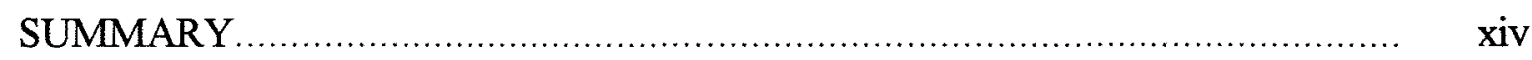

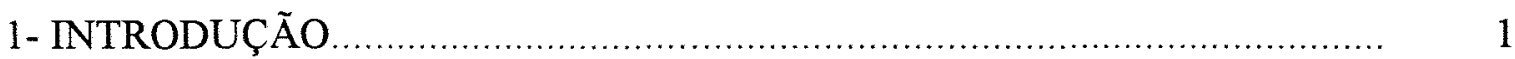

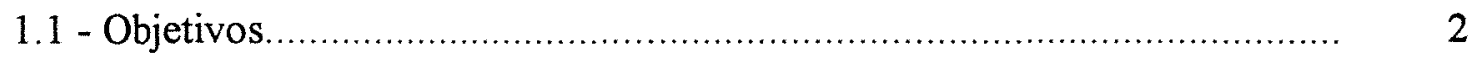

2 - ASPECTOS ECONÔMICOS DA SOJA. ........................................... 4

2.1 - Evolução da Cultura da soja no Brasil ........................................ 8

2.2 - Características da comercialização da soja........................................ 13

2.3 - Evolução dos Preços no Período de 1980-96 ...................................... 14

2.4 - A Sojicultura no Estado do Paraná................................................. 16

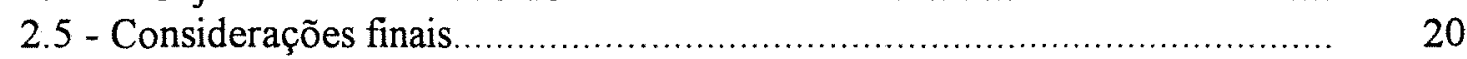

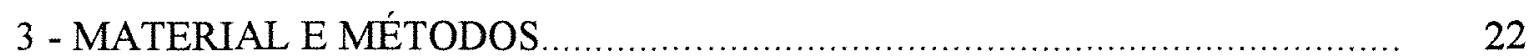

3.1 - O Risco nas Decisões de Mercado....................................................... 22

3.2 - Alternativas de Comercialização .......................................................... 25

a) Contrato de Produção Antes da Colheita................................... 25

b) Venda na Época da Colheita.................................................... 26

c) Estocagem do Produto para Especulação.................................... 28

d) Vendas com Preço Autorizado................................................. 28

e) Vendas com Preço a Fixar...................................................... 28

f) Vendas em Comum ou "Pooling" .......................................... 29

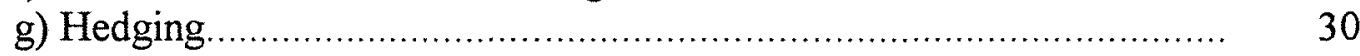

3.3 - Modelos de Decisão envolvendo risco ............................................ 30

3.4 - Modelo Matemático proposto....................................................... 45

3.5 - Especificação dos Dados................................................................ 49

3.6 - Considerações finais ................................................................ 54 


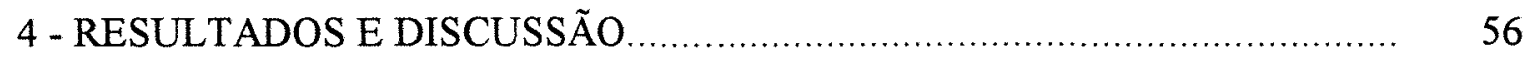

4.1 - Análises e Soluções do Modelo Básico ................................................. 58

4.2 - Efeitos da Aversão de Risco sobre a Renda Líquida Esperada............... 65

4.3 - A Fronteira Eficiente da Média-Variância............................................. 67

4.4 - Simulações do Modelo Básico .................................................................. 69

4.4.1 - O Efeito da Redução na Taxa de Juros................................... 69

4.4.2 - O Efeito da Elevação na Taxa de Juros .................................. $\quad 75$

4.4.3 - O Efeito da Elevação no Custo de Armazenagem..................... $\quad 80$

4.4.4 - O Efeito da Redução no Custo de Armazenagem...................... $\quad 86$

4.4.5 - O Efeito da Elevação no Custo de Transporte.......................... 92

4.4.6 - O Efeito da Redução no Custo de Transporte.......................... 97

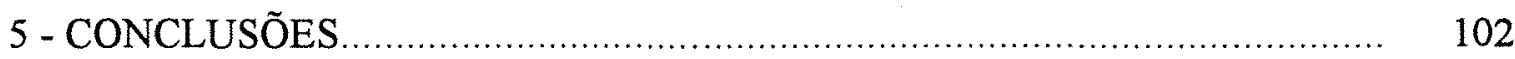

REFERÊNCIAS BIBLIOGRÁFICAS_........................................................ 105

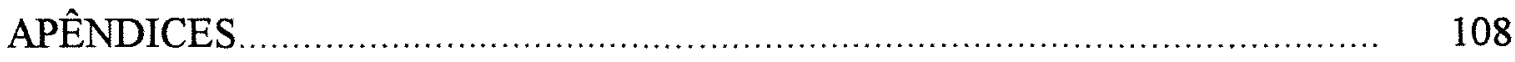

1. A Função Quadrática de Utilidade .............................................................. 109

2. Novas Alternativas de Comercialização de soja ........................................... 110

3. A Matriz de Variância-Covariância do Modelo Básico ..................................... 113

4. A Matriz do Modelo Básico .................................................................... 114

5. A Rotina do Modelo Básico Utilizada pelo GAMS ......................................... 115 


\section{LISTA DE TABELAS}

Tabela Página

1. Evolução da produção mundial de soja segundo os principais produtores, período de 1990-95.

2. Comparativo de competitividade da soja em grão entre países e regiões do Brasil (US\$/t) - estimativa para 1995-96.

3. Comparação de custos de transporte da soja em diferentes regiões até Roterdã (Holanda), Brasil, 1996 (US\$/t).

4. Soja, área plantada, produtividade e produção no Brasil, 1966-96..........

5. Soja, evolução da produção por Estados, Brasil, 1985-96, em mil t ........ 12

6. Comparação da evolução do PIB (\%) por setores no Paraná, 1970-94.... 16

7. Brasil, capacidade estática dos armazéns cadastrados, Região Sul, 1995 (em mil toneladas)

8. Produção mundial de óleos e gorduras, 1970-95, em milhões de $t$

9. Capacidade nominal de processamento instalada no PR para obtenção de óleo vegetal - 1994.

10. Indice sazonal de preços recebidos pelos produtores de soja no Estado do Paraná no período de 1980-95.

11. Variação percentual (\%) da Renda Líquida Média Esperada e do Risco Associado em relação à solução ótima obtida pela programação linear para as Estratégias de Comercialização de soja - Modelo Básico - PR $1980-95$

12. Percentagem de venda de soja, por estratégia de comercialização, segundo coeficiente de aversão ao risco - Modelo Básico - PR - 1980-95.

13. Percentagem de venda de soja, discriminação mensal, segundo coeficiente de aversão ao risco - Modelo Básico - PR - 1980-95. 
14. Renda líquida média esperada, coeficiente de aversão ao risco, risco associado às estratégias de comercialização de soja e elasticidade Risco -Renda - Modelo Básico - PR - 1980-95

15. Percentagem de venda de soja, por estratégia de comercialização, segundo coeficiente de aversão ao risco - Simulação da redução da taxa de juros - PR - 1980-95.

16. Percentagem de venda de soja, discriminação mensal, segundo coeficiente de aversão ao risco - Simulação de redução da taxa de juros - PR - 198095.

17. Renda líquida média esperada, coeficiente de aversão ao risco, risco associado às estratégias de comercialização de soja e elasticidade Risco -Renda - Simulação de redução na taxa de juros - PR - 1980-95.

18. Percentagem de venda de soja, por estratégia de comercialização, segundo coeficiente de aversão ao risco - Simulação da elevação da taxa de juros - PR - 1980-95.

19. Percentagem de venda de soja, discriminação mensal, segundo coeficiente de aversão ao risco - Simulação da elevação da taxa de juros - PR - 1980 $-95$

20. Renda líquida média esperada, coeficiente de aversão ao risco, risco associado às estratégias de comercialização de soja e elasticidade RiscoRenda - Simulação da elevação da taxa de juros - PR - 1980-95

21. Percentagem de venda de soja, por estratégia de comercialização, segundo coeficiente de aversão ao risco - Simulação da elevação no custo de armazenagem - PR - 1980-95.

22. Percentagem de venda de soja, discriminação mensal, segundo coeficiente de aversão ao risco - Simulação da elevação no custo de armazenagem PR - 1980-95.

23. Renda líquida média esperada, coeficiente de aversão ao risco, risco associado às estratégias de comercialização de soja e elasticidade RiscoRenda - Simulação da elevação no custo de armazenagem - PR - 1980-95... 
Tabela Página

24. Percentagem de venda de soja, por estratégia de comercialização, segundo coeficiente de aversão ao risco - Simulação da redução no custo de armazenagem - PR - 1980-95

25. Percentagem de venda de soja, discriminação mensal, segundo coeficiente de aversão ao risco - Simulação da redução no custo de armazenagem - PR $-1980-95$

26. Renda líquida média esperada, coeficiente de aversão ao risco, risco associado às estratégias de comercialização de soja e elasticidade RiscoRenda - Simulação da redução no custo de armazenagem - PR - 1980-95..

27. Percentagem de venda de soja, por estratégia de comercialização segundo coeficiente de aversão ao risco - Simulação da elevação no custo de transporte - PR - 1980-95

28. Percentagem de venda de soja, discriminação mensal, segundo coeficiente de aversão ao risco - Simulação da elevação no custo de transporte - PR 1980-95

29. Renda líquida média esperada, coeficiente de aversão ao risco, risco associado às estratégias de comercialização de soja e elasticidade RiscoRenda - Simulação da elevação no custo de transporte - PR - 1980-95.

30. Percentagem de venda de soja, por estratégia de comercialização segundo coeficiente de aversão ao risco - Simulação da redução no custo de transporte - PR - 1980-95

31. Percentagem de venda de soja, discriminação mensal, segundo coeficiente de aversão ao risco - Simulação da redução no custo de transporte - PR 1980-95.

32. Renda líquida média esperada, coeficiente de aversão ao risco, risco associado às estratégias de comercialização de soja e elasticidade RiscoRenda - Simulação da redução no custo de transporte - PR - 1980-95. 


\section{LISTA DE FIGURAS}

Figura

Página

1. Soja, evolução da produção e área plantada, Brasil, 1970-96 .................. 9

2. Distribuição da área plantada de soja por Estados, Brasil, 1995-96........ 12

3. Índice sazonal de preços recebidos pelos produtores de soja do Estado do

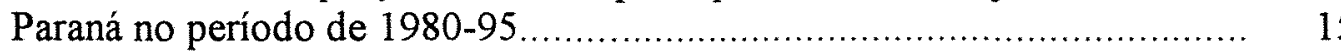

4. Preços pagos aos produtores de soja, Brasil, 1980-96..................... 16

5. Curvas de utilidade e o comportamento individual ............................ 33

6. Espaço E-V da fronteira eficiente e utilidade..................................... 44

7. Estratégias de comercialização de soja no espaço da Média-Variância, Modelo Básico - PR - 1980-95.

8. Percentagem de venda de soja segundo meses selecionados e coeficientes de aversão ao risco - Modelo Básico - PR - 1980-95

9. Efeitos do coeficiente de aversão ao risco sobre a decisão de comercialização de soja - Modelo Básico - PR - 1980-95.

10. Efeitos do coeficiente de aversão ao risco sobre a renda líquida média esperada pelos produtores - Modelo Básico - PR, 1980-95.

11. Fronteira eficiente da Média-Variância para o Modelo Básico - PR, 1980 -95 .

12. Fronteira eficiente da Média-Variância para a Simulação da redução da taxa de juros - PR - 1980-95.

13. Fronteira eficiente da Média-Variância para a Simulação da elevação da taxa de juros - PR - 1980-95.

14. Fronteira eficiente da Média-Variância para a Simulação da elevação do custo de armazenagem - PR - 1980-95. 
15. Fronteira eficiente da Média-Variância para a Simulação da redução do custo de armazenagem - PR - 1980-95

16. Fronteira eficiente da Média-Variância para a Simulação da elevação no custo de transporte - PR - 1980-95.

17. Fronteira eficiente da Média-Variância para a Simulação da redução no custo de transporte - PR - 1980-95. 


\title{
ESTRATÉGIAS DE COMERCIALIZAÇÃO DE SOJA \\ FRENTE AO RISCO DE MERCADO
}

\author{
Autor: João Batista Padilha Júnior \\ Orientador: Prof. Dr. José Vicente Caixeta Filho
}

\section{RESUMO}

A soja lidera a pauta de exportações brasileiras, mostrando a importância que a cultura apresenta como grande geradora de divisas para o nosso país e de renda aos produtores rurais.

Entretanto, anualmente na época da comercialização da produção, os sojicultores defrontam-se com o dilema de "quanto", "quando" e "como" vender sua produção, devido às condições de risco e de incerteza do mercado brasileiro.

O problema foi equacionado por um conjunto de estratégias de comercialização que foi otimizado por programação quadrática. Desta forma, obteve-se planos eficientes de comercialização da produção, maximizando a renda esperada pelo produtor para determinado nível de risco.

A solução mais eficiente, obtida dentre todas as alternativas, indicou que os produtores deveriam armazenar a produção na época da colheita com posterior venda mensal fracionada. A composição de vendas ocorreria em abril, setembro, outubro, novembro e dezembro, onde $96,4 \%$ da comercialização concentraria-se nos últimos quatro meses do ano. 


\title{
SOYBEANS MARKETING STRATEGIES \\ UNDER MARKET RISK
}

\author{
Author: João Batista Padilha Júnior \\ Adviser: Prof. Dr. José Vicente Caixeta Filho
}

\section{SUMMARY}

Soybean is one of the most important commodities in the Brazilian international trade. This commodity generates a large amount of foreign revenue to the country and significant income to the rural producers.

However, each year, at the time of soybean marketing, producers face a dilemma: "when", "how much" and "how" to sell their production, due to the uncertainties and risk of the market.

This problem was modeled through a set of marketing strategies which were optimized via the use of quadratic programming. The most efficient marketing plan was obtained by maximizing the expected farmer's income for a given level of risk.

The solution obtained from all tested alternatives indicated that the farmers should store their production and follow a monthly sale strategy.

The best alternative would be salling in April, September, October, November and December, being $96,4 \%$ of the production sold in the last four months. 


\section{1 - INTRODUÇÃo}

O desafio da produção agrícola é uma tarefa árdua, onde os empresários rurais enfrentam em todas as etapas do processo produtivo as cargas inerentes do risco e incerteza desta atividade. Esta falta de controle que a agricultura apresenta é proveniente da imprevisibilidade de certos fatores, tais como os ambientais (incontroláveis), e os de mercado (via oscilações de preço), os quais afetam diretamente os retornos esperados pêlos produtores rurais. Vencida a etapa da produção, novamente o produtor rural defronta-se com outra situação de incerteza, que seria a de "quanto", "quando", e "como" vender a sua produção, dado que no processo de seleção de atividades de venda não se pode considerar apenas aquelas alternativas que maximizam o lucro mas também aquelas que proporcionem um menor risco associado.

Tome-se como exemplo o lucro de um produtor rural em um mercado sob concorrência perfeita. Admitindo-se que o processo produtivo já tenha se encerrado, a única maneira de se obter um lucro maior seria através da negociação do preço. Admitindo-se que o produtor é um tomador de preços, e que apresenta um comportamento típico de aversão ao risco, faz-se necessária a busca de um melhor preço, que só será possível através da escolha das melhores estratégias de comercialização da produção. Isto justifica o objetivo central deste estudo, que consiste na busca e determinação das melhores estratégias de venda da produção, com as quais os produtores de soja, cooperativas e outras instituições possam assegurar uma eficiente comercialização de seus produtos. 


\section{1 - Objetivos}

O objetivo central deste estudo consiste basicamente na busca e determinação das melhores estratégias de comercialização da produção de soja, para que produtores, cooperativas ou outros órgãos ligados ao setor possam assegurar uma venda eficiente desse produto, na época certa e da maneira mais apropriada possível.

Especificamente, os objetivos são:

a) Selecionar portfolios eficientes, ou seja, buscar dentre uma série de estratégias pré-estabelecidas, qual ou quais constituem a opção mais eficiente para o produtor de soja, no sentido de maximizar a renda com certo nível de risco, ou minimizar o risco para certos níveis de renda, com base nos preços praticados para a soja entre 1980 e 1995;

b) Determinação do coeficiente de elasticidade risco-renda a partir do modelo básico formulado e das simulações realizadas;

c) Orientar os produtores e suas cooperativas sobre a época e a maneira mais apropriada de comercializar a produção de soja;

d) Parametrizar algumas das variáveis exógenas utilizadas no modelo básico, com o intuito de avaliar a sensibilidade do modelo a alterações das condições de contorno do mesmo.

O estudo em questão está organizado em cinco capítulos. No próximo capítulo faz-se uma breve análise dos aspectos econômicos da cultura da soja no contexto nacional e internacional, da evolução da cultura da soja no Brasil e em particular no Estado do Paraná, das características de sua comercialização e da evolução dos preços no período 1980-95, destacando-se os aspectos fundamentais que motivaram e nortearam o trabalho. No capítulo três faz-se uma revisão bibliográfica sobre o risco nas decisões de 
mercado, descrevendo-se as alternativas de comercialização de soja disponíveis aos produtores. São também definidas as pressuposições sobre o risco nas decisões de mercado, formulando-se um modelo matemático de programação quadrática para a determinação das estratégias de comercialização de soja frente ao risco de mercado, o qual fundamenta e gera os dados para a análise realizada no capítulo quatro. Finalmente, no capitulo cinco, são apresentadas as principais conclusões decorrentes deste estudo. 


\section{2 - ASPECTOS ECONÔMICOS DA SOJA}

De acordo com a OCEPAR (1996) analisando-se o comportamento do complexo soja no último quinquênio (1990-95), observa-se que os Estados Unidos, Brasil, Argentina e China juntos, foram responsáveis por cerca de $87 \%$ da produção mundial de soja.

O maior produtor mundial do complexo soja são os Estados Unidos, que responde por praticamente $50 \%$ do total produzido. O Brasil vem logo em seguida ocupando o segundo lugar com cerca de $18 \%$ do total mundial do quinquênio, seguido pela Argentina e China, cada um com uma participação média de $10 \%$, conforme pode ser observado na Tabela 1.

Tabela 1 - Evolução da produção mundial de soja e participação dos principais produtores, período 1990-95, em milhões de toneladas.

\begin{tabular}{cccccccc}
\hline Países & $1990-91$ & $91-92$ & $92-93$ & $93-94$ & $94-95$ & $\begin{array}{c}\text { média } \\
90-95\end{array}$ & $\begin{array}{c}\text { Participação } \\
1990-95(\%)\end{array}$ \\
\hline EUA & 52,4 & 54,1 & 59,6 & 49,2 & 69,9 & 57,0 & 49 \\
Brasil & 15,8 & 19,2 & 22,3 & 24,7 & 25,5 & 21,5 & 18 \\
Argentina & 11,5 & 11,2 & 11,2 & 12,3 & 12,7 & 11,8 & 10 \\
China & 11,0 & 9,7 & 10,3 & 13,0 & 13,8 & 11,6 & 10 \\
Demais Países & 13,4 & 13,2 & 13,7 & 18,3 & 16,5 & 15,0 & 13 \\
\hline Total Mundial & 104,1 & 107,4 & 117,1 & 117,5 & 138,1 & 116,9 & 100 \\
\hline Fonte: USDA & & & & & & &
\end{tabular}

Ainda conforme a OCEPAR (1996), nas safras agrícolas de 1994 e 1995, observou-se que a produção norte-americana sofreu significativas oscilações, devido as condições climáticas adversas naquele país, e isso provocou grandes variações nos preços internacionais, devido a importância que a oferta americana de soja possui no cenário mundial, com reflexo direto e positivo para a renda dos sojicultores brasileiros e sobre o desempenho de nossas exportações. 
Segundo a AGRIANUAL (1996) o complexo soja brasileiro ocupa atualmente uma área de cerca de 12 milhões de hectares e produz entre 25 a 26 milhões de toneladas por safra, esta "commodity" hoje responde como a segunda maior lavoura do país, perdendo apenas para o milho. O complexo soja gera anualmente algo entre US\$ 3,5 bilhões a US\$ 5 bilhões de divisas, mantendo este complexo na liderança absoluta da pauta de exportações brasileira e contribuindo sobremaneira para equilibrar a balança comercial deficitária. Os volumes exportados no último ano agrícola (94-95) foram de 10,3 milhões de toneladas de farelo de soja, 4,9 milhões de toneladas de soja-grão e 1,5 milhões de toneladas de óleo de soja.

Além disso, os subprodutos da moagem da soja grão, tal como o farelo de soja (a fonte mais barata de proteína vegetal) permitiram que a avicultura e a suinocultura nacionais experimentassem um grande incremento em seu desenvolvimento.

A soja, dentro deste contexto pró-desenvolvimento econômico observado no período 1980-95, tornou-se uma das mais importantes fontes tanto de renda do setor agrícola como de divisas para o país.

O preço da "commodity" soja no mercado interno é fortemente influenciado tanto pelas cotações da Bolsa de Chicago, como também pelo prêmio pago sobre essas cotações no Porto do país exportador.

O prêmio é uma espécie de ágio ou deságio que se agrega às cotações, variando de acordo com: qualidade do produto; condições de transporte marítimo e de financiamento; subsídios; oferta e procura propriamente ditas. Tais aspectos serão fundamentais, naturalmente, para a definição da competitividade do país.

Conforme cita Vasconcelos (1994), existem ainda diferenças significativas entre os países com relação aos custos da soja, no tocante a fretes, despesas portuárias e impostos.

O custo total destes itens somados representa para o Brasil, de acordo com Vasconcelos (1994), 27\% da receita obtida pelo exportador, se a soja for produzida na Região Sul e $38 \%$ se for produzido no Centro-Oeste. 
$\mathrm{Na}$ Argentina, esses mesmos custos representam $31 \%$ da receita. Considerando a redução de impostos de exportação, a participação desses custos na receita dos exportadores argentinos cai para 23\%, enquanto nos Estados Unidos esses impostos não ultrapassam $8 \%$ da receita obtida pêlos exportadores. Um maior detalhamento dessa composição de custos pode ser observado na Tabela 2 .

Tabela 2 - Comparativo de competitividade da soja em grão entre países e regiões do Brasil (US\$/t) - estimativas para 1995/96.

\begin{tabular}{|c|c|c|c|c|}
\hline \multirow{2}{*}{$\begin{array}{c}\text { País/região } \\
\text { Receita/item de custo }\end{array}$} & \multicolumn{2}{|c|}{ BRASIL } & \multirow[b]{2}{*}{ EUA } & \multirow[b]{2}{*}{ Argentina } \\
\hline & Sul & Centro-Oeste & & \\
\hline A - Cotação F.O.B. porto ${ }^{2}$ & 225,6 & 225,6 & 225,6 & 225,6 \\
\hline B - Frete ao porto ${ }^{\mathrm{b}}$ & 20 & 45 & 15 & 14 \\
\hline C - Despesas portuárias & 10 & 10 & 3 & 5 \\
\hline D - Impostos Incidentes ${ }^{c}$ & 30 & 30 & - & $51 \backslash 33^{c}$ \\
\hline E - Custos Totais $(B+C+D)$ & 60 & 85 & 18 & $70 / 52^{c}$ \\
\hline F - Receita Líquida $(\mathrm{A}-(\mathrm{B}+\mathrm{C}+\mathrm{D}))$ & 165,6 & 140,6 & 207,6 & $155 \backslash 174^{\mathrm{c}}$ \\
\hline G - Receita Líquida F/A (\%) & 73 & 62 & 92 & $69 \backslash 77^{\mathrm{c}}$ \\
\hline
\end{tabular}
(a) Base $=$ US\$ 6,14/bushell, preço médio do periodo 1979/95, segundo SEAB-PR.
(b) Segundo a OCEPAR.
(c) $\mathrm{Na}$ Argentina o imposto foi reduzido a $23 \%$ para soja em grão e $15 \%$ para farelo e óleo.

Com relação ao transporte da soja, destaque-se que tal como para a maioria dos produtos agrícolas brasileiros está basicamente concentrado na modalidade rodoviária, o que encarece de sobremaneira os custos de comercialização. Segundo o GEIPOT (1994), a matriz de transportes brasileira está composta pêlos seguintes modais: $55,9 \%$ rodoviária, $20,6 \%$ ferroviária, $14,4 \%$ hidroviária e $0,3 \%$ aeroviária, sendo que para o transporte da soja e seus subprodutos no Brasil tem-se a seguinte matriz de transporte: $70 \%$ da produção é movimentada pelo modal rodoviário, $26 \%$ pelo ferroviário e $4 \%$ pelo hidroviário.

Jank (1990) e Larson (1989) apontam que os custos das despesas portuárias e frete são ainda os principais fatores que prejudicam e atrasam o aumento da competitividade da soja brasileira no exterior. O custo de despesa portuária no Brasil é três vezes maior do que o americano e duas vezes maior do que o argentino. 
De acordo com a Manchete Rural (1996) quanto ao custo de frete ao porto no Brasil, o mesmo hoje vem apresentando diferenças regionais bastante significativas, devido ao surgimento de novas vias de escoamento no Centro-Norte do país. Na Região Sul, o custo de frete ao porto apresenta-se cerca de 30\% superior ao americano e $40 \%$ superior ao argentino, enquanto que no Centro-Oeste é cerca de três vezes maior que o americano e argentino, quando a produção é entregue nos portos do Sul/Sudeste do país. Todavia se a mesma soja que é produzida no Centro-Oeste for exportada pelo porto da Ponta da Madeira, no Maranhão, o frete ao porto, as despesas portuárias e o transporte marítimo ficam em média cerca de $9,0 \%$ mais baratos que os valores praticados na Região Sul, tornando assim a soja do Centro-Norte brasileiro mais competitiva no mercado internacional. O custo de transporte da soja da Região Centro-Norte (BalsasMA) até o Porto de Roterdã (Holanda), é de US\$37,30/t, enquanto que das regiões de Diamantino (MT) eleva-se para US\$ 70,00/t e em Cascavel (PR) em torno de US\$ 41,00/t. Uma sumarização mais detalhada desses valores é apresentada na Tabela 3.

Tabela 3 - Comparação de custos de transporte da soja em diferentes regiões até Roterdã (Holanda), Brasil, 1996, (em US\$/t).

\begin{tabular}{lcccc}
\hline \multicolumn{1}{c}{ Item de custo } & A & B & C & D \\
\hline Rodoviário & 42,00 & 10,75 & 4,56 & 15,00 \\
Ferroviário & - & 8,15 & 9,5 & - \\
Despesas Portuárias & 11,00 & 4,40 & 4,40 & 9,00 \\
Subtotal & 53,00 & 23,30 & 18,46 & 24,00 \\
Marítimo & 17,00 & 14,00 & 14,00 & 17,00 \\
\hline Total & 70,00 & 37,30 & 32,46 & 41,00 \\
\hline Fonte: Confederação Nacional da Agricultura. & & & \\
A - Diamantino (MT), 2.015 Km de Santos (SP). & & & \\
B - Balsas (MA), 1.000 Km de Ponta da Madeira (MA). & \\
C- Paragominas (PA), via Rodo-Ferroviária, 870 Km de Ponta da Madeira (MA). & & \\
D-Cascavel (PR), 600 Km de Paranaguá. &
\end{tabular}

Ainda conforme a Manchete Rural (1996) este aumento de competitividade alcançado pela Região Centro-Norte do país, em grande parte, deve-se à entrada em operação do primeiro trecho da Ferrovia Norte-Sul e sua integração com a já existente Estrada de Ferro Carajás, que integra este corredor multimodal de transporte. 
O corredor Noroeste, que está sendo implantado, futuramente trará beneficios desta grandeza ao Estado de Mato Grosso. Além destes, existem projetos de instalação de mais sete empreendimentos: Corredor Norte, Saída para o Caribe, Corredor Nordeste, Corredor Centro-Leste, Corredor Paraná-Paraguai, Corredor Cuiabá-Santarém e Corredor Mercosul.

De acordo com Branco (1996), com relação aos impostos incidentes, a recente isenção do ICMS sobre as exportações de produtos primários e semi-elaborados, que no caso da soja vinha sendo de $13 \%$, deverá conferir maior competitividade às exportações agroindústrias; e provavelmente, um encarecimento da matéria-prima no mercado interno, já que as indústrias serão forçadas a desembolsar mais pêlos produtos, evitando com isto que os mesmos sejam comercializados no mercado externo.

A redução do "Custo Brasil" poderá assim corrigir as distorções que há muito atrapalham as exportações brasileiras de grãos, uma vez que o Brasil é o único país do mundo que vinha taxando suas exportações. Além disto, pode efetivamente abrir caminho para um aumento da área plantada e conseqüente expansão da produção.

\section{1 - Evolução da Cultura da soja no Brasil}

Segundo a EMBRAPA (1987), vários foram os fatores que concorreram para o sucesso da fixação e desenvolvimento da soja no Brasil, principalmente na região Sul do país, que a partir do final da década de sessenta apresentou excelentes taxas de crescimento, mudando significativamente sua importância relativa no cenário nacional e internacional. Analisando-se de forma comparativa o final da década de sessenta e o momento atual da sojicultura no Brasil, nota-se que em relação ao aumento de área plantada houve um incremento de $2.081 \%$, com relação a produção este crescimento foi bastante acentuado e ficou em torno de $3.777 \%$ e finalmente a produtividade aumentou cerca de $77,7 \%$ no período em questão (vide Tabela 4 e Figura 1). 
Tabela 4 - Soja, área plantada, produtividade e produção no Brasil , 1966-96.

\begin{tabular}{cccc}
\hline SAFRA & $\begin{array}{c}\text { ÁREA } \\
(\mathrm{mil} \mathrm{ha})\end{array}$ & $\begin{array}{c}\text { PRODUTIVIDADE } \\
(\mathrm{kg} / \mathrm{ha})\end{array}$ & $\begin{array}{c}\text { PRODUÇÃO } \\
(\mathrm{mil} \mathrm{t})\end{array}$ \\
\hline 1968 & 722 & 906 & 654 \\
1970 & 1.200 & 1.250 & 1.500 \\
1975 & 5.824 & 1.699 & 9.895 \\
1980 & 8.776 & 1.728 & 15.164 \\
1985 & 10.153 & 1.800 & 18.275 \\
1990 & 11.595 & 1.732 & 19.888 \\
1991 & 9.665 & 1.553 & 14.938 \\
1992 & 9.451 & 2.034 & 19.150 \\
1993 & 10.636 & 2.134 & 22.694 \\
1994 & 11.494 & 2.157 & 24.798 \\
1995 & 11.678 & 2.243 & 26.194 \\
1996 & 10.709 & 2.154 & 23.067 \\
\hline
\end{tabular}

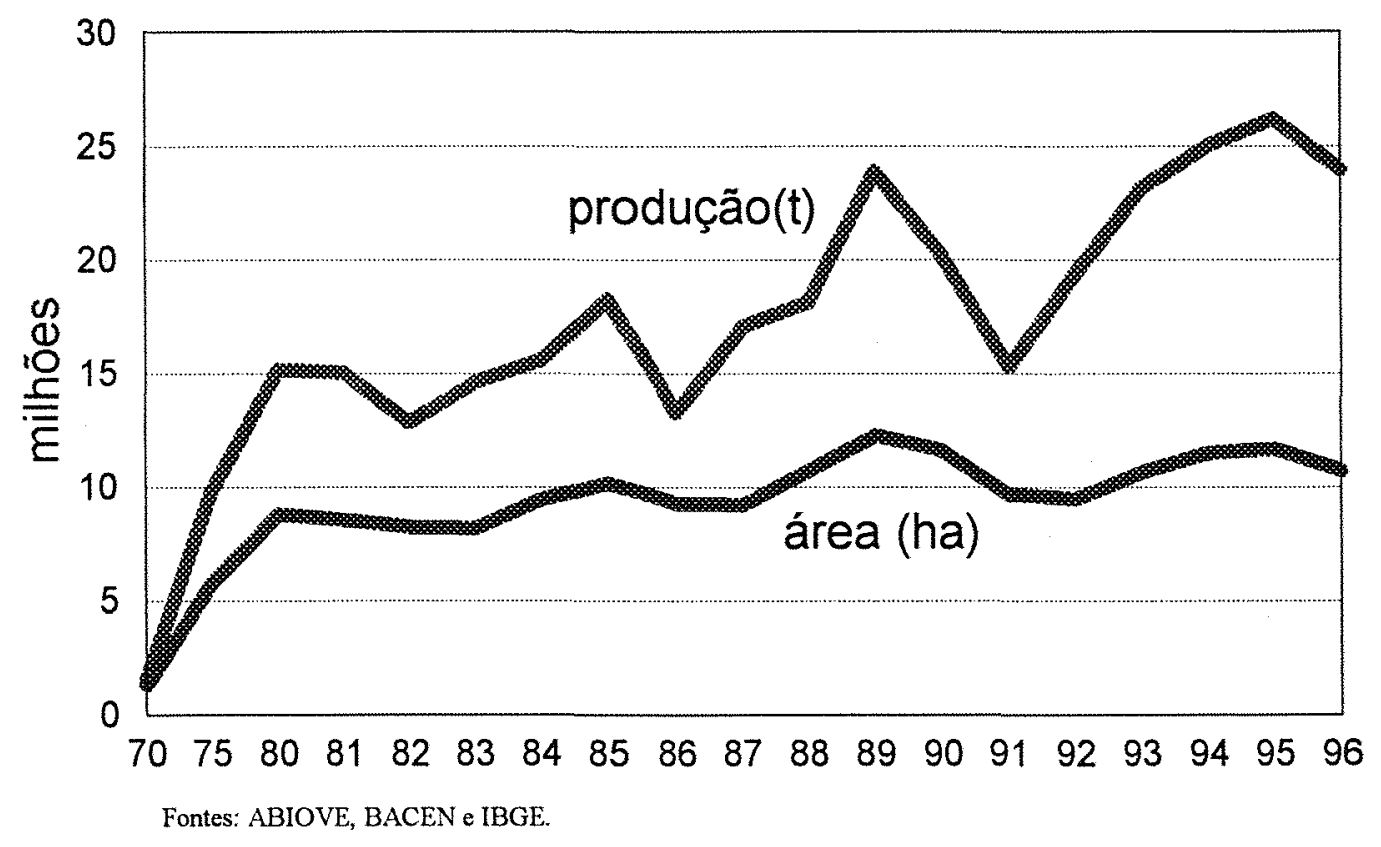

Figura 1 - Soja, evolução da produção e área plantada, Brasil, 1970-96. 
Segundo o SENAR (1996), essa modernização e crescimento da sojicultura foi favorecido pela farta utilização de crédito agrícola subsidiado; significativo crescimento no uso de fertilizantes, defensivos, sementes melhoradas e mecanização agrícola.

De acordo com a EMBRAPA (1987), dentre os principais fatores que de certa forma foram fundamentais para a fixação e desenvolvimento da cultura da soja no Brasil, podem ser citados:

- boa adaptabilidade das variedades e técnicas de cultivo provenientes do Sul dos Estados Unidos que aqui foram implantadas;

- a sucessão soja/trigo, que possibilitou o aproveitamento da mesma área, das máquinas e equipamentos, dos armazéns, da mão-de-obra e favoreceu a rotação de culturas;

- possibilidades de mecanização total da cultura;

- elevada cotação da soja no mercado internacional no início dos anos setenta;

- condições favoráveis do mercado externo, uma vez que, a produção brasileira está disponível no primeiro semestre, período de entressafra norte-americana e quando os preços, via de regra, estão em alta;

- carência de óleos vegetais comestíveis em substituição à gordura animal;

- rápido desenvolvimento do parque de processamento, garantindo a total absorção da matéria-prima existente;

- maior participação das cooperativas no apoio à produção e no processo de comercialização;

- política de auto-suficiência do trigo, que possibilitou uma maior capitalização por parte dos produtores;

- geração de tecnologias criadas no Brasil e adaptadas às diferentes condições edafobioclimáticas, possibilitando ganhos em produtividade, expansão para novas regiões e redução dos custos de produção.

Como pode ser observado na Tabela 4 , desde o início da implantação da sojicultura no Brasil, a área plantada foi crescendo anualmente até a safra de 1980 , quando atingiu uma área de 8,8 milhões de hectares. 
Desta safra até a de 1983, a área plantada sofreu um declínio de 636,9 mil hectares, voltando a ter incrementos novamente a partir do ano agrícola 1985, atingindo então uma área de aproximadamente 12,0 milhões de hectares na safra de 1995.

A redução de área, no período 1980/83, ocorreu principalmente nos Estados do Sul, em especial no Rio Grande do Sul e no Paraná, tendo como causas principais a elevação de custos de produção em niveis bastante superiores aos preços recebidos pêlos produtores, sendo que uma segunda causa ou hipótese bastante discutida está associada ao incentivo dado à produção de milho, que nessa época passou a ocupar áreas antes utilizadas pela soja, mostrando desta maneira que a soja tem na cultura do milho a sua maior competidora por área para a produção. Segundo a OCEPAR (1996), a maior taxa de expansão da cultura ocorreu na década de 70. Durante este período, elevadas cotações do mercado internacional estimularam muito a substituição das culturas vigentes pela então emergente soja. Em termos de produtividade, a década de 80 mostrou um crescimento médio em torno de $2 \%$ nos últimos cinco anos, com uma média de 1.707 $\mathrm{kg} / \mathrm{ha}$

Já no início da década de 90 , houve uma retomada do aumento da produtividade da soja, com um salto na produtividade da safra $91 / 92$ de cerca de $31 \%$, ficando o incremento nos anos seguintes na média de 3,3\%, com uma média 90/96 em torno de $2.000 \mathrm{~kg} / \mathrm{ha}$. Desde o início da implantação da cultura no Brasil até o momento atual a produtividade da soja teve um incremento médio da ordem de $90 \%$.

Segundo Vasconcelos (1994), o rendimento médio da cultura da soja no Brasil está um pouco abaixo do observado nos principais países exportadores. Para a safra 95/96, a produtividade dos EUA ficará em torno dos $2.814 \mathrm{~kg} / \mathrm{ha}$ e a da Argentina cerca de $2.309 \mathrm{~kg} / \mathrm{ha}$.

De acordo com a EMBRAPA (1987), a soja sofreu também uma grande expansão rumo às regiões Centro-Oeste e Nordeste (Mato Grosso, Mato Grosso do Sul, Goiás e Bahia) conforme pode ser observado na tabela 5 . 
Tabela 5 - Evolução da produção de soja por Estados, Brasil, 1985-96, em mil t.

\begin{tabular}{cccccc}
\hline Estado & 1985 & 1994 & 1995 & $1996\left(^{*}\right)$ & média 1994/96 \\
\hline RS & 5.710 & 5.691 & 6.150 & 4.497 & 5.446 \\
PR & 4.413 & 5.280 & 5.407 & 6.009 & 5.565 \\
MT & 2.562 & 2.440 & 2.415 & 2.064 & 2.306 \\
MS & 1.654 & 4.970 & 5.738 & 4.555 & 5.087 \\
GO & 1.266 & 2.387 & 2.155 & 1.955 & 2.165 \\
Outros & 2.573 & 4.236 & 4.329 & 3.987 & 4.188 \\
\hline Total & 18.178 & 25.011 & 26.194 & 23.067 & 24.757 \\
\hline Fontes: Agrianual e Agromarket & & & &
\end{tabular}

Nessas regiões, a cultura começou a ter volume significativo em meados da década de 70, tomando impulso a partir da safra 1976/77. Analisando-se comparativamente, a safra 1963/64 das regiões de Cerrados "nova fronteira" respondiam por $0,5 \%$ e $0,6 \%$ da área colhida e produção nacional, respectivamente. Já na safra $1973 / 74$, a sua participação foi de $6,5 \%$ em relação a área colhida e $5,9 \%$ da produção brasileira.

Na safra agrícola 1984/85, a chamada região de expansão da soja foi responsável por $33,5 \%$ da área colhida e $36,3 \%$ da produção total, enquanto na safra 1993/94, as regiões da "nova fronteira", juntas, contribuíram com $55,6 \%$ da área e 58,3\% da produção de soja (vide Figura 2).

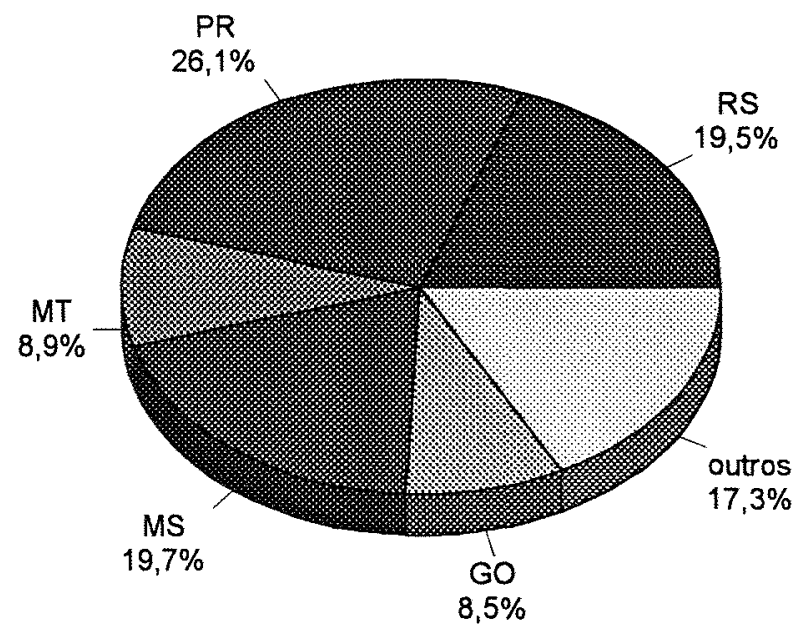

Fontes: Agrianual e Agromarket.

Figura 2 - Distribuição de área plantada de soja por Estados, Brasil, 1995/96. 


\section{2 - Características da Comercialização da soja}

De acordo com a OCEPAR (1996), historicamente, o Brasil ocupa a posição de maior exportador mundial de farelo de soja, sendo o segundo maior de soja-grão e terceiro de óleo de soja. No último ano agrícola (fevereiro de 1994 a janeiro de 1995) os volumes exportados foram de 10,3 milhões de toneladas de farelo de soja, 4,9 milhões de toneladas de soja-grão e 1,5 milhões de toneladas de óleo de soja. Nota-se que mais de $70 \%$ da produção brasileira de farelo de soja são destinados à exportação, principalmente para a União Européia. No caso do óleo de soja, as exportações brasileiras ficam em torno dos $25 \%$ do total produzido, muito embora, nas duas últimas safras tenha superado os $40 \%$ devido aos altos preços internacionais e quebra na produção de outros óleos vegetais.

Segundo a OCEPAR (1996), a soja é um produto de relativamente curto canal de comercialização e exportação, ou seja, sem muitos intermediários no processo de venda. Isto ocorre devido ao fato das atividades fisicas de comercialização com este produto serem a granel, ou seja, requerem grandes volumes. Na região Sul, mais da metade da produção é inicialmente comercializada através de cooperativas, as quais por sua vez, vendem para firmas exportadoras e para a indústria. Nas demais regiões produtoras, as fábricas de farelo, de óleo e as firmas exportadoras absorvem a maior parcela da produção, porém com participação crescente das cooperativas, principalmente no estado de São Paulo.

Ainda conforme a OCEPAR (1996), grande maioria das indústrias estão localizadas junto às principais zonas produtoras, sendo o produto adquirido diretamente do produtor. Algumas firmas mantêm os agentes compradores nas regiões produtoras, atuando diretamente com os sojicultores e, geralmente, dispondo de depósito para o recebimento de grãos. Desta maneira, os sojicultores possuem algumas despesas com a comercialização da sua produção. Existem os descontos, que são referentes à qualidade da soja comercializada, conforme o grau de umidade e quantidade de impurezas contidas no produto, que podem atingir cifras de $22,3 \%$ e $16 \%$, respectivamente. Além destes, existem ainda outros descontos que são referentes à taxa de capital (para associados às 
cooperativas) em torno de 0,5\%, taxa de administração de 1,5\% e FUNRURAL de 2,5\%. A carga tributária incidente sobre a exportação, antes da isenção do ICMS, era de $13 \%$ para a soja em grão, $11,1 \%$ para farelo e $8 \%$ para óleo de soja.

A soja, apesar de competitiva, enfrenta ainda no Brasil alguns problemas estruturais como o elevado custo de transporte, a excessiva tributação e as despesas portuárias. Mas, dadas as atuais mudanças conjunturais que a economia brasileira tem vivido nos últimos tempos, buscando uma globalização através de privatizações, reduções de impostos, estímulos ao setor, notadamente existe uma tendência de mudança em tais fatores, concorrendo para que a soja nacional torne-se mais competitiva ainda em âmbito mundial.

\section{3 - Evolução dos Preços no Período 1980-96}

Oscilações anuais do preço da soja ao nível de produtor foram verificadas durante o período analisado com várias tendências distintas. Esta sazonalidade para os preços recebidos pode ser visualizada na Figura 3, onde nota-se que na época da colheita (março-abril) os preços recebidos pêlos produtores são os mais baixos, devido ao excesso de oferta no período. Após julho, os mesmos voltam a reagir positivamente devido à entressafra americana, quando são atingidos os maiores níveis de preços, basicamente nos últimos quatro meses do ano.

Analisando-se o período entre 1980/82, nota-se que os preços tiveram uma leve queda de $1,6 \%$, passando de US\$ 186,30/t em 1980 para US\$ 183,40/t em 1982, e obtendo posteriormente uma rápida recuperação nos anos de 1983/84, quando os preços atingiram um patamar de US\$217,10/t e US\$222,00/t, respectivamente, ou seja, um incremento de $21,1 \%$ sobre os preços recebidos em 1982. No período compreendido entre os anos de 1985/87, os preços voltaram a cair, chegando a US\$161,90/t em 1987, mostrando uma redução de $27,0 \%$ do preço atingido em 1984. 


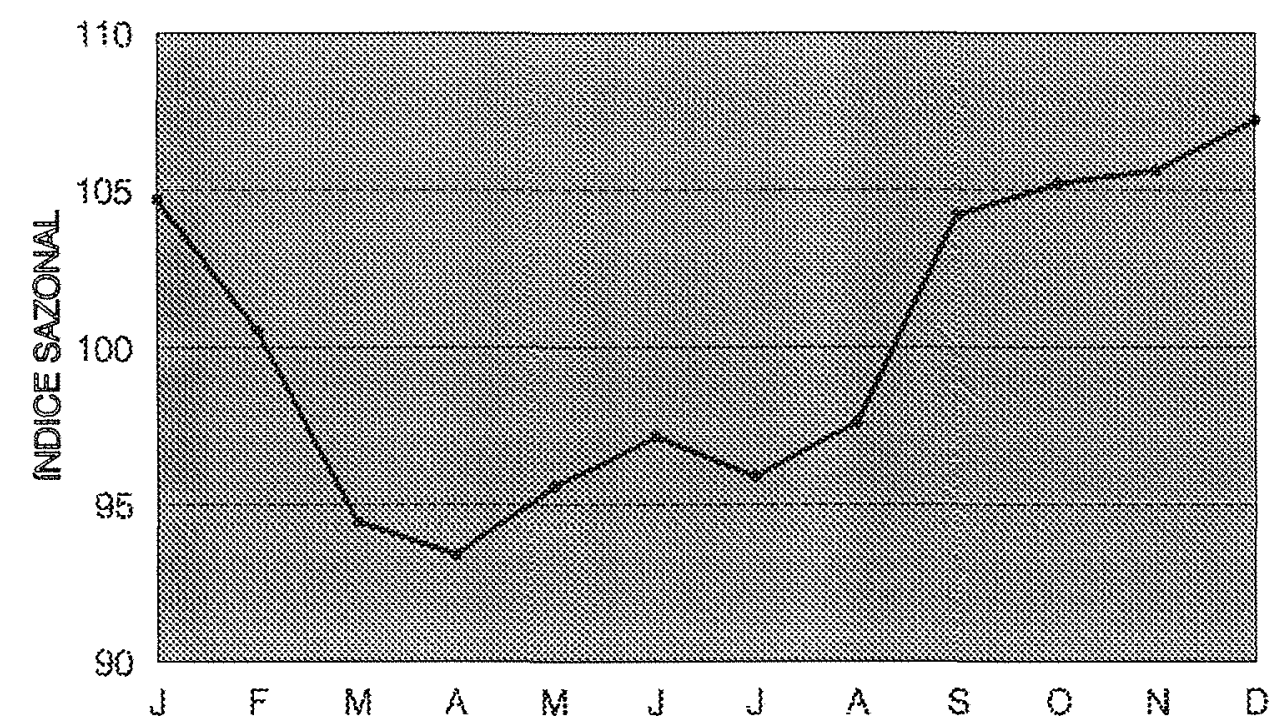

Fonte: SEAB-PR

Figura 3 - Índice sazonal de preços recebidos pelos produtores de soja no estado do Paraná no período de 1980-96.

No ano de 1988 houve uma retomada dos preços, os quais conseguiram se recuperar e alcançar a cotação mais elevada do período analisado, chegando à US\$ $236,90 /$ t ou seja, uma recuperação de $46,2 \%$ dos preços cotados em 1987.

Nos anos compreendidos entre 1989/1992, houve uma leve tendência de redução dos preços da soja, os quais atingiram a cotação de US\$189,70/t em 1989, US\$165,70/t em 1990, 172,50/t em 1991 e US\$173,60/t em 1992. Nos anos 1993/94, os preços de cotação da soja voltaram a reagir positivamente, mostrando uma recuperação devido ao fato da produção americana ter sofrido sérias oscilações, devido as condições climáticas adversas, as quais provocaram grandes variações nos preços internacionais.

Em 1995, continuou este aumento dos preços, passando à US\$196,20/t e nos primeiros meses de 1996 (janeiro-maio), observou-se uma alta nos preços da ordem de $17 \%$ (US\$ 229,00/t), a maior observada desde 1988/89, devido à continuidade dos problemas climáticos nos EUA e redução do estoque mundial de soja, conforme pode ser visualizado na Figura 4. 


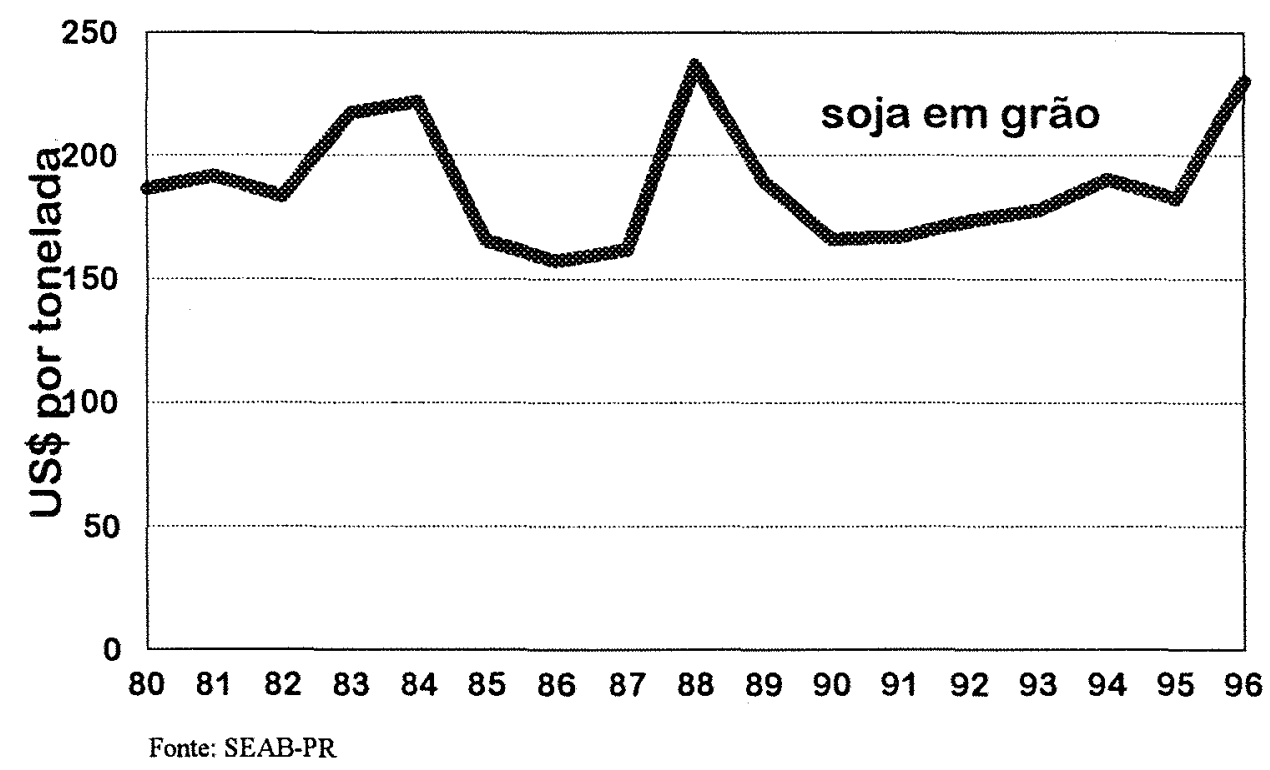

Figura 4 - Preço pagos aos produtores de soja, Brasil, 1980-96.

\section{4 - A Sojicultura no Estado do Paraná}

Segundo o IPARDES (1994), no Estado do Paraná, a maior disponibilidade de infra-estrutura em termos de rodovias, ferrovias, energia elétrica, portos e armazenagem começou a se desenvolver a partir da década de 70 . Uma acentuada modificação ou diversificação do aparelho produtivo ocorreu. A agropecuária, embora reduzindo sua participação na renda gerada de 25,6\% em 1970 para cerca de 15,0\% em 1994, conforme apresentado na Tabela 6, experimentou expressiva mudança ou modernização, associada à mudança de sua base técnica de produção, com destaque à grande expansão da soja $\mathrm{e}$ trigo e ao declínio do peso relativo do café, e em menor proporção, do algodão.

Tabela 6 - Comparação da evolução do PIB (\%) por setores no Paraná - 1970/94.

\begin{tabular}{cccc}
\hline ANO & AGROPECUARIA & INDÚSTRIA & SERVIÇOS \\
\hline 1970 & 25,6 & 23,6 & 50,8 \\
1980 & 19,4 & 28,8 & 51,8 \\
1985 & 20,8 & 25,4 & 53,8 \\
1989 & 14,0 & 26,6 & 59,7 \\
1994 & 15,0 & 28,0 & 57,0 \\
\hline Fonte: IPARDES & & &
\end{tabular}


De acordo com o IPARDES (1994) na década de 80 houve uma desaceleração dessa tendência de forte expansão e diversificação da base econômica iniciada nos anos 70 , devido principalmente à crise e ao esgotamento das fronteiras agrícolas. Ainda assim, a economia paranaense prosseguiu com moderado dinamismo, crescendo a taxas superiores às da economia brasileira (5,7 a.a. contra 2,8 a.a.). Naquele período, o Estado não sentiu muito o impacto na economia devido a fatores tais como a expansão da oferta agropecuária e o prosseguimento da diversificação da agroindústria, principalmente a do complexo soja.

$\mathrm{Na}$ década de 90, com um PIB de cerca de 33 bilhões de dólares e uma renda "per capita" próxima de US $\$ 3.800,00$, ou seja, $10 \%$ acima da média nacional, o Estado do Paraná contribui com cerca de $6,2 \%$ do PIB nacional.

O complexo soja responde por $39,4 \%$ das exportações do Estado sendo $28,1 \%$ farelo, $8,1 \%$ de soja em grão e $3,3 \%$ de óleo de soja.

De acordo com a OCEPAR (1996), o Paraná tradicionalmente tem sido o segundo maior produtor de soja no Brasil, com uma produção média estimada de 5,5 milhões de toneladas nos anos de 1994/96, além de deter uma das maiores produtividades médias da soja nacional, o que determina uma excelente produção total, que corresponde aproximadamente a um quinto do valor bruto da produção agropecuária do Estado. No período de 1990/94, a produtividade média da soja paranaense ficou em torno de 2.114 $\mathrm{kg} / \mathrm{ha}$, sendo que neste período o Paraná atingiu uma participação de $21,6 \%$ na produção de soja no Brasil. Além disso, o Estado do Paraná possui uma capacidade nominal instalada para processamento de óleo vegetal da ordem de 33.940 toneladas por dia, sendo $87 \%$ exclusiva para soja, representando uma participação de $32,6 \%$ da capacidade nacional instalada. Quanto à capacidade de refino do Estado do Paraná, ela é da ordem de $610.200 \mathrm{t} / \mathrm{dia}$, estando superdimensionada para um consumo estimado de 111.000 t/ano no Estado.

Desta maneira, para a análise de estratégias de comercialização de soja, seria interessante analisar o Estado do Paraná, pois o mesmo apresenta a cultura da soja em um alto grau de especialização com os produtores integrados, operando em um sistema de mercado, e com canais de comercialização eficientes. Note-se que de acordo com a 
CONAB (1995), a região Sul dispõe da melhor e maior capacidade armazenadora do país para um volume de 31,2 milhões de toneladas ou $45,5 \%$ da capacidade total da armazenamento do país. Só o Estado do Paraná tem capacidade de armazenamento de 13,6 milhões de toneladas, ou quase um quinto da capacidade total de armazenamento do país, conforme pode ser observado na Tabela 7.

Tabela 7 - Brasil: capacidade estática dos armazéns cadastrados, região Sul, 1995 (em mil t).

\begin{tabular}{ccccccccc}
\hline \multirow{2}{*}{ ESTADO } & \multicolumn{2}{c}{ OFICIAIS } & \multicolumn{2}{c}{ PRIVADOS } & \multicolumn{2}{c}{ COOPERATIVAS } & \multicolumn{2}{c}{ TOTAL } \\
\cline { 2 - 9 } & conv. & granel & conv. & granel & conv. & granel & conv. & granel \\
\hline PR & 611 & 696 & 2.132 & 2.739 & 1.957 & 5.479 & 4.699 & 8.914 \\
SC & 16 & 129 & 859 & 909 & 449 & 458 & 1.324 & 1.494 \\
RS & 78 & 839 & 3.315 & 4.229 & 1.257 & 5.106 & 4.649 & 10.173 \\
\hline SUBTOTAL & 5.710 & 4.324 & 16.997 & 21.381 & 5.716 & 14.627 & 28.428 & 40.291 \\
\hline TOTAL & 10.034 & \multicolumn{2}{c}{38.378} & 20.343 & 68.719 \\
\hline Fonte: CONAB(1995) & \multicolumn{1}{c}{} & \multicolumn{10}{c}{}
\end{tabular}

Segundo Dossa \& Dias (1989), uma característica bastante interessante é a de que a sojicultura é cultivada em pequenas, médias e grandes propriedades, atingindo bons níveis de produtividade em quaisquer dos estratos considerados. $\mathrm{O}$ acesso aos meios de comunicação e às cooperativas permitem que os produtores se beneficiem de vantagens comparativas que a cultura apresenta, principalmente pela antecipação de resultados de pesquisas, pelo contato permanente com técnicos e extensionistas que atuam no setor, permitindo que mais de $90 \%$ dos produtores de soja vivam exclusivamente de renda auferida em sua propriedade.

Além destes fatores, a soja é a principal cultura do Paraná e de maior potencial econômico, principalmente pêlos efeitos agregados que proporciona, tanto na aquisição de insumos como na produção de serviços dentro da sociedade.

No Paraná, segundo a OCEPAR (1989, p.5), “a indústria de óleos vegetais passou a ter a soja como parte da matéria-prima para obtenção de óleo a partir de 1954. Todavia, sua importância como fonte de matéria-prima para extração de óleos e produção de farelos cresce de $1970 \mathrm{em}$ diante, tornando-se a principal oleaginosa a ser 
utilizada pela indústria". A participação do óleo de soja, comparativamente à produção de outros tipos de óleos, pode ser observada na Tabela 8.

Tabela 8 - Produção mundial de óleos e gorduras, 1970-95, em milhões de toneladas.

\begin{tabular}{ccccccc}
\hline Produto & 1970 & 1975 & 1980 & 1985 & 1990 & 1995 \\
\hline Soja & 6,4 & 8,0 & 13,4 & 13,9 & 15,8 & 18,2 \\
Palma & 1,8 & 2,9 & 4,6 & 6,9 & 11,2 & 17,8 \\
Girassol & 3,5 & 3,9 & 5,0 & 6,5 & 8,0 & 9,3 \\
Colza & 1,8 & 2,4 & 3,5 & 6,0 & 7,5 & 8,6 \\
Sebo & 4,9 & 5,3 & 6,3 & 6,6 & 6,8 & 7,1 \\
Banha & 3,9 & 4,3 & 5,0 & 5,3 & 5,7 & 6,2 \\
Outros & 9,2 & 10,2 & 11,2 & 13,0 & 14,9 & 17,2 \\
\hline Total & 31,5 & 37,0 & 49,0 & 58,2 & 69,9 & 84,4 \\
\hline Fonte: Grupo Real & & & & & &
\end{tabular}

O parque processador existente no Estado (vide Tabela 9) conta com 35 plantas industriais, com capacidade nominal instalada de $32.860 \mathrm{t} /$ dia, sendo $87 \%$ exclusiva para soja e, as demais, para outros grãos.

Tabela 9 - Capacidade nominal de processamento instalado no Paraná para obtenção de óleo vegetal - 1994.

\begin{tabular}{cccc}
\hline $\mathrm{N}^{\circ} \mathrm{DE}$ & $\begin{array}{c}\text { CAPACIDADE } \\
\text { INSTALADA (t/dia) }\end{array}$ & $\begin{array}{c}\text { PARTICIPAČ̃̃O } \\
\text { (\%) DAS COOPERATIVAS }\end{array}$ & $\begin{array}{c}\text { MATÉRIA PRIMA } \\
\text { PROCESSADA }\end{array}$ \\
\hline 35 & 32.860 & 19,2 & soja \\
05 & 2.450 & 16,3 & algodão \\
06 & 2.040 & 29,4 & milho \\
01 & 300 & 0,0 & amendoim/mamona \\
\hline
\end{tabular}

Fontes: IPARDES, OCEPAR.

De acordo com o IPARDES (1994), a rede paranaense de escoamento das safras está ligada a Ponta Grossa, que é ainda o principal centro industrial para a soja, e a Paranaguá, que é o principal porto de exportação dos produtos do complexo soja. Paranaguá é responsável pela maior parcela das exportações de cereais via portos do sul e sudeste, com $75 \%$ do seu movimento no sentido de exportação e $25 \%$ no de importação.

As operações com granéis sólidos representam a parte mais expressiva e rendosa do porto, constituindo-se essencialmente de exportações de soja em grão, farelo de soja e milho. 
A estocagem de grãos e farelos é da ordem de 989 mil t. A capacidade de armazenamento estática do porto é da ordem de $137 \mathrm{mil} \mathrm{m}^{3}$ e sua capacidade total de recepção e embarque é, respectivamente, de $4.350 \mathrm{~m}^{3} / \mathrm{h}$ e $6.840 \mathrm{~m}^{3} / \mathrm{h}$. A carga a granel gera cerca de $37 \%$ da receita cambial do porto.

A isenção do ICMS para as exportações trará conseqüências significativas para a economia paranaense, principalmente para a agricultura. Dados levantados pela OCEPAR (1996), mostram que no exercício de 1997 a agricultura do Estado terá um ganho de R\$ 290 milhões devido ao não recolhimento do ICMS, e isto sem dúvida permitirá tanto ao estado quanto ao país incrementar suas exportações. No período 1994/96, segundo a OCEPAR (1996), este incremento foi de $14,3 \%$, contra $50 \%$ da Coréia e $24,8 \%$ da Argentina. No curto prazo, estas mudanças devem promover uma alta dos preços internos pagos pelo setor industrial, equiparando-se aos preços praticados no exterior, visando com isto não perder matéria-prima para a exportação.

\section{5 - Considerações Finais}

Neste capítulo, realizou-se uma análise sucinta sobre os principais aspectos econômicos da sojicultura, tanto a nível internacional quanto nacional, focando sua importância como fator gerador de desenvolvimento econômico; destacaram-se os fatores fundamentais que permitiram a fixação e o desenvolvimento da soja no Brasil; caracterizou-se o processo de comercialização da produção; analisou-se a evolução dos preços recebidos pêlos produtores de soja do Estado do Paraná no período de 1980-96 e finalmente realizou-se um breve comentário sobre a sojicultura no Estado do Paraná, citando-se os principais fatores que concorreram para a realização deste estudo.

No próximo capítulo, faz-se uma revisão bibliográfica sobre a importância do risco na tomada de decisões; caracteriza-se a diferença entre situações de risco e incerteza, descreve-se o comportamento do produtor diante do risco e sugere-se maneiras para contornar o problema. Posteriormente, detalha-se as principais alternativas de comercialização de soja atualmente vigentes; estabelece-se as principais pressuposições sobre o risco nas decisões de mercado; formula-se um modelo 
matemático de programação quadrática para obtenção das estratégias de comercialização de soja frente ao risco de mercado e finalmente especifica-se os dados necessários para que a análise possa ser realizada. 


\section{3 - MATERIAL E MÉTODOS}

Neste capítulo apresenta-se o método utilizado para a determinação das estratégias de comercialização de soja frente ao risco de mercado.

Inicia-se o estudo através de uma revisão bibliográfica que estabelece as condições de risco e incerteza que interferem nas decisões de mercado; em seguida descrevem-se as principais alternativas de comercialização que estão atualmente disponiveis aos sojicultores; discorre-se sobre modelos de decisão envolvendo risco; propõe-se um modelo matemático utilizado por Markowitz-Tobin (1959) que será utilizado na determinação das estratégias de vendas e finalmente, especificam-se os dados necessários para que a análise possa ser processada.

\section{1 - O Risco nas Decisões de Mercado}

Normalmente na agricultura pode-se caracterizar uma diferença entre situações de risco e incerteza. Uma situação de risco seria aquela em que o agricultor possui uma idéia subjetiva da probabilidade de ocorrência de determinado evento ligado ao processo produtivo ou ao mercado do produto. De maneira contrária, as situações de incerteza seriam caracterizadas por absoluto desconhecimento por parte do tomador de decisões quanto às probabilidades da ocorrência dos eventos.

Souza (1990) cita Knight $(1972)^{1}$ mostrando que risco e incerteza são termos comumente empregados como sinônimos. Estabelece uma outra diferença entre risco e incerteza, dizendo que "risco" encontra-se muitas associado associado à idéia de perdas e

\footnotetext{
${ }^{1}$ KNIGTH, F.H. Risco, incerteza e lucro. Tradução de Cantuária, H. Rio de Janeiro, Expressão e Cultura, $1972,385 p$.
} 
"Incerteza" a de ganhos. A noção de "risco-incerteza" estaria também associada à medição. O "fisco" seria algo mensurável, enquanto que a "incerteza" seria imensurável. O risco estaria associado à probabilidades objetivas, mas a incerteza diz respeito à probabilidades subjetivas e sendo assim, quanto mais conhecimentos acumula-se dos fatos, mais as incertezas transformam-se em risco.

Segundo a $\operatorname{ABAG}(1993, \mathrm{p} .49)$, "o agricultor reage ao aumento do risco econômico na sua atividade de duas maneiras. Pela primeira, decide reduzir ou manter a área de plantio, sem se aventurar a trabalhar em novas áreas. Pela segunda, busca maneiras de reduzir custos de produção, ainda que se valendo de padrões tecnológicos menos avançados, ou seja, comprando menos insumos básicos de produção, como fertilizantes, defensivos, sementes melhoradas e adiando para o futuro a decisão de repor máquinas envelhecidas, para fugir do endividamento e do custo elevado do dinheiro que ocorre em épocas de inflação, onde os juros são abusivos”.

$O$ incremento da produção de soja, associado às melhorias nas funções de armazenamento, transporte e industrialização, tem levado os produtores a buscar novas maneiras de comercializar sua produção para tentar fugir às constantes flutuações de preço da soja entre o período de plantio até a sua venda efetiva. Esta incerteza que ronda o mercado trá sérias preocupações aos produtores que buscam o retorno esperado ao seu esforço despendido. Mendes $\left(1980\right.$, p.3) cita Schnittker $(1975)^{2}$ dizendo que "os mercados sinalizam erroneamente aos produtores, pois, são caracterizados pela extrema incerteza e instabilidade, onde, certeza e estabilidade são preferidas pêlos produtores e consumidores, os quais desejam um uso mais eficiente dos seus recursos e melhor distribuição da produção. Então, faz se necessário o desenvolvimento de técnicas para estabilização".

De acordo com Mendes (1980), a incerteza de um bom preço gera um efeito contínuo e de cadeia, pois os agentes financeiros também não sabem se a receita gerada será suficiente para que o produtor salde os compromissos assumidos anteriormente. Devido a esta flutuação constante de preços, também conhecido como risco de mercado, faz-se

\footnotetext{
${ }^{2}$ SCHNITTKER, J.A., "An Economic Appraisal of Recent Commodity Market Performances", American Journal of Agricultural Economics, Vol.57, December 1975, pp.863-865.
} 
necessária a busca de melhores alternativas de comercialização da soja, para que se possa encontrar uma resposta ao clássico problema econômico de "quando" e "como" vendê-la.

A busca desta resposta não é só de interesse dos produtores rurais, mas das cooperativas, bancos e outros órgãos ligados ao setor, já que uma eficiente seleção de alternativas de comercialização auxiliará os produtores na tomada de decisão, podendo gerar uma receita maior, mais estável e com menores riscos.

Noronha (1981, p.233) cita que, "as incertezas surgem em primeiro lugar porque estamos trabalhando com valores futuros. $\mathrm{Na}$ fase de elaboração e avaliação de um projeto tudo é incerto, até mesmo o investimento inicial e o horizonte do projeto. Neste sentido, a palavra incerteza engloba todas as ações e resultados dos quais ainda não se tem certeza. Portanto, decisões de investimento têm necessariamente que ser tomadas sob condições de risco e incerteza. A finalidade da análise de um projeto é exatamente diminuir o grau de risco assumido nas decisões. Tanto os riscos diretos (relacionados com as decisões diárias) como os indiretos (sobre os quais o agricultor não possui nenhum controle) afetam todas as áreas de administração da empresa - produção, comercialização e finanças - e envolvem os aspectos quantitativos e qualitativos das decisões".

Nesta mesma linha, Mendes (1980), cita que os produtores constantemente se defrontam com dois tipos de risco. O primeiro tipo é o chamado "risco de produção", causado por fatores incontroláveis como clima, doenças, insetos e outros. O segundo é o "risco de mercado", causado por drásticas variações de preço de venda (por exemplo da soja) durante o ano e que tem levado a um incremento do risco nos negócios da fazenda.

Marques (1992) cita que riscos de variações de preços são muito grandes em mercados competitivos como os agropecuários. Fatores como variação na renda dos consumidores, mudanças de hábitos de consumo e variações na quantidade ofertada, tanto sazonal como no longo prazo, podem afetar grandemente os preços agrícolas.

Esse risco de variações de preços pode ser reduzido com uma eficiente política de preços agrícolas. A manutenção de estoques reguladores, por parte do governo ou da iniciativa privada, pode contribuir para que os preços não se elevem exageradamente, enquanto que o estabelecimento de preços mínimos de garantia pode evitar quedas 
acentuadas na rentabilidade do produtor. Em países mais desenvolvidos, a saída encontrada para contornar esse problema de variabilidade de preços, sem a intervenção governamental, tem sido a integração vertical, a boa infra-estrutura de armazenagem e o comércio a termo de mercadorias, através do mercado de futuros. O processo de decisão do agricultor para vender sua produção é uma situação de incerteza e que envolve o risco de mercado, exigindo reflexão sobre as alternativas possíveis de ação e suas potenciais conseqüências.

\section{2 - Alternativas de Comercialização}

Entende-se como alternativa de comercialização a maneira pela qual o produtor rural pode vender ou tentar influenciar os termos de venda de seu produto. Estas alternativas surgiram devido ao aumento na capacidade física de estocagem de grãos, nos anos mais recentes, propiciando ao produtor a possibilidade de buscar um preço de venda mais condizente ao seu produto, já que todo o processo produtivo da agricultura, constantemente, é cercado de incertezas.

Entre as principais alternativas de comercialização disponíveis ao produtor para comercialização da produção antes da colheita, segundo LOPES (1994), estão:

a) Contrato de produção antes da colheita:

a. 1) Soja verde

a.2) CM-G - Certificado de Mercadoria com emissão garantida

a.3) CPR - Cédula de Produto Rural

a.4) CLB - Commodity Linked Bond

As principais características técnico-operacionais dessas alternativas de comercialização conforme documento elaborado por Lopes (1994), e que não foram incorporadas ao modelo devido a falta de informações disponíveis, podem ser visualizadas no apêndice 2 .

Segundo Lopes (1994), com a crise fiscal do governo, os financiamentos realizados pelo Estado, tanto para o custeio quanto para a comercialização padecem devido a uma crônica falta de recursos que tem comprometido as necessidades da agricultura. O setor 
privado respondeu a esta demanda por crédito de forma rápida, criando mecanismos (de certificados ou de contratos) para atender às necessidades de financiamento.

De acordo com a Superintendência do Banco do Brasil - PR, as operações de venda antecipada da produção são muito recentes, variando de safra para safra e dependendo muito do volume de recursos liberado pelo governo federal. No estado do Paraná, o número de contratos realizados em CPR até o período de janeiro de 1996 foi de 598, com um volume negociado de 400 mil toneladas de soja-grão e cujo valor chegou a R\$62,3 milhões. Dados do BB-PR mostram que para o ano de 1995 no estado do Paraná apenas 1\% da área plantada foi financiada através da CPR e que em relação as outras modalidades de contratos antecipados da produção não existem estatísticas.

Entre as principais alternativas de comercialização normalmente disponíveis ao sojicultor, de acordo com Mendes (1980), estão:

b) Venda na época da colheita

c) Estocagem do produto para especulação

d) Venda com preço autorizado

e) Venda com preço a fixar

f) Vendas em comum ou "Pooling"

g) Hedging

Segundo Mendes (1980), as principais alternativas de comercialização normalmente disponíveis aos sojicultores são:

\section{b) Venda na época da colheita}

Com as sensiveis melhorias e alterações de forma, tempo e espaço que as atividades de comercialização exercem sobre a matéria prima agrícola, novas alternativas de 
comercialização passaram a ter maior importância que a venda da produção na época da colheita. A análise de um índice sazonal de preços recebidos pêlos produtores para o período de 1980/95 (vide tabela 10) mostra que, na época da colheita (março-maio), os preços da soja são normalmente cotados abaixo de sua média anual, devido ao excesso de oferta de produto neste período, enquanto níveis mais elevados de preços ocorrem na segunda metade do ano.

Tabela 10 - Índice sazonal de preços recebidos pêlos produtores de soja no Estado do Paraná no período de 1980-95.

índice sazonal - soja - PR - 1980-95

\begin{tabular}{cccccccccccc}
\hline jan & fev & mar & abr & mai & jun & jul & ago & set & out & nov & dez \\
\hline 104,7 & 100,5 & 94,4 & 93,4 & 95,5 & 97,1 & 95,8 & 97,6 & 104,2 & 105,2 & 105,6 & 107,2 \\
\hline Fonte: SEAB-PR
\end{tabular}

Ao selecionar esta alternativa de comercialização, o produtor abandona qualquer possibilidade de obter um retorno mais condizente com o investimento despendido na elaboração da lavoura, pois perde a possibilidade de obter um preço mais alto de mercado (o preço dos fretes e custos de armazenagem estão relativamente altos na época da colheita devido ao excesso de demanda), o que pode ser obtido através de vendas em diversos períodos. Por outro lado, a venda na época da colheita traz como principais vantagens o fato de que o produtor não vai ter custos de estocagem, a não existência de risco de deterioração do produto e uma imediata disponibilidade de caixa (o que muitas vezes passa a ser interessante, pois é na época da colheita que normalmente ocorrem as cobranças de dívidas contraídas por motivo da implantação da lavoura). Associados a estas vantagens estão outros fatores que forçam o produtor a utilizar esta alternativa, tais como a falta de capacidade de estocagem de seu produto ao nível da propriedade; vencimento de compromissos financeiros na época da colheita; e a falta de recursos para o financiamento da comercialização. 


\section{c) Estocagem do produto para especulação}

Esta estratégia de comercialização permite ao produtor estocar sua produção na época da colheita para posterior venda futura, quando o preço de mercado for eventualmente melhor. $O$ produtor que realiza o armazenamento acredita que fatores exógenos vão proporcionar um incremento no preço da soja maior ou igual ao custo de armazenagem no período em questão. Geralmente se espera até um incremento de preço suficiente para cobrir os juros, os custos de armazenagem, seguro e permitir ainda um lucro razoável em função do risco assumido.

\section{d) Vendas com preço autorizado}

Nesta estratégia de comercialização, o produtor entrega sua produção ou títulos associados à mesma a uma cooperativa na época da colheita, determinando o preço de venda de sua produção em uma data posterior, quando o preço de mercado atingir o nível de preço desejado. Caso os preços de mercado não atinjam o nível estipulado pelo produtor, então ele deverá renovar a sua autorização a um nível de preço mais baixo.

A principal vantagem desta estratégia para o produtor é que devido ao grande volume de soja disponível na cooperativa, existe a possibilidade de se especular por um preço melhor, mesmo que não estejam disponíveis as facilidades do armazenamento.

\section{e) Venda com preço a fixar}

Forma de especulação que não requer a disponibilidade de armazenamento, esta alternativa apresenta duas modalidades, em função da operação ser efetuada com particulares (atacadistas, indústrias, etc.) ou através de cooperativas.

No preço a fixar com particular, o produtor entrega e transfere o título do produto ao comprador, geralmente na época da colheita, mas o produtor retém o privilégio de fixar o preço mais tarde, normalmente dentro de 6 meses, e com um custo mensal de 
armazenamento já pré-fixado. Alguns compradores, que via de regra são grandes empresas ligadas à industrialização e ou à exportação da soja, evitam cobrar os custos de armazenamento como meio de atrair o produtor. Se, por um lado, o produtor tem o privilégio de fixar o preço, por outro lado, o comprador tem o privilégio de ter a posse efetiva da mercadoria, podendo, portanto, vendê-la ou industrializá-la sem a necessidade de consultar o produtor. A grande vantagem para o produtor é que ele pode especular sem possuir armazéns ou silos.

No preço a fixar através da cooperativa, a operação é efetuada através da mesma, mas a mercadoria ainda pertence ao produtor e a cooperativa não pode efetuar a venda antes que o associado decida fixar o preço. Esta alternativa, ao contrário da anterior, está se tornando cada vez mais importante para o produtor, cujas cooperativas são fortes e detêm uma grande capacidade de estocagem. A responsabilidade da decisão de venda (preço e época) do produto recai sobre o associado, razão pela qual tem havido uma certa orientação das diretorias das cooperativas no sentido de efetuar a comercialização através desta alternativa, apesar de que, para as cooperativas, este método resulta em menor flexibilidade em termos de movimentação da mercadoria.

\section{f) Vendas em comum ou "Pooling".}

Uma estratégia de comercialização muito utilizada pêlos produtores de soja brasileiros é a venda em comum ou 'Pooling", através do marketing das cooperativas. Neste processo, o produtor transfere as funções de armazenamento e venda para a sua cooperativa. O acompanhamento de preços é feito pela cooperativa e quando ocorre a venda, há um recebimento de lucro parcial por parte do produtor. O balanço ou acerto ocorre no final do período de vendas da cooperativa. Freqüentemente este marketing das cooperativas pode garantir a estabilidade de preços desejada pelo produtor. Além disso, o conhecimento da cooperativa sobre o comportamento da mercadoria, condições de mercado, gerenciamento especializado, podem aumentar o retorno esperado. Ao contrário da alternativa "preço a fixar", este método repassa toda a responsabilidade da decisão de 
venda para a diretoria da cooperativa, razão pela qual não há orientação para que os associados optem por esta alternativa.

\section{g) "Hedging"}

O mercado futuro corresponde à compra e à venda de contratos para entrega futura de mercadorias. Nos EUA, já há um número significativo de produtores, principalmente de soja, que utilizam este tipo de operação de mercado, embora no Brasil seja ainda pouco conhecido. As compras e vendas se dão nas bolsas de mercadorias, que administram contratos padronizados em função da: quantidade, qualidade, época e local de entrega dos produtos.

O uso do "Hedging" oferece um aumento de flexibilidade ao mercado da soja, constituindo uma ferramenta de comercialização para gerenciamento do risco de mercado. $\mathrm{O}$ mercado futuro tende a ser uma opção emergente e persistente, especificamente no caso das "Commodities", as quais estão constantemente sujeitas a grandes variações de preço. Neste tipo de mercado, há dois tipos de negociantes: os hedgers e os especuladores. $\mathrm{O}$ especulador compra e vende contratos futuros baseados na sua expectativa de preços futuros. $\mathrm{O}$ 'hedger", ao contrário, usa o mercado como uma ferramenta comercial para complementar seu programa de comercialização. O "Hedging" pode ser definido como um processo de estabelecimento simultâneo de posições opostas no mercado disponível e no mercado futuro.

Tendo em vista que a estratégia de "Hedging" ainda não é vastamente utilizada no Brasil, esta alternativa não será incorporada ao modelo.

\section{3 - Modelos de Decisão Envolvendo Risco}

Souza (1990) cita Arrow (1974) $)^{3}$ e Schoemaker (1982) ${ }^{4}$ para caracterizar o comportamento dos indivíduos nos processos de escolha, diante da incerteza. Os estudos

\footnotetext{
${ }^{3}$ ARROW, P.J.H. Essay in the theory of risk-bearing. North Holland Company. 1974. 276p.
} 
iniciais sobre a Teoria da Utilidade Esperada foram propostos por Gabriel Crammer em 1728 e Daniel Bernoulli em 1738, os quais procuravam explicar o Paradoxo de Petersburg. Investigavam o motivo pelo qual as pessoas pagariam uma pequena quantia por um jogo de infinitas expectativas matemáticas. Para explicar o Paradoxo, Bernoulli sugeriu que as pessoas tendem mais a maximizar a utilidade esperada em vez do valor monetário esperado.

A teoria da decisão de Bernoulli, segundo Dillon (1971), é uma abordagem generalizada para a tomada de decisão sob condições de risco. É uma teoria normativa baseada em probabilidades subjetivas do tomador de decisão a respeito da ocorrência de eventos incertos, e, em preferências pessoais, pelas conseqüências potenciais destes eventos. Este princípio, colocado em termos de um único objetivo, envolve alguns axiomas básicos, de acordo com Henderson \& Quandt (1976, p.41), que são descritos a seguir.

\section{a) Ordenamento}

A ordem de preferência de uma pessoa por alternativas de ação pode ser representada por um ordenamento. Sendo assim, ao se defrontar com duas alternativas A e B, ou prefere A ou prefere $\mathrm{B}$ ou ainda pode ser indiferente a ambas. $\mathrm{O}$ axioma de Ordenamento, de certa forma, assegura a transitividade da escolha de eventos incertos por parte do tomador de decisões, no sentido de que se $\mathrm{A}$ é preferido a $\mathrm{B}$ e $\mathrm{B}$ é preferido a $\mathrm{C}$, então A será preferido a C. Neste axioma, os indivíduos têm preferências entre alternativas e conseguem expressá-las;

\section{b) Continuidade}

Suponha-se que a alternativa A é preferível à alternativa $B$ e que a alternativa $B$ seja preferivel à alternativa C. O axioma da continuidade afirma que existe uma certa probabilidade $\mathrm{P}, 0<\mathrm{P}<1$, tal que o consumidor seja indiferente entre o resultado $\mathrm{B}$ com certeza e um bilhete de loteria com probabilidade $\mathrm{P}$ de dar A e 1-P de dar C;

\footnotetext{
${ }^{4}$ SCHOEMAKER, P.J.H. Expected Utility Model: its variances, purpuses, evidences and limitations, Jounal of Economic Literature, v.20, n.2, p.529-563, 1972.
} 
c) Indiferença

Suponha-se que um consumidor seja indiferente entre as alternativas A e B e que a alternativa $\mathrm{C}$ seja um resultado qualquer. Se uma loteria oferece os resultados $\mathrm{A}$ e $\mathrm{C}$ com as probabilidades $\mathrm{P}$ e 1-P, respectivamente, e outra loteria fornece os resultados $\mathrm{B}$ e $\mathrm{C}$ com as mesmas probabilidades $\mathrm{P}$ e 1-P, o consumidor é indiferente entre ambas.

Os três axiomas resultam no princípio de Bernoulli ou Teorema da Utilidade Esperada, e segundo Pereira (1985), se um indivíduo se comporta de acordo com estes axiomas propostos, um índice que expresse suas preferências tanto para resultados certos de ocorrerem quanto para a escolha em situações de risco pode ser derivado, ou seja, é factível de estabelecermos uma função de utilidade envolvendo o risco.

Foi com John Von Newmann e Oskar Morgenstern que a maximização da utilidade esperada foi formalmente explicada como um critério de decisão racional. A utilidade de Von Newmann e Morgenstern aplica-se a qualquer tipo de resultado, inclusive àqueles que envolvem valores monetários.

Souza (1990) citando Schoemaker (1982) $)^{5}$ conclui que os axiomas são suficientes para garantir que há um índice de utilidade tal que a ordenação de loterias por sua utilidade coincide com as preferências das pessoas. Pela utilização dos axiomas citados torna-se possível a obtenção de pontos de utilidade, através dos quais a função de utilidade pode ser interpolada. Pela construção e observação dos diferentes tipos de função de utilidade dos indivíduos geradas por tais axiomas, surge a noção de aversão ao risco.

Souza (1990) cita Stone $(1970)^{6}$ dizendo que a medida do risco seria a diferença entre a utilidade de ganhos futuros esperados e a esperança da utilidade dos ganho futuros, ou seja,

$$
\phi=U(\bar{y})-E[U(\tilde{y})]
$$

onde: $\phi=$ coeficiente de risco

\footnotetext{
${ }^{5}$ SCHOEMAKER, P.J.H. Expected Utility Model: its variances, purpuses, evidences and limitations, Journal of Economic Literature, v.20, n.2, 1972.

${ }^{6}$ STONE, B.K. Risk, Return and Equilibrium, Cambridge, Mit Press, 1970.
} 
$U(\bar{y})=$ utilidade de ganhos futuros esperados

$E[U(\tilde{y})]=$ esperança da utilidade de ganhos futuros

Pela Figura 5, podem ser identificados o investidor avesso ao risco, $\phi>0$ (curva 1), indiferente se $\phi=0$ (curva 3) e propenso a risco se $\phi<0$ (curva 2). Em outras palavras, o investidor será avesso ao risco se a utilidade da média da distribuição for maior que a utilidade esperada.

O investidor avesso ao risco preferiria a média da distribuição como certo a correr o risco oferecido pela distribuição de probabilidade. O risco não é, como a variância, apenas uma função de distribuição da probabilidade dos ganhos, mas depende da forma da função de utilidade. Para os avessos ao risco ela seria côncava, para os indiferentes ao risco a forma da função seria linear, e convexa aos propensos ao risco.

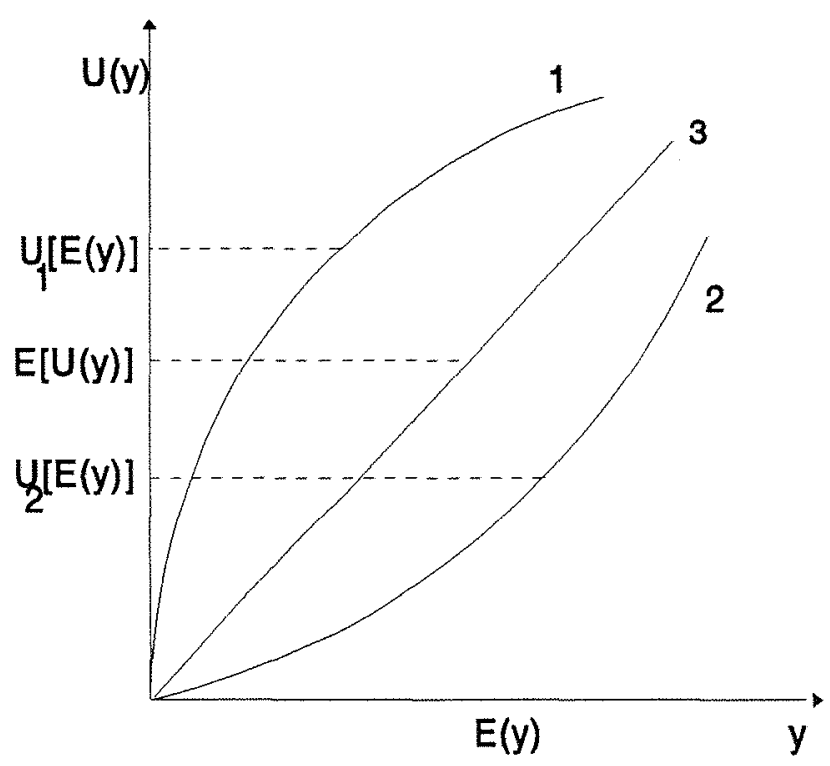

Figura 5 - Curvas de Utilidade e o comportamento individual do consumidor. 
Souza (1990) cita Arrow $(1974)^{7}$, que propôs como medidas de aversão ao risco uma relação negativa entre a derivada segunda $\left[U^{\prime \prime}(y)\right]$ e a derivada primeira $\left[U^{\prime}(y)\right]$ da função de utilidade $[\mathrm{U}(\mathrm{y})]$. As medidas de aversão absoluta e relativa ao risco podem ser calculadas, respectivamente, por:

$$
\begin{aligned}
& \operatorname{Ra}(y)=-U^{\prime}(y) / U^{\prime}(y) \\
& \operatorname{Rr}(y)=-y \cdot U^{\prime \prime}(y) / U^{\prime}(y)
\end{aligned}
$$

onde:

$\operatorname{Ra}(\mathrm{y})=$ coeficiente de aversão absoluto

$\operatorname{Rr}(\mathrm{y})=$ coeficiente de aversão relativo

$y=$ renda ou ganhos do investidor

$\mathrm{U}^{\prime}(\mathrm{y})=$ derivada primeira da função utilidade

$U^{\prime \prime}(y)=$ derivada segunda da função utilidade

Estas medidas foram tomadas por serem invariantes com qualquer transformação linear. Para indivíduos avessos ao risco elas assumiriam valores positivos, pois $U^{\prime}(y)>0$ e $\mathrm{U}^{\prime \prime}(\mathrm{y})<0$. Para os propensos ao risco, tanto Ra como Rr seriam menores, pois $\mathrm{U}^{\prime \prime}>0$.

Dentro dos conceitos estudados, os indivíduos considerados avessos ao risco apresentam utilidade marginal da renda positiva, porém decrescente. Eles só aceitam aumentos no nível de risco se forem acompanhados de ganhos mais do que proporcionais. Baseiam sua decisão não na maximização de lucros mas na maximização da Utilidade Esperada, envolvendo, portanto, critérios individuais de ordem econômica, cultural e psicológica.

$\mathrm{Na}$ tentativa da resolução de problemas envolvendo decisão, esbarra-se freqüentemente nas dificuldades de se conseguir medidas exatas das preferências, ou seja, das probabilidades subjetivas e das funções de Utilidade. Conhecidos estes elementos, o processo se tornaria relativamente fácil, porém, dadas as dificuldades, não se pode fazer

\footnotetext{
ARROW, J.K. Essay in the theory of risk-bearing. North Holland Company, 1974, 276p.
} 
estimativas sobre as melhores alternativas. Para fugir da questão de escolha puramente intuitiva, diversos processos de classificação de alternativas têm sido propostos.

Contini, Araújo \& Garrido (1986) citam que o problema que envolve decisão tem sido analisado com bastante profundidade pela teoria da Administração e, particularmente, pêlos tratados sobre organizações (Simon 1960; March \& Simon 1958).

Com o surgimento da pesquisa operacional, mais recentemente, tem se dedicado atenção crescente à "análise de decisão" através da formulação de modelos (Brown et al., 1974; Thiriez \& Zionts, 1976; Dyer \& Shapiro, 1982). Se a incerteza é uma situação dada e comum na atividade agrícola, o problema é determinar como se pode incorporar o risco em modelos de decisão. Bernoulli incorpora o risco em sua teoria de decisão baseando-se nas probabilidades subjetivas do tomador de decisão a respeito da ocorrência de eventos incertos, e em preferências pessoais pelas conseqüências potenciais destes eventos. A partir do Teorema da Utilidade esperada de Bernoulli, Markowitz, Tobin e Feldstein desenvolveram o modelo média-variância. De acordo com este modelo, presume-se que o tomador de decisão escolha a alternativa que apresente menor variância para uma mesma média, ou a alternativa com a maior média para um nivel igual de variância. Segundo Contini, Araújo \& Garrido (1986), quando uma alternativa apresenta maior média e maior variância, vários critérios foram desenvolvidos para a decisão, como o de segurança mínima de Roy (1952), o da máxima chance condicionada de Telser (1955) e da segurança fixa de Kataoka (1963).

Segundo Cruz (1986), mesmo considerando que o risco seja algo subjetivo para cada tomador de decisão, torna-se dificil a obtenção de funções particularizadas de utilidade para cada indivíduo, conforme exige o princípio de Bernoulli. Para contornar tal problema, desenvolveram-se regras de dominância estocástica, que levam em conta toda a distribuição cumulativa de probabilidade dos retornos, ao invés de simplesmente média e variância dos retornos esperados (Quiry \& Saposnik, 1962; Hadar \& Russell, 1969; Anderson, 1974 e Meyer, 1977). Baseados nos axiomas de Bernoulli e no Teorema de Utilidade Esperada, Hanoch e Levy (1970) adicionaram as hipóteses de que a função de distribuição de probabilidade dos retornos é simétrica. 
Foram desenvolvidos também modelos de incorporação de risco para a propriedade agrícola. How \& Hazell (1968) aplicaram a programação quadrática. Posteriormente, Hazell na década de 70 propôs o uso do "Minimization of total Absolute Deviation" (MOTAD), o qual é um modelo alternativo à análise de média-variância, que faz uso dos desvios totais absolutos, e não da variância, assumindo-se que a função de utilidade do tomador de decisão seja quadrática e com distribuição normal. Neste caso, um risco maior será assumido apenas se houver um maior retorno. O crescimento do retorno deve ser mais do que proporcional ao crescimento do risco, podendo-se para tais situações se utilizar de aplicativos de programação linear para sua resolução.

De acordo com Cruz (1986), outra alternativa para incorporar risco em modelos de planejamento da propriedade agrícola é a teoria dos jogos (Neumann \& Morgestern, 1947), a qual busca apresentar uma modificação na tradicional estrutura da otimização, através da obtenção de um máximo entre um conjunto de mínimos (maxmin), ou de um mínimo entre um conjunto de máximos (minimax). Segundo Chiang (1982), um jogo é uma situação na qual dois ou mais participantes, chamados de jogadores, confrontam-se em busca de determinados objetivos, que podem ser conflitantes. Portanto, pode ficar caracterizada a situação em que os objetivos de todos os jogadores não podem ser simultaneamente alcançados, e assim alguns ganham e outros perdem.

Basicamente, existem duas categorias principais de jogos: jogos de azar e jogos de estratégia, que é a categoria que demanda uma maior necessidade da inteligência dos oponentes. Nesta categoria, cada jogador possui um número de alternativas, finitas ou infinitas, chamadas estratégias. Os resultados ou pagamentos dos jogos são sumarizados como funções das diferentes estratégias para cada jogador. Um determinado jogo com dois jogadores, onde o ganho de um jogador é igual a perda de outro jogador é conhecido como jogo de soma zero com duas pessoas. Os jogos de estratégia são completamente descritos por meio de matrizes conhecidas como matrizes de pagamento.

De qualquer forma, antes do estabelecimento do modelo matemático de MarkowitzTobin a ser assumido para a análise das estratégias de comercialização, algumas pressuposições devem ser feitas. Inicialmente com relação à teoria da firma, a noção de que 
os produtores têm perfeito conhecimento dos valores das variáveis que afetam os processos de suas atividades e que tomam decisões objetivando a maximização de lucro, deve ser questionada. Segundo Mendes (1980), essas pressuposições implicam na não estocasticidade das variáveis, e que o único critério para seleção de uma alternativa é o seu retorno esperado (modelo determinístico). Em outras palavras, isto significa que, como resultado, a seleção e combinação dos empreendimentos agrícolas numa solução ótima leva o produtor rural planejar e produzir em um excessivo grau de especialização ou de concentração da comercialização em uma única estratégia, gerando uma alta variabilidade na renda esperada, que muitas vezes pode ser observado em soluções obtidas por programação linear.

A pressuposição da maximização do lucro, na qual os empresários igualam a sua receita marginal ao custo marginal, é valida somente em condições onde prevalece a neutralidade de risco. Mendes (1980) cita Soares (1977, p.9), afirmando que "o impacto da aversão ao risco na tomada de decisão deve ser considerado como a mais importante característica neoclássica da agricultura tradicional". Entretanto, como os produtores se defrontam constantemente em condições de risco tanto na produção como na comercialização de seus produtos, o critério básico estabelecido pela teoria clássica não auxilia em muito as decisões do produtor. Da mesma maneira, esta situação sugere o uso de modelos alternativos (modelos estocásticos), os quais incorporam o risco, aproximando-se, assim, de condições mais realísticas.

Segundo Takayama \& Batterham (1972) em 1952, Markowitz introduziu o conceito de Seleção de Portfólios, no campo do gerenciamento de investimentos. Markowitz (1959) desenvolveu a teoria da análise de portfólio, a qual propicia a introdução e aplicação da programação estocástica em problemas econômicos agrícolas, e que facilitou, sobremaneira, o processo de tomada de decisão frente ao risco de mercado.

Souza (1990) cita Stone $(1970)^{8}$, afirmando que os indivíduos formam distribuições de probabilidade a respeito dos retornos das alternativas a escolher, e que as preferências dos indivíduos são função da média e da variância daquelas distribuições. Para um determinado retorno esperado, os indivíduos escolheriam a alternativa que oferecesse menor

\footnotetext{
${ }^{8}$ STONE, B.K. Risk, Return and Equilibrium, Cambridge, Mit Press, 1970.
} 
variância. Já no caso de uma certa variância, teria preferência a alternativa com mais elevado

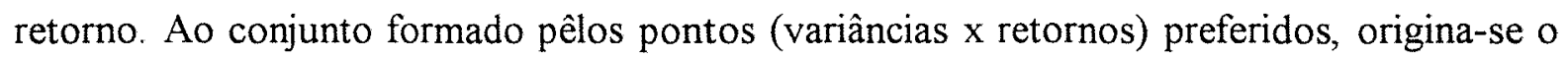
que se conhece como fronteira eficiente da média-variância (fronteira $\mathrm{E}-\mathrm{V}$ ).

A análise de portfólio está fundamentada nos princípios propostos por Bernoulli, o qual sugere que o empresário tenta obter a maximização de sua utilidade esperada, em vez do lucro. A utilidade esperada é uma função da renda (retorno esperado) e do grau de risco dos retornos (variância). A estimativa do risco representa o problema central, pois, segundo Mendes (1980), a expectância da função utilidade esperada, expandida pela "Série de Taylor", mostra que esta é uma função da renda esperada e de n-1 parâmetros que representam o risco.

Segundo Mendes (1980), partindo-se de uma função utilidade $U(x)$ qualquer e expandindo-a pelo uso da "Série de Taylor" ao redor da média $\mathrm{E}(\mathrm{x})$, que significa no presente contexto transformar a função em um polinômio no qual os coeficientes dos vários termos são expressos em termos dos valores das derivadas, temos:

$$
\mathrm{U}(\mathrm{x})=\mathrm{ax}+\mathrm{bx}^{2}+\mathrm{cx}^{3}+\mathrm{dx^{4 }}+\ldots+\mathrm{nx}^{\mathrm{n}}
$$

Aplicando-se Esperança Matemática nesta função polinomial, os elementos $\mathrm{E}\left(\mathrm{x}^{\mathrm{n}}\right)$ obtidos podem ser expressos em termos dos $n$ momentos ao redor da média, como apresentado abaixo para os três primeiros termos da função polinomial.

$$
\mathrm{U}(\mathrm{x})=\mathrm{E}(\mathrm{x})+\mathrm{b}\left\{\mathrm{m}_{2}(\mathrm{x})+[\mathrm{E}(\mathrm{x})]^{2}\right\}+\mathrm{c}\left\{\mathrm{m}_{3}(\mathrm{x})+3 \mathrm{E}(\mathrm{x}) \mathrm{m}_{2}(\mathrm{x})+[\mathrm{E}(\mathrm{x})]^{3}\right\}
$$

onde $m_{2}(x)$ e $m_{3}(x)$ representam o segundo (variância) e o terceiro (assimetria) momentos, respectivamente, da distribuição dos retornos ao redor da média.

Conforme discute Mendes (1980), para a utilização do método de análise da MédiaVariância torna-se necessário que a função de utilidade do tomador de decisões seja quadrática, e que a distribuição de freqüências dos retornos possua uma distribuição normal, e desse modo deve-se levar em conta apenas dois parâmetros: o retorno esperado e a variância do retorno esperado. Caso a função utilidade esperada for de ordem superior à quadrática, ou se a distribuição dos retornos esperados não for normal, mais parâmetros deverão ser considerados para que a análise se processe. 
Souza (1990) cita que Feldstein $(1969)^{9}$ e Borch $(1968)^{10}$ criticaram a utilização do método de Markovitz no tocante à validade de seu emprego. Tal fato levou Tobin (1969), um dos pioneiros da análise E -V ('Expected Value - Variance') a admitir que a aplicação do método se restringiria aos casos em que a função utilidade do tomador de decisão é quadrática, ou quando se considera que os retornos têm uma função de densidade de probabilidade com distribuição normal.

Tsiang (1972), discutindo o assunto, argumentou que a função quadrática, como qualquer polinomial, além das limitações quanto à aplicabilidade, implicaria em aversão absoluta a risco crescente com o aumento da riqueza do indivíduo, ou seja, indivíduos mais ricos prefeririam incorrer em menos riscos em termos absolutos, e desta forma obteria-se resultado discordante em relação ao comportamento esperado dos indivíduos e portanto considerado absurdo.

Tsiang (1972) demonstra em seu estudo que há justificativa para a utilização da análise $\mathrm{E}-\mathrm{V}$, mesmo que a função não seja polinomial, pois qualquer que seja a função de utilidade, a mesma pode ser aproximada para uma polinomial ao sofrer expansão de acordo com a "Série de Taylor", desde que certas condições sejam satisfeitas, ou seja, admitir pequenas variações do coeficiente de aversão ao risco em torno do ponto escolhido sobre a função de utilidade que foi expandida pela 'Série de Taylor". Desta maneira, a utilidade esperada passa a depender então somente dos dois primeiros momentos centrais da distribuição.

Segundo Mendes (1980), "a seleção de alternativas baseadas na renda e na variância não implica necessariamente que a função utilizada seja quadrática, mas a mesma apresenta ótimos resultados quando utilizada para representar a função de utilidade do indivíduo, se comparada com outras funções polinomiais."

Nesta mesma linha, Mendes (1980) cita Anderson, Dillon \& Hardaker $(1977)^{11}$, dizendo que as funções quadráticas de utilidade podem ser utilizadas como aproximações

\footnotetext{
${ }^{9}$ FELDSTEIN, M.S. Mean variance analysis in the theory of liquidity preference and portfolio selection. R. Econ. Stud., 36(1):5-14, 1969.

${ }^{10}$ BORCH, K. Economics of uncertainty. Princeton, Princeton University Press, 1968.

${ }^{11}$ ANDERSON, J.R.; DILLON,J.L. and HARDAKER, B. Agricultural Decision Analysis, The Iowa State University Press, Ames, Iowa, 1977.
} 
das funções "reais" de utilidade, através da expansão pela "Série de Taylor". Eles observaram a veracidade deste fato, toda vez que as derivadas, além da segunda, são suficientemente pequenas para serem ignoradas, ou seja, se o risco agregado assumido pêlos produtores é pequeno, em proporção às riquezas totais.

Conforme Mendes (1980), se x é o risco esperado, a expressão que se aproxima da função de utilidade quadrática, $\mathrm{U}(\mathrm{x})=\mathrm{x}+\mathrm{bx}^{2}$, pode ser escrita como:

$$
\mathrm{U}(\mathrm{x})=\mathrm{E}(\mathrm{x})+\mathrm{bE}(\mathrm{x})^{2}+b m_{2}(\mathrm{x})
$$

a qual muitas vezes pode ser representada em termos da média (E) e variância (V) como:

$$
\mathrm{U}=\mathrm{E}+\mathrm{bE} \mathrm{E}^{2}+\mathrm{bV}
$$

onde $\mathrm{E}$ é a $\mathrm{E}(\mathrm{x})$ e $\mathrm{V}$ é $\mathrm{m}_{2}(\mathrm{x})$ ". Uma dedução mais detalhada desta função utilidade pode ser encontrada no Apêndice 1.

Segundo Takayama \& Batterham (1972), Mendes (1980) e Pereira (1985), seja a expressão (6) a função utilidade de um indivíduo qualquer, e a variável $\mathrm{x}$ considerada a renda, então existem derivadas de ordem n qualquer associadas a esta função, onde concluise o seguinte:

$$
\partial \mathrm{U} / \partial \mathrm{E}=1+2 \cdot \mathrm{b} \cdot \mathrm{E}>0
$$

tal derivada primeira demonstra a utilidade marginal, se for positiva, implica que a função utilidade é crescente enquanto $x$ cresce. Maiores valores para a utilidade refletem maior satisfação, sendo assim, podemos concluir que neste caso o indivíduo prefere mais unidades monetárias a menos,

$$
\partial \mathrm{U} / \partial \mathrm{V}=\mathrm{b}
$$

ou seja o sinal de $\mathrm{b}$ fornece o comportamento do produtor frente à variabilidade do retorno. Se a relação é negativa, fica demonstrada a aversão ao risco ou seja preferência pela estabilidade dos resultados. Se nula (igual a zero) ou positiva, o produtor é indiferente ao risco ou propenso ao risco, respectivamente.

$$
\partial^{2} \mathrm{U} / \partial \mathrm{E}^{2}=2 \mathrm{~b}<0
$$

Esta derivada segunda demonstra a concavidade da função. Se positiva, a função é estritamente convexa e implica na existência de propensão ao risco. Se ela for nula, a função não tem concavidade ou convexidade estrita, refletindo neutralidade ao risco. Se for 
negativa, a função é estritamente côncava, implicando em aversão ao risco e garantindo a idéia de que a utilidade marginal dos resultados é decrescente, sugerindo um nível máximo de utilidade, fazendo com que o risco envolvido atue como um moderador das preferências.

Objetivamente, derivada segunda de $\mathrm{U}$ com respeito a $\mathrm{E}\left(\partial^{2} \mathrm{U} / \partial \mathrm{E}^{2}\right)$ mostra que se $\mathrm{b}<$ 0 , haverá decréscimo da utilidade marginal enquanto $E$ sofre incremento, ou seja, a variabilidade do retorno não é desejada e o produtor mostra-se avesso ao risco.

Assim sendo, o comportamento presumido pela Análise E-V expressa-se através da utilidade marginal dos resultados positiva e decrescente, aliada à utilidade marginal da variância, que é negativa.

Outra pressuposição que é considerada como comum à função de utilidade é a de que a mesma seja estritamente côncava ou estritamente quase-côncava, implicando que o produtor tenha aversão ao risco. Mendes (1980) cita Francis $(1976)^{12}$, o qual sugere que esta é uma pressuposição razoável, porque uma função de utilidade convexa implica afirmar que o produtor rural prefere o risco, e isto aparentemente representa uma situação anormal, pois no mundo real, poucos tomadores de decisões demonstraram tal comportamento. A situação mais comum parece ser a de indivíduos avessos ao risco, uns mais e outros menos. No caso de um produtor avesso ao risco, quanto maior a variância da renda esperada, devido a uma maior variabilidade nos preços do produto, menor o nível de utilidade deste indivíduo. A aversão ao risco implica necessariamente que o produtor requer aumentos na renda a taxas crescentes para cada unidade adicional de risco.

Segundo Peixoto (1976), as características de comportamento associadas a função de utilidade podem ser derivadas a partir das curvas de iso-utilidade do indivíduo, obtidas a partir da equação (7), mantido um nível fixo de utilidade, $U^{*}$, de forma que,

$$
\mathrm{U}^{*}=\mathrm{E}+\mathrm{b} \cdot \mathrm{E}^{2}+\mathrm{b} \cdot \mathrm{V}
$$

Dividindo-se a equação (11) por b e rearranjando, tem-se

$$
\mathrm{V}=\mathrm{U}^{*} / \mathrm{b}-\mathrm{E} / \mathrm{b}-\mathrm{E}^{2}
$$

As propriedades das curvas de iso-utilidades no plano [E, V], são conseguidas pela diferenciação de (11), ou seja:

\footnotetext{
${ }^{12}$ FRANCIS, J.C. Investments: Analysis and managment, McGraw Hill, Inc., Second Edition, 1976.
} 


$$
\begin{gathered}
\mathrm{dE} / \mathrm{dV}=-\mathrm{b} /[1+2 \cdot \mathrm{b} \cdot \mathrm{E}]>0 \\
\mathrm{~d}^{2} \mathrm{E} / \mathrm{dV^{2 }}=2 \mathrm{~b}^{2} /[1+2 \cdot \mathrm{b} \cdot \mathrm{E}]^{2} \cdot \mathrm{dE} / \mathrm{dV}>0
\end{gathered}
$$

Face à aversão ao risco (expressão 9) e à utilidade marginal dos retornos positiva (expressão 8), as expressões (13) e (14) se tornam positivas. Com isso verifica-se que o mapa de indiferença do indivíduo avesso ao risco é composto por curvas de indiferença inclinadas positivamente e com a concavidade voltada para cima, expressas em termos de retorno esperado e variância.

Uma interpretação sobre a atitude tomada pelo produtor frente ao risco pode ser obtida a partir do comportamento do retorno esperado em função da variância de um sistema de curvas de indiferença, o qual pode ser derivado da sua função de utilidade. De acordo com Peixoto (1976), um sistema de curvas de indiferença descreve quanto o retorno de um determinado investimento pode aumentar para compensar um aumento na variância do risco de um investimento. Uma curva específica de indiferença, ou iso-utilidade, é o "locus" de todas as combinações de média-variância que fornece o mesmo nível de utilidade. A inclinação de uma curva de indiferença em qualquer ponto fornece a taxa marginal de substituição entre média e variância. Quanto maior for a inclinação $(\partial \mathrm{E} / \partial \mathrm{V})$ de uma curva de indiferença, maior o grau de aversão ao risco que ela fornece.

Para Mendes (1980), um aspecto bastante relevante a ser considerado na seleção de atividades dominantes é o conceito de diversificação introduzido por Markovitz, o qual envolve a combinação de investimentos com correlações positivas menos que perfeitas, com o objetivo de reduzir o risco de um portfólio sem sacrificar o retorno esperado. Geralmente, quanto menor o grau de correlação entre as atividades de um portfólio, menor o risco que o mesmo fornece. Num portfólio com um grande número de atividades correlacionadas, as covariâncias se tornam mais importantes que as variâncias, ou seja, uma atividade adiciona mais ou menos variabilidade a um portfólio de acordo com a soma de sua covariância com as outras atividades. Dado um retorno esperado, variância e covariância dos retornos das atividades, a principal preocupação da análise do portfólio é a computação de uma fronteira eficiente E-V. Uma fronteira eficiente E-V é baseada na dominância de certos princípios, de tal forma que: 
a) dentre todos os investimentos com uma dada taxa de retorno, o que oferece mínimo risco é o mais desejável ou;

b) dentre todas as alternativas de uma dada classe de risco, a que oferece a mais alta taxa de retorno é a preferível.

Segundo Mendes (1980) como resultado, a fronteira eficiente E-V é o "locus" dos pontos de renda-variância esperados de uma atividade dominante. Com a fronteira eficiente (E-V) da renda-variância esperada, o produtor é obrigado a selecionar um ponto sobre a fronteira, de acordo coma sua função de utilidade original. A pressuposição básica é a de que o produtor deseja maximizar a sua utilidade esperada sujeito a um dado coeficiente de aversão ao risco e restrição de recursos. Portanto, características de um produtor individual, incluindo suas condições financeiras e aversão ao risco, afetam sobremaneira a escolha de alternativas de comercialização.

Partindo de um coeficiente de aversão ao risco, pode-se construir curvas de indiferença ou iso-utilidade, com $\mathrm{U} 1<\mathrm{U} 2<\mathrm{U} 3$, conforme representado na Figura 6. Os pontos $\mathrm{A}, \mathrm{B}$ e $\mathrm{C}$ representam diferentes pontos de maximização de utilidade, de acordo com os diferentes coeficientes de aversão ao risco $(\alpha)$. Estes pontos compreendem um conjunto de estratégias de comercialização que maximizam a renda esperado para um dado risco, ou minimizam o risco para um dado nível de renda esperada.

Para um dado coeficiente de aversão ao risco $\alpha_{B},\left(\alpha_{A}>\alpha_{B}>\alpha_{C}\right)$ a utilidade pode ser maximizada no ponto $B$, onde a curva de indiferença ou iso-utilidade é tangente a fronteira eficiente E-V. O ponto $\mathrm{P}$ no topo da fronteira eficiente determina a máxima renda, e é idêntica à solução de maximização da renda esperada encontrada na programação linear. 


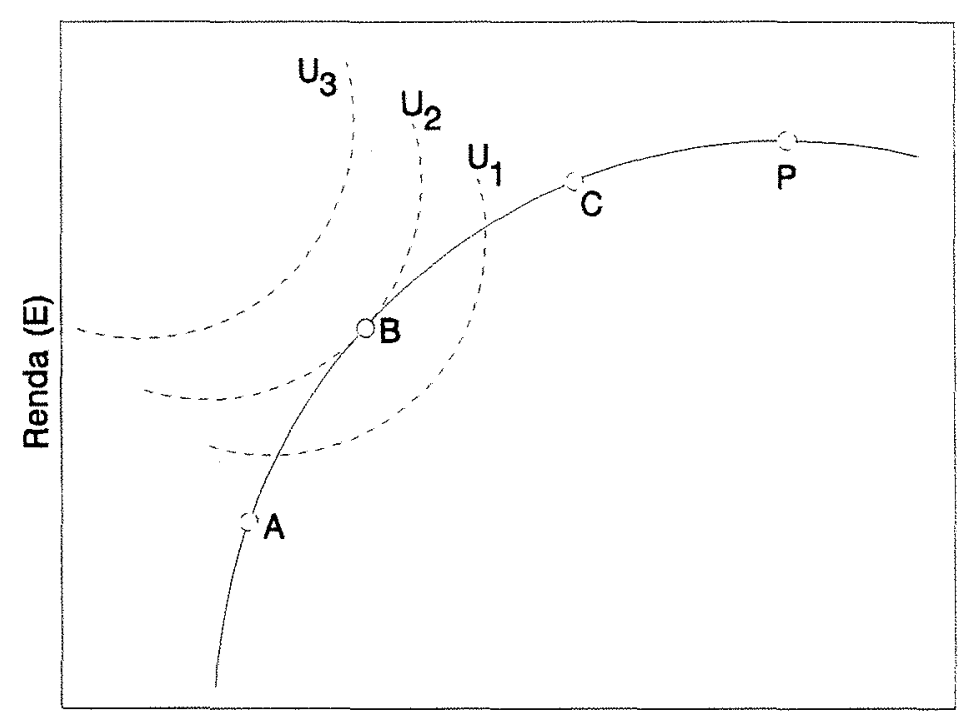

Variância $(N)$

Figura 6 - Espaço E-V da fronteira eficiente e utilidade

Segundo Mendes (1980), movimentos descendentes sobre a fronteira eficiente E-V indicam Portfólios com grande diversificação - o aumento da diversificação incrementa a correlação positiva entre as rendas esperadas com uma redução no risco. Entretanto, a análise E-V proporciona uma série de alternativas eficientes, sendo a melhor seleção uma função subjetiva do tomador de decisão.

Especificamente, as pressuposições discutidas acima para seleção do modelo são:

a) $\mathrm{O}$ produtor possui uma função de utilidade quadrática e a distribuição de freqüência dos retornos esperados é normal, implicando com isso que ele somente vai considerar a renda esperada (E) e a variância (V) da renda esperada da sua decisão, sempre observando sua limitação de aplicabilidade que implicaria em aversão absoluta a risco crescente com o aumento da riqueza e que deve-se admitir somente pequenas variações do coeficiente de aversão ao risco em torno da expansão com a "Série de Taylor".

b) O produtor é avesso ao risco, implicando que ele deseja um aumento no nível de seu retorno para compensar um aumento adicional no nível de risco. 
c) Dados de preços passados são fontes confiáveis para guiar o tomador de decisão na escolha das suas estratégias de comercialização.

d) Sabendo-se das limitações da análise E-V e guardando-se as condições básicas de aplicabilidade usou-se o Método de Markowitz para determinação de estratégias eficientes de comercialização de soja para o Estado do Paraná no período de 1980-95.

\section{4 - Modelo Matemático Proposto}

De acordo com Mendes (1980), partindo dos pressupostos citados, a programação quadrática pode ser selecionada para avaliar as estratégias de comercialização e estimar a fronteira eficiente (E-V) de renda-risco. Outros métodos de avaliação relacionados com a tomada de decisão frente ao risco de mercado são: o modelo MOTAD, e a Dominância Estocástica, aos quais cabe um breve comentário.

Segundo Lopez (1977) o MOTAD (Minimization of Total Absolute Deviation), foi proposto por Hazell (1971) e surgiu como uma alternativa à análise da fronteira eficiente (EV), pois o mesmo utiliza os desvios totais absolutos, em vez da variância. Como característica principal, apresenta a vantagem de transformar o problema de programação quadrática em programação linear. O método apresenta resultados confiáveis se as seguintes condições forem simultaneamente satisfeitas: a) a função de utilidade do tomador de decisão é quadrática ou a distribuição de freqüência dos retornos é normal; b) o tamanho da amostra é considerável.

A maior restrição ao uso deste método neste estudo, consiste no fato do MOTAD ser uma aproximação linear do Método de análise E-V. Assim sendo, optou-se pela utilização do Método de análise $\mathrm{E}-\mathrm{V}$, mais realístico para o caso em questão que a aproximação a ser obtida pelo MOTAD.

De acordo com Souza (1990), o método da Dominância Estocástica, desenvolvido por Quirk \& Saposnik (1962), e revisto por Hadar \& Russel (1969), é um método que difere do anterior por não levar em conta apenas os dois primeiros momentos da distribuição ao redor da média ou suas aproximações; ele considera o terceiro momento em relação à 
média, o qual mede a assimetria das distribuições de probabilidade, ou seja, sua inclinação para a direita ou para a esquerda. Este método possui as características de poder classificar alternativas incertas, mesmo desconhecendo-se maiores detalhes sobre a função de utilidade do tomador de decisão e sem considerar ainda que os retornos possuem densidade de probabilidade com distribuição normal.

Souza (1990) cita que Porter \& Gaumnitz (1972), compararam exaustivamente os dois métodos a partir de um grande número de alternativas. Gerada a fronteira eficiente E$\mathrm{V}$, e de posse do grupo de alternativas dominantes pela DEP (dominância estocástica de primeiro grau), DES (dominância estocástica de segundo grau) e DET (dominância estocástica de terceiro grau), concluiu-se que o uso da DEP como critério de seleção mostrou-se ineficiente, pois poucas alternativas foram eliminadas. A DET, por sua vez, reduziu bastante o número de alternativas, eliminando o conflito quanto à eficiência dos métodos.

Comparando as alternativas escolhidas com a utilização DES e o método E-V, nos casos em que havia elevados retornos e variância, ou seja aquelas alternativas preferidas por investidores menos avessos ao risco, pode-se aplicar indiferentemente os dois métodos, uma vez que quanto mais elevadas as médias e variâncias, mais os grupos eficientes de acordo com a E-V e DES se tornam semelhantes. Já no caso de investidores altamente avessos ao risco, utilizando-se alternativas classificadas pelo método $\mathrm{E}-\mathrm{V}$, há maior probabilidade de que elas apresentem mais baixos retornos que no emprego da DES.

Neste estudo optou-se pelo enfoque da programação quadrática (PQ), como modelo teórico a ser utilizado. Segundo Cutler \& Pass (1971) a programação Quadrática (PQ) é uma extensão da programação linear (PL), que possibilita, no caso, a consideração de risco (a PL ignora a matriz de variância-covariância entre as estratégias de comercialização). $\mathrm{O}$ modelo de programação quadrática parte dos seguintes pressupostos: a) o objetivo de maximização de lucro, por parte do produtor rural, é diretamente afetado pela sua aversão ao risco; b) à medida em que o valor do coeficiente de aversão ao risco diminui, a renda esperada tende a aumentar; c) o aumento da renda está associado a uma maior variabilidade da mesma. 
A programação quadrática, freqüentemente citada na literatura de economia agrícola, tem sido usada para analisar ajustamentos na produção e políticas de comercialização (tais como em contratos, 'Hedging", 'Pooling", venda seqüencial, em investimentos e financiamentos).

Seguindo Markowitz (1959), Takayama \& Batterham (1972) e Mendes (1980) a derivação do modelo matemático de Markowitz-Tobin que vai ser utilizado neste estudo para a seleção de Portfólios eficientes será discutida a seguir.

Inicialmente, definem-se as variáveis:

$\mathrm{p}_{\mathrm{ij}}=$ preço líquido esperado por unidade de atividade $\mathrm{i}$ no mês $\mathrm{j}(\mathrm{i}=1,2 \ldots \mathrm{n} ; \mathrm{j}=$ $1, \ldots, 12)$

$\sigma_{\mathrm{ij}}=$ covariância do preço líquido unitário da atividade i no mês $\mathrm{j}$;

$\mathrm{x}_{\mathrm{ij}}=$ unidades de produção esperada alocadas para a atividade i no mês $\mathrm{j}$;

$\mathrm{A}_{\mathrm{ij}}=$ custo de armazenagem por unidade de atividade i no mês $\mathrm{j}$;

$\mathrm{T}_{\mathrm{ij}}=$ custo de transporte por unidade de atividade i no mês $\mathrm{j}$;

$\mathrm{R}_{\mathrm{ij}}=$ custo de repagamento por unidade de atividade $\mathrm{i}$ no mês $\mathrm{j}$;

$\mathrm{C}_{\mathrm{ij}}=$ custo variável menos o valor básico de custeio por unidade de atividade i no mês j.

Qualquer combinação específica de $n$ atividades de risco vai proporcionar um retorno líquido esperado (E) de:

$$
E=\sum_{i=1}^{n} \sum_{j=1}^{i 2} p_{i j}-\sum_{i=1}^{n} \sum_{j=1}^{12}\left(A_{i j}+T_{i j}+R_{i j}+C_{i j}\right) \cdot x_{i j}
$$

sendo a variância do retorno líquido esperado $V(E)$ igual a:

$$
\mathrm{V}(\mathrm{E})=\sum_{i=1}^{n} \sum_{j=1}^{12} \sigma_{i j} x_{i j} x_{i j}
$$

Substituindo as equações (15) e (16) na função de utilidade quadrática do tomador de decisão (U), apresentada em (7), o problema passa a ser representado por um conjunto de valores para $\mathrm{x}_{\mathrm{ij}}$ que maximizem:

$$
\sum_{i=1}^{n} \sum_{j=1}^{12} p_{i j} x_{i j} \sum_{i=1}^{n} \sum_{j=1}^{12}\left(A_{i j}+T_{i j}+R_{i j}+C_{i j}\right) x_{i j}+b\left[\sum_{i=1}^{n} \sum_{j=1}^{12} p_{i j} x_{i j}-\sum_{i=1}^{n} \sum_{j=1}^{12}\left(A_{i j}+T_{i j}+R_{i j}+C_{i j}\right) x_{i j}\right]^{2}+b\left[\sum_{i=1}^{n} \sum_{j=1}^{12} \sigma_{g} x_{i j} x_{i j}\right]
$$


sujeito a um conjunto de restrições de recursos, assim como a $\mathrm{x}_{\mathrm{ij}} \geq 0$.

Mendes (1980) cita que Taha (1976, p.327) concluiu que, 'usando a expansão pela série de Taylor, podemos demonstrar que os três primeiros termos da função de utilidade esperada proporciona um critério semelhante ao apresentado a seguir":

$$
Z=\sum_{i=1}^{n} \sum_{j=1}^{12} p_{i j} x_{i j}-\sum_{i=1}^{n} \sum_{j=1}^{12}\left(A_{i j}+T_{i j}+R_{i j}+C_{i j}\right) x_{i j}-\alpha \sum_{i=1}^{n} \sum_{j=1}^{12} \sigma_{i j} x_{i j} x_{i j}
$$

a qual, em notação matricial, poderia ser representada por:

$$
Z=P X-(A+T+R+C) X-\alpha X^{\prime} D X
$$

onde: $\mathrm{Z}$ = função objetivo a ser maximizada;

$\mathrm{P}=$ vetor-linha dos preços líquidos unitários por estratégia de comercialização;

$\mathrm{X}=$ vetor-coluna do nível de estratégias;

$\mathrm{A}=$ vetor-linha dos custos unitários de armazenagem por estratégia/mês;

$\mathrm{T}$ = vetor-linha dos custos unitários de transporte por estratégia/mês;

$\mathrm{R}$ = vetor-linha dos custos unitários de repagamento por estratégia/mês;

$\mathrm{C}=$ escalar do custo variável de produção;

$\alpha=$ coeficiente de aversão ao risco ou escalar;

$\mathrm{D}=$ matriz de variância-covariância

Taha (1976), enfatizou que a expressão (19) é compativel com o uso da utilidade como critério na decisão, pois o fator da aversão ao risco $(\alpha)$ é um indicador da atitude do empresário frente a um desvio excessivo dos valores esperados.

Portanto, o objetivo é maximizar a expressão (19) sujeito às seguintes restrições:

$$
R V=\sum_{i=1}^{n} \sum_{j=1}^{12} x_{i j}=1
$$




$$
\begin{aligned}
A X & \leq B \\
X & \geq 0
\end{aligned}
$$

onde:

$$
\begin{aligned}
& \mathrm{RV}=\text { restrição de venda } \\
& \mathrm{A}=\text { coeficiente da matriz de insumo-produto, } \mathrm{e} \\
& \mathrm{B}=\text { vetor-coluna dos níveis de recursos e outras restrições. }
\end{aligned}
$$

De acordo com Takayama \& Batterham (1972), neste modelo, $\alpha$ desempenha o papel de ajustar o ótimo das estratégias de comercialização. Desta forma, o escalar $\alpha$, aplicado às relações de variância-covariância para refletir a aversão ao risco, sofre parametrização no intervalo de 0 a 1 , em valor absoluto, objetivando gerar soluções para tomadores de decisão com comportamento diferente em relação ao risco de mercado. $\mathrm{O}$ valor zero para o coeficiente de aversão ao risco $(\alpha=0)$, ou seja, a não existência do elemento risco vai converter o modelo de PQ em um modelo de PL (produtores indiferentes frente ao risco de mercado). À medida em que a parametrização aumenta, ou seja, $\alpha$ sofre incremento, o modelo fornece planos de comercialização formados por um conjunto de estratégias de comercialização.

\section{5 - Especificação dos Dados}

Para o processamento da análise, utilizou-se o modelo proposto por MarkowitzTobin (1972), sobre o qual alterações foram incorporadas, dentre elas a utilização de custos de armazenagem e transporte, aplicação do VBC (Valor Básico de Custeio) como indicador de necessidade de capital para plantio. Foi necessária também a utilização de uma série de preços recebidos pelos produtores de soja no Estado do Paraná (médias mensais) para o periodo correspondente entre os anos de 1980 e 1995, preços estes coletados junto à Secretaria da Agricultura do Estado do Paraná (SEAB-PR). A série de preços forneceu parte das informações necessárias para a elaboração das estratégias de comercialização, 
juntamente com outros dados como: custos de produção de soja (com base em valores estimados pela SEAB e pelas Cooperativas); necessidade de crédito agrícola e financiamentos; custos de transporte; taxas de juros; custos de armazenamento; e produtividade.

O modelo de programação quadrática a ser utilizado compreende 20 estratégias de comercialização, as quais tentam refletir as alternativas de venda atualmente disponíveis aos produtores. Uma estratégia de comercialização poderá assim compreender uma alternativa de venda ou combinação de mais de uma dessas alternativas.

As estratégias são as seguintes:

a) Venda na época da colheita:

$\mathrm{EC}_{1}, \mathrm{EC}_{2}$ - venda total da produção ou parte dela na época da colheita, em março ou abril.

b) Armazenagem para venda futura:

$\mathrm{EC}_{3} ; \ldots, \mathrm{EC}_{10}$ - armazenar a produção na época da colheita, para posterior venda futura quando o preço for compensador durante o ano.

c) Vendas diversificadas:

$E_{11}$ - armazenar na época da colheita, para posterior venda de $1 / 2$ em maio e $1 / 2$ em setembro, respectivamente.

$E_{12}$ - armazenar na época da colheita, para posterior venda de $1 / 3 \mathrm{em}$ maio, $1 / 3$ em julho e $1 / 3$ em setembro, respectivamente.

$\mathrm{EC}_{13}$ - armazenar na época da colheita, para posterior venda de $1 / 3 \mathrm{em}$ maio, $1 / 3$ em agosto e $1 / 3$ em outubro, respectivamente. 
$E C_{14}$ - armazenar na época da colheita, para posterior venda de $1 / 4 \mathrm{em}$ abril, $1 / 4$ em junho, $1 / 4$ em agosto e $1 / 4$ outubro, respectivamente.

$\mathrm{EC}_{15}$ - armazenar na época da colheita, para posterior venda de $1 / 2$ em agosto e $1 / 2$ em outubro, respectivamente.

$\mathrm{EC}_{16}$ - armazenar na época da colheita, para posterior venda de $1 / 2$ em julho e $1 / 2$ em setembro, respectivamente.

$\mathrm{EC}_{17}$ - armazenar na época da colheita, para posterior venda de $1 / 2$ em setembro e $1 / 2$ em outubro, respectivamente.

$\mathrm{EC}_{18}$ - armazenar na época da colheita, para posterior venda de $1 / 2$ em outubro e $1 / 2$ em novembro, respectivamente.

$\mathrm{EC}_{19}$ - armazenar na época da colheita, para posterior venda de $1 / 2$ em setembro e $1 / 2$ em dezembro, respectivamente.

$\mathrm{EC}_{20}$ - armazenar na época da colheita, para posterior venda de $1 / 3 \mathrm{em}$ abril, $1 / 3$ em setembro e $1 / 3$ em dezembro, respectivamente.

O procedimento para o cálculo dos preços líquidos para cada estratégia de comercialização foi a seguinte:

$\mathrm{EC}_{1}$ - preço médio de venda em março menos o repagamento dos empréstimos e o custo de transporte.

$\mathrm{EC}_{2}$ - preço médio de venda em abril menos o repagamento dos empréstimos e o custo de transporte. 
$\mathrm{EC}_{3}, \ldots, \mathrm{EC}_{10}$ - preço médio de venda em cada mês correspondente menos o custo de armazenamento, repagamento dos empréstimos e o custo de transporte.

$\mathrm{EC}_{11}$ - preço médio de venda em maio e setembro menos os custos de armazenagem, repagamento dos empréstimos e custo de transporte.

$\mathrm{EC}_{12}$ - preço médio de venda em maio, julho e setembro menos os custos de armazenagem, repagamento dos empréstimos e custo de transporte.

$\mathrm{EC}_{13}$ - preço médio de venda em maio, agosto e outubro menos os custos de armazenagem, repagamento dos empréstimos e custo de transporte.

$\mathrm{EC}_{14}$ - preço médio de venda em abril, junho, agosto e outubro menos os custos de armazenagem, repagamento dos empréstimos e custo de transporte.

$\mathrm{EC}_{15}$ - preço médio de venda em agosto e outubro menos os custos de armazenagem, repagamento dos empréstimos e custo de transporte.

$\mathrm{EC}_{16}$ - preço médio de venda em julho e setembro menos os custos de armazenagem, repagamento dos empréstimos e custo de transporte.

$\mathrm{EC}_{17}$ - preço médio de venda em setembro e outubro menos os custos de armazenagem, repagamento dos empréstimos e custo de transporte.

$\mathrm{EC}_{18}$ - preço médio de venda em outubro e novembro menos os custos de armazenagem, repagamento dos empréstimos e custo de transporte. 
$\mathrm{EC}_{19}$ - preço médio de venda em setembro e dezembro menos os custos de armazenagem, repagamento dos empréstimos e custo de transporte.

$\mathrm{EC}_{20}$ - preço médio de venda em abril, setembro e dezembro menos os custos de armazenagem, repagamento dos empréstimos e custo de transporte.

Das alternativas consideradas na teoria, algumas não foram incorporadas ao modelo devido à falta de dados disponíveis ou por não haver uma série de dados suficiente para ser utilizada (no caso, aquelas relativas a contratos de produção antes da colheita, vendas em comum ou 'Pooling" e "Hedging'). De qualquer forma, para o modelo proposto, não importa onde a soja esteja armazenada (na fazenda ou no armazém), quem possua os títulos de venda da mesma (o produtor ou o armazenador) e o tempo que o produtor vai esperar para vender sua soja numa data posterior.

O custo de armazenamento foi calculado a partir de uma série de dados fornecida pela CONAB (Companhia Nacional de Abastecimento, antiga CIBRAZEM - Companhia Brasileira de Armazenagem) e pela CODAPAR (Companhia de Abastecimento do Paraná), para os últimos cinco anos.

O empréstimo foi calculado pelo antigo VBC (valor básico de custeio), valor médio para os últimos cinco anos, baseado na produtividade média da propriedade em questão, cujo repagamento será feito inicialmente com uma taxa de juros de mercado de $16 \%$ a.a. ou 1,24\% a.m. Se houver necessidade, este empréstimo será convertido em EGF (empréstimo do governo federal) para possibilitar uma prorrogação de pagamentos que possibilite um preço futuro melhor.

Os custos de produção foram determinados com base em levantamentos feitos pelo DERAL (Departamento de Economia Rural)/SEAB-PR e pela COTREFAL (Cooperativa Agropecuária Três Fronteiras Ltda.), para agricultores que adotam tecnologias modernas no Paraná e que produzem cerca de $3.000 \mathrm{~kg} /$ ha ou seja 50 sacas de $60 \mathrm{~kg}$ por hectare. A área média cultivada correspondeu a 150 ha. 
Quanto aos custos de transporte, os mesmos sofrem uma sazonalidade de oferta e preço durante o ano. Quando está ocorrendo a colheita, a demanda por transporte normalmente aumenta, encarecendo desta maneira o custo de transporte, o qual vai reduzindo-se gradativamente durante $o$ ano até estabilizar-se. Este custo foi calculado para o período dos últimos cinco anos, segundo dados de Safras \& Mercados (1996).

Para a realização das simulações do Modelo de Programação foram testados dois pacotes computacionais distintos. Inicialmente usou-se o ORSYS - Operational Research System, da Eastern Software, no qual foram realizadas simulações admitindo a ausência de risco - Modelo de Programação Linear. Entretanto quando da incorporação da matriz de variância-covariância (parte quadrática do modelo) ao Modelo Linear, o ORSYS não respondeu adequadamente, optando-se então por outro pacote computacional denominado GAMS - General Algebraic Modelling System, o qual demonstrou ser muito mais flexível para a realização de repetidas simulações de programação linear assim como das simulações inerentes ao modelo de programação quadrática. Para a obtenção da matriz de variânciacovariância do Modelo Básico, utilizou-se dados de preços das estratégias de comercialização existentes que foram aplicados ao programa MATLAB que gerou então tal matriz.

\section{6 - Considerações Finais}

Neste capítulo, realizou-se inicialmente uma revisão bibliográfica mostrando a importância do risco e da incerteza, e sua influência sobre a tomada de decisão principalmente no setor agrícola; apresentou-se posteriormente as principais estratégias de comercialização da produção vigentes aos produtores rurais; discutiu-se sobre os modelos de decisão envolvendo risco; formulou-se um modelo matemático para a análise das estratégias de comercialização de soja e finalmente especificou-se os dados necessários para que a análise fosse realizada.

No próximo capítulo realizam-se as análises dos resultados fornecidos pelo modelo básico, discutem-se os efeitos da aversão ao risco sobre a renda líquida esperada pêlos 
sojicultores; analisam-se a fronteira eficiente da média-variância para o modelo básico e finalmente realizam-se as análises sobre as simulações do modelo básico. 


\section{4 - RESULTADOS E DISCUSSÃO}

O objetivo maior deste capítulo consiste na análise dos efeitos da variabilidade dos preços da soja associados aos diferentes valores do coeficiente de aversão ao risco $(\alpha)$ dos produtores, na determinação de estratégias de comercialização de soja com risco mínimo e na elaboração da fronteira eficiente de renda-risco.

O modelo de programação quadrática, pela maximização da função objetivo, como especificado no capítulo 3 , equação 18 , proporciona um plano ótimo, o qual compreende uma estratégia ou a combinação de um conjunto de estratégias de comercialização para a produção.

Segundo Takayama \& Batterham (1972), conforme varia o coeficiente de aversão ao risco $(0<\alpha<1)$, uma série de planos ótimos são gerados, uma vez que há um plano ótimo para cada escalar. Altos valores para o coeficiente de aversão ao risco vão implicar necessariamente um alto grau de aversão ao risco por parte dos produtores. De outra maneira, se o coeficiente de aversão ao risco aproximar-se de zero, o produtor tende a permanecer indiferente ao risco.

Quando o elemento risco é nulo, ou seja, se o coeficiente de aversão ao risco é zero ou se a matriz de variância-covariância é uma matriz nula, então o plano ótimo de comercialização de soja obtido é o mesmo proporcionado pelo modelo de programação linear.

Neste estudo, dado que a matriz de variância-covariância não é uma matriz nula, o completo desconhecimento do risco só é possível no caso em que o coeficiente de aversão ao risco for igual a zero. 
Os preços médios recebidos pelos produtores de soja no estado do Paraná, no período de 1980-95, assim como suas respectivas variâncias para cada estratégia de comercialização, são apresentados na Figura 7. Os dados mostram que a estratégia com menor preço médio recebido é a $\mathrm{EC}_{2}$ (venda em abril, época da colheita) e a que apresenta o maior preço médio recebido é a $\mathrm{EC}_{10}$ (venda em dezembro), enquanto que a estratégia com menor variância é a $\mathrm{EC}_{13}$ (venda de 1/3 da produção em maio, $1 / 3$ em agosto e $1 / 3 \mathrm{em}$ outubro) e a com maior variabilidade nos preços é a $\mathrm{EC}_{7}$ (venda em setembro).

Sabe-se que são preferidas as estratégias com maiores preços associadas às menores variâncias. Neste caso, a estratégia $\mathrm{EC}_{13}$ é preferível à $\mathrm{EC}_{12}$ (venda de $1 / 3$ da produção em maio, $1 / 3$ em julho e $1 / 3$ em setembro), a estratégia $\mathrm{EC}_{20}$ (venda de $1 / 3 \mathrm{em}$ abril, $1 / 3 \mathrm{em}$ setembro e $1 / 3$ em dezembro), é em princípio melhor do que a $\mathrm{EC}_{5}$ (venda em julho), e assim por diante.

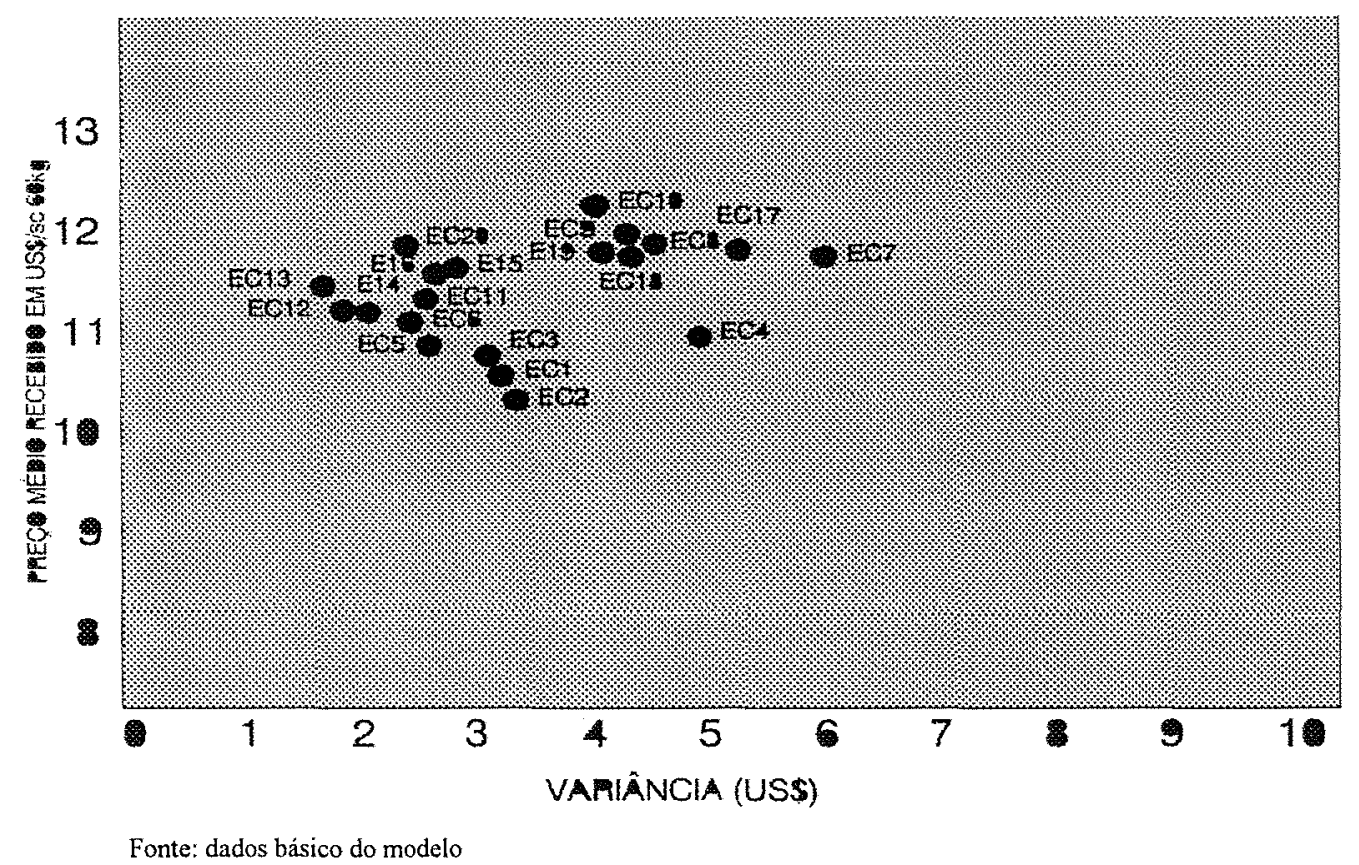

Figura 7 - Estratégias de Comercialização de soja no Espaço da Média-Variância, Modelo Básico - PR - 1980-95. 


\section{1 - Análise das Soluções do Modelo Básico}

O modelo básico pode ser caracterizado por representar uma propriedade típica do Estado do Paraná produzindo soja em um alto grau de especialização e com uso intensivo de tecnologias. A área plantada corresponde a 150 ha e apresenta uma produtividade de 50 sacas de $60 \mathrm{~kg}$ por hectare ou $3.000 \mathrm{~kg}$ de soja por hectare; o custo variável por saca de 60 $\mathrm{kg}$ produzida é de US\$ 5,45; a necessidade de capital para o plantio é de US\$ 4,50 por saca de $60 \mathrm{~kg}$; o custo de armazenagem é de US\$ 0,08 por saca de $60 \mathrm{~kg}$ por mês, a taxa de juros para o repagamento dos empréstimos é de $16 \%$ a.a. ou $1,24 \%$ a.m. e o custo de transporte considerando a distância de $600 \mathrm{~km}$ (Cascavel - Paranaguá) é de US\$25,00 por tonelada na época de safra e US\$ 17,00 por tonelada na entressafra.

Os resultados obtidos pelo Modelo Básico indicam que produtores de soja com "maior aversão ao risco" selecionam, a princípio, um conjunto de estratégias de comercialização diferente daquele selecionado por tomadores de decisão que possuem uma "menor aversão ao risco".

O plano ótimo mais eficiente dentre todos, ou seja, a melhor combinação de Estratégias de comercialização da produção proporcionado pelo Modelo Básico diz respeito aos produtores com "media aversão ao risco" ( $\alpha$ entre 0,25 e 0,30 ), porque em relação à renda líquida média esperada haveria uma queda de apenas 3,5\% na mesma, e uma redução do risco em torno de $92,7 \%$, conforme pode ser observado na Tabela 11.

O Modelo Básico para este caso selecionou a seguinte combinação ótima de estratégias de vendas (vide Tabela 12), comercializando: 10,0\% em setembro, $12,3 \%$ em outubro, $12,7 \%$ em novembro, $15,7 \%$ em dezembro, $11,2 \%$ através da estratégia $\mathrm{EC}_{17}$ (venda de $1 / 2$ em setembro e $1 / 2$ em outubro), 13,5\% através da estratégia $\mathrm{EC}_{18}$ (venda de $1 / 2$ em outubro e $1 / 2$ em novembro), $13,6 \%$ através da estratégia $\mathrm{EC}_{19}$ (venda de $1 / 2$ em setembro e $1 / 2$ em dezembro) e $11,0 \%$ através da estratégia $E_{20}$ (venda de $1 / 3$ em abril, $1 / 3$ em setembro e $1 / 3$ em dezembro). 
Tabela 11 - Variação percentual (\%) da Renda Líquida Média Esperada e do Risco Associado em relação à solução ótima obtida pela programação linear para as Estratégias de Comercialização de Soja - Modelo Básico - PR, 1980-95.

\begin{tabular}{ccc}
\hline $\begin{array}{c}\text { Coeficiente de Aversão ao Risco } \\
(\propto)\end{array}$ & $\begin{array}{c}\text { Variação percentual da renda liquida média } \\
\text { esperada (US\$) em relação à solução da P.L.( }\left(^{*}\right)\end{array}$ & $\begin{array}{c}\text { Variação percentual do risco associado (US\$) em } \\
\text { relação à solução da P.L.(*) }\end{array}$ \\
\hline 0,0 P.L.( $\left(^{*}\right)$ & - & - \\
0,002 & $-0,15$ & $-63,8$ \\
0,003 & $-0,20$ & $-72,1$ \\
0,004 & $-0,25$ & $-77,2$ \\
0,005 & $-0,29$ & $-79,9$ \\
0,01 & $-0,43$ & $-83,8$ \\
0,02 & $-0,61$ & $-85,3$ \\
0,03 & $-0,76$ & $-86,2$ \\
0,1 & $-1,71$ & $-89,3$ \\
0,2 & $-2,94$ & $-91,8$ \\
0,25 & $-3,50$ & $-92,7$ \\
0,3 & $-4,05$ & $-93,4$ \\
0,4 & $-5,07$ & $-94,5$ \\
0,5 & $-5,99$ & $-95,2$ \\
0,6 & $-6,80$ & $-95,7$ \\
0,7 & $-7,52$ & $-96,0$ \\
0,8 & $-8,17$ & $-96,2$ \\
0,9 & $-8,76$ & $-96,3$ \\
1,0 & $-9,13$ & $-96,3$ \\
\hline
\end{tabular}

Fonte: Resultados do modelo básico.

(*) resultado obtido com a programação linear.

Tabela 12 - Percentagem de venda de soja, por Estratégia de Comercialização, segundo coeficiente de aversão ao risco - Modelo Básico - PR - 1980-95.

\begin{tabular}{|c|c|c|c|c|c|c|c|c|c|c|c|c|c|c|c|}
\hline \multirow{3}{*}{$\begin{array}{l}\text { Renda } \\
\text { Liquida } \\
\text { Esperada } \\
\text { (US\$) }\end{array}$} & \multirow{3}{*}{$\begin{array}{l}\text { Coeficiente } \\
\text { de Aversão } \\
\text { ao Risco } \\
(\alpha)\end{array}$} & \multicolumn{14}{|c|}{ Estratégias de Comercializacão de soja (\%) } \\
\hline & & EC & EC & $\mathrm{EC}$ & $\mathrm{EC}$ & EC & EC & EC & EC & $E C_{t}$ & $\mathrm{EC}$ & EC & $\mathrm{EC}$ & $\mathrm{EC}$ & $\mathrm{EC}$ \\
\hline & & 7 & 8 & 9 & 10 & 11 & 12 & 13 & 14 & $s$ & 16 & 17 & 18 & 19 & 20 \\
\hline $38.169,00$ & 0,0 (P.L.*) & & & & 100 & & & & & & & & & & \\
\hline $38.111,00$ & 0.002 & & & & 84,2 & & & & & & & & & 15,8 & \\
\hline $38.091,00$ & 0,003 & & & & 73,7 & & & & & & & & & 26,3 & \\
\hline $38.073,00$ & 0,004 & 0,4 & & & 66,4 & & & & & & & 3,5 & & 29,7 & \\
\hline $38.058,00$ & 0,005 & 4,4 & & & 59,1 & & & & & & & 7,4 & & 29,1 & \\
\hline $38.034,00$ & 0,007 & 7,8 & 2,0 & & 49,3 & & & & & & & 10,7 & 3,2 & 27,1 & \\
\hline $38.015,00$ & 0,009 & 9,0 & 5,3 & & 42,6 & & & & & & & 11,6 & 6,5 & 25,0 & \\
\hline $38.006,00$ & 0,01 & 9,4 & 6,4 & & 40,3 & & & & & & & 11,9 & 7,7 & 24,2 & \\
\hline $37.936,00$ & 0,02 & 10,9 & 11,1 & 2,6 & 29,4 & & & & & & & 13,0 & 12,5 & 20,4 & \\
\hline $37.878,00$ & 0,03 & 11,0 & 12,1 & 6,9 & 25,1 & & & & & & & 12,9 & 13,5 & 18,5 & \\
\hline $37.516,00$ & 0,1 & 11,0 & 13,5 & 12,9 & 19,1 & & & & & & & 12,7 & 14,9 & 15,9 & \\
\hline $37,045,00$ & 0,2 & 10,1 & 12,7 & 12,9 & 16,4 & & & & & & & 11,6 & 13,9 & 14,1 & 8,2 \\
\hline $36.833,00$ & 0,25 & 10,0 & 12,3 & 12,7 & 15,7 & & & & & & & 11,2 & 13,5 & 13,6 & 11,0 \\
\hline $36.624,00$ & 0,3 & 9,7 & 12,1 & 12,6 & 15,3 & & & & & & & 11,0 & 13,3 & 13,3 & 12,7 \\
\hline $36.235,00$ & 0,4 & 9,0 & 11,3 & 11,9 & 14,1 & 2,2 & & & & 2,6 & & 10,3 & 12,4 & 12,3 & 13,9 \\
\hline $35.883,00$ & 0,5 & 8,3 & 10,5 & 11,1 & 12,9 & 4,6 & & & & 4,4 & 2,1 & 9,5 & 11,5 & 11,3 & 13,8 \\
\hline $35.573,00$ & 0,6 & 7,7 & 9,8 & 10,4 & 12,0 & 5,9 & & 1,6 & 0,25 & 5,5 & 3,6 & 8,8 & 10,7 & 10,5 & 13,5 \\
\hline $35.297,00$ & 0,7 & 7,2 & 9,0 & 9,6 & 11,0 & 6,4 & 1,3 & 3,2 & 1,6 & 5,8 & 4,3 & 8,1 & 9,9 & 9,7 & 12,9 \\
\hline $35.051,00$ & 0,8 & 6,7 & 8,5 & 9,0 & 10,3 & 6,7 & 2,4 & 4,3 & 2,7 & 6,0 & 4,7 & 7,6 & 9,3 & 9,1 & 12,3 \\
\hline $34.825,00$ & 0,9 & 6,3 & 8,0 & 8,5 & 9,7 & 6,9 & 3,3 & 5,1 & 3,5 & 6,1 & 5,0 & 7,2 & 8,7 & 8,6 & 11,9 \\
\hline $34.615,00$ & 1,0 & 6,0 & 7,6 & 8,1 & 9,2 & 7,0 & 4,0 & 5,7 & 4.1 & 6,2 & 5,2 & 6.8 & 8,3 & 8,1 & 11,5 \\
\hline
\end{tabular}

Fonte: Resultados do modelo básico.

(P.L.*) solução obtida por programação linear. 
Tal plano ótimo de comercialização corresponde à armazenagem da produção na época da colheita com posterior venda mensal fracionada da produção através da seguinte composição: $3,6 \%$ em abril, $26,1 \%$ em setembro, $24,7 \%$ em outubro, $19,5 \%$ em novembro e $26,1 \%$ em dezembro, onde, $96,4 \%$ de todas as vendas se concentraram nos últimos quatro meses do ano (vide Tabela 13 e Figura 8).

Tabela 13 - Percentagem de venda de soja, Discriminação mensal, segundo coeficiente de Aversão ao Risco - Modelo Básico - PR, 1980-95.

\begin{tabular}{|c|c|c|c|c|c|c|c|c|c|c|}
\hline \multirow{2}{*}{$\begin{array}{l}\text { Coeficiente de } \\
\text { Aversão ao Risco } \\
\qquad(\alpha)\end{array}$} & \multicolumn{10}{|c|}{ Discriminação Mensal de vendas dos Planos Otimos (\%) } \\
\hline & MAR & ABR & MAI & JUN & JL & $\mathrm{AGO}$ & SET & OUT & NOV & DEZ \\
\hline $0,0\left(\right.$ P.L. $\left.{ }^{*}\right)$ & & & & & & & & & & 100 \\
\hline 0,002 & & & & & & & 7,9 & & & 92,1 \\
\hline 0,003 & & & & & & & 13,2 & & & 86,8 \\
\hline 0,004 & & & & & & & 16,9 & 1,8 & & 81,3 \\
\hline 0,005 & & & & & & & 22,7 & 3,7 & & 73,6 \\
\hline 0,007 & & & & & & & 26,5 & 9,0 & 1,6 & 62,9 \\
\hline 0,009 & & & & & & & 27,2 & 14,4 & 3,3 & 55,1 \\
\hline 0,01 & & & & & & & 27,5 & 16,2 & 3,9 & 52,4 \\
\hline 0,02 & & & & & & & 27,6 & 23,9 & 8,9 & 39,6 \\
\hline 0,03 & & & & & & & 26,6 & 25,3 & 13,7 & 34,4 \\
\hline 0,1 & & & & & & & 25,1 & 27,4 & 20,4 & 27,1 \\
\hline 0,2 & & 2,7 & & & & & 25,7 & 25,5 & 19,9 & 26,2 \\
\hline 0,25 & & 3,6 & & & & & 26,1 & 24,7 & 19,5 & 26,1 \\
\hline 0,3 & & 4,2 & & & & & 25,7 & 24,3 & 19,6 & 26,2 \\
\hline 0,4 & & 4,6 & 1,1 & & & 1,3 & 26,0 & 24,0 & 18,1 & 24,9 \\
\hline 0,5 & & 4,6 & 2,3 & & 1,1 & 2,2 & 26,7 & 23,2 & 16,7 & 23,2 \\
\hline 0,6 & & 4,6 & 3,5 & & 1,8 & 3,3 & 26,7 & 22,9 & 15,4 & 21,8 \\
\hline 0,7 & & 4,7 & 4,7 & 0,4 & 2,6 & 4,4 & 26,2 & 22,4 & 14,4 & 20,2 \\
\hline 0,8 & & 4,8 & 5,6 & 1,1 & 3,2 & 5,1 & 25,7 & 22,1 & 13,4 & 19,0 \\
\hline 0,9 & 0,5 & 4,8 & 6,3 & 1,6 & 3,6 & 5,6 & 25,2 & 21,6 & 12,8 & 18,0 \\
\hline 1,0 & 1,1 & 4,9 & 6,7 & 2,1 & 3,9 & 6,0 & 24,7 & 21,2 & 12,3 & 17,1 \\
\hline
\end{tabular}

Fonte: resultados do modelo básico.

(P.L.*) = solução obtida por programação linear.

Para produtores com "elevada aversão ao risco" $(\alpha=1)$, o Modelo Básico seleciona uma combinação ótima de vendas com uma composição diferente da solução obtida anteriormente (produtores com 'média aversão ao risco'), diversificando bastante as vendas com objetivo de reduzir o risco de mercado associado a esta atividade de venda. Assim sendo, tem-se a comercialização de $1,1 \%$ da sua produção na época da colheita em março; $1,1 \%$ em junho; $6,0 \%$ em setembro; $7,6 \%$ em outubro; $8,1 \%$ em novembro; $9,2 \%$ em dezembro; 7,0\% através da estratégia $\mathrm{EC}_{11} ; 4,0 \%$ através da estratégia $\mathrm{EC}_{12} ; 5,7 \%$ através da estratégia $\mathrm{EC}_{13} ; 4,1 \%$ através da estratégia $\mathrm{EC}_{14} ; 6,2 \%$ através da estratégia $\mathrm{EC}_{15} ; 5,2 \%$ 
através da estratégia $\mathrm{EC}_{16} ; 6,8 \%$ através da estratégia $\mathrm{EC}_{17} ; 8,3 \%$ através da estratégia $\mathrm{EC}_{18} ; 8,1 \%$ através da estratégia $\mathrm{EC}_{19}$ e $11,5 \%$ através da estratégia $\mathrm{EC}_{20}$.

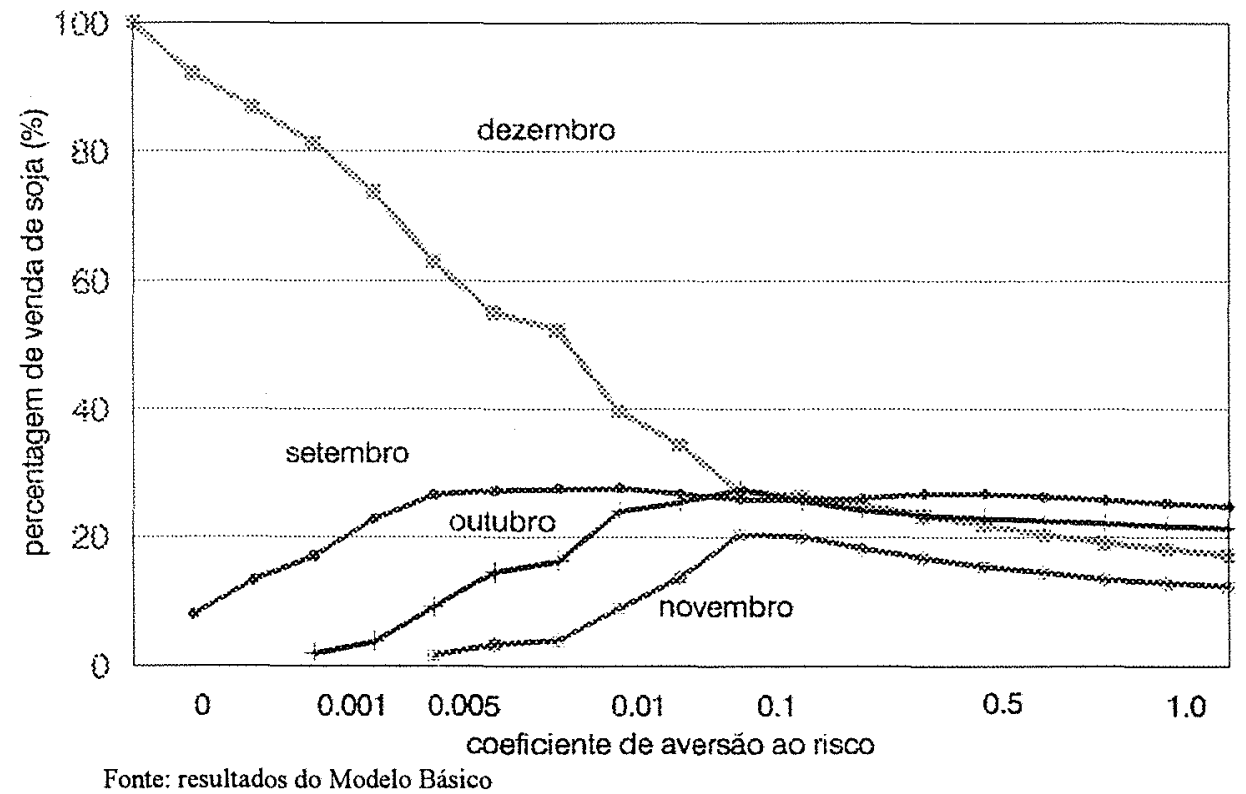

Figura 8 - Percentagem de venda de soja segundo meses selecionados e coeficientes de aversão ao risco - Modelo Básico - PR, 1980-95.

A tal composição de estratégias de venda, corresponde à armazenagem da produção na época da colheita com posterior venda mensal da produção através da seguinte distribuição de vendas, comercializando: $1,1 \%$ em março; 4,9\% em abril; 6,7\% em maio; $2,1 \%$ em junho; $3,9 \%$ em julho; $6,0 \%$ em agosto; $24,7 \%$ em setembro; $21,2 \%$ em outubro; $12,3 \%$ em novembro e $17,1 \%$ em dezembro.

Estes resultados, comparativamente aos obtidos para a solução ótima do Modelo Básico, mostram que ocorreu uma combinação mais acentuada de vendas mensais durante o ano, onde foram selecionados novos meses (março, maio, junho e julho) para a composição do plano ótimo de vendas, tentando reduzir o risco da atividade. Mesmo assim, ainda continuou existindo uma grande concentração de vendas nos últimos quatro meses do ano, onde $75,4 \%$ da produção é comercializada. 
Analisando-se ainda a Tabela 12, observa-se que a estratégia $E_{10}$ participou praticamente de todos os planos ótimos de comercialização, demonstrando, além do maior valor esperado de preços, a importância da introdução do conceito de covariâncias na seleção de um conjunto de estratégias de comercialização, para a composição de uma plano ótimo.

A importância das covariâncias na análise é baseada no conceito de diversificação, desenvolvido originalmente por Markowitz, no qual combinações de estratégias com correlação positiva menos que perfeita (covariância negativa) podem reduzir o risco de um plano ótimo sem acarretar com isto em uma redução drástica na renda média esperada dos produtores.

Em virtude disso, uma estratégia de comercialização adiciona mais ou menos variabilidade ao plano ótimo dependendo da soma de suas covariâncias com as covariâncias de outras estratégias. Quando a matriz de variância-covariância gerada não possuir elementos com covariâncias negativas, o modelo é forçado a utilizar-se das covariâncias positivas na seleção de estratégias para a composição de um plano ótimo. O problema neste caso consiste no fato de que duas estratégias com covariâncias positivas resultam em um aumento de variabilidade e risco a um plano ótimo.

Assim sendo, na combinação ótima proporcionada pelo Modelo Básico, "produtores com média aversão ao risco" ( $\alpha$ entre 0,25 e 0,30 ), que se traduz na melhor combinação de vendas entre todas geradas pelo modelo porque associa nível elevado de renda esperada (apenas 3,5\% inferior à da programação linear) com risco relativamente baixo (redução de $92,7 \%$ em relação à programação linear), existe uma diversificação de estratégias de comercialização na formação do plano ótimo de vendas, e isto é devido ao fato de que as estratégias que compõem o plano estão positivamente correlacionadas (covariâncias positivas). $\mathrm{EC}_{10}$ participa do plano ótimo pois está positivamente correlacionada com $\mathrm{EC}_{7}$, $\mathrm{EC}_{8}, \mathrm{EC}_{9}, \mathrm{EC}_{17}, \mathrm{EC}_{18}, \mathrm{EC}_{19} \mathrm{e} \mathrm{EC}_{20}$ (vide matriz de variância-covariância do Modelo Básico no Apêndice 2).

Este plano ótimo proporcionado pelo Modelo Básico consiste na armazenagem da produção na época da colheita, com posterior venda mensal fracionada da produção 
segundo os meses selecionados de venda, fornecendo com isto uma renda líquida média esperada de US\$36.833,00.

Para produtores com "elevada aversão ao risco" ou coeficiente de aversão $\alpha=1$, observa-se que o modelo diversificou bastante a combinação estratégias de comercialização para a formação do plano ótimo de vendas. Novamente $\mathrm{EC}_{10}$ participa do plano ótimo, pois, está positivamente correlacionada (covariância positiva) com $\mathrm{EC}_{1}, \mathrm{EC}_{4}, \mathrm{EC}_{7}, \mathrm{EC}_{8}, \mathrm{EC}_{9}$, $\mathrm{EC}_{11}, \mathrm{EC}_{12}, \mathrm{EC}_{13}, \mathrm{EC}_{14}, \mathrm{EC}_{15}, \mathrm{EC}_{16}, \mathrm{EC}_{17}, \mathrm{EC}_{18}, \mathrm{EC}_{19} \mathrm{e} \mathrm{EC}_{20}$. Neste plano ótimo de comercialização armazena-se a produção na época da colheita, com posterior venda nos meses selecionados pelo modelo, fornecendo uma renda líquida média esperada de US\$ $34.615,00$

Quanto ao produtor "indiferente ao risco" $(\alpha=0)$, diferentemente do produtor que possui "áversão ao risco", pode-se observar que o mesmo selecionaria um plano ótimo de vendas completamente diferente dos anteriores, no qual toda a venda ficaria concentrada basicamente em uma única estratégia de comercialização, a qual ele julga ser capaz de maximizar a sua renda esperada para dado nível de risco associado.

Isto ocorre devido ao fato de existir uma completa desconsideração por parte do produtor a respeito da matriz de variância-covariância dos preços das estratégias de comercialização, uma vez que seu objetivo é o de maximização do lucro. Este é um caso típico de programação linear, o que leva o produtor a selecionar a estratégia $\mathrm{EC}_{10}$, ou seja, armazenar no época da colheita e vender $100 \%$ da produção em dezembro, mês que proporciona o maior preço esperado de venda entre todos considerados.

Esta estratégia possui uma variância de US $\$ 4,05 / \mathrm{sc}$. e oferece um preço médio esperado de US\$ $12,16 / \mathrm{sc}$., o que proporciona um retorno líquido médio esperado de US\$ $38.169,00$.

O plano ótimo para o produtor com "baixa aversão ao risco" $(\alpha=0,002)$, o qual compreende a venda de $84,2 \%$ da produção através da estratégia $\mathrm{EC}_{10}$ e $15,8 \%$ pela estratégia $\mathrm{EC}_{19}$, significaria armazenar a produção na época da colheita e vender $7,9 \%$ da produção em setembro e os $92,1 \%$ restantes em dezembro. Esta combinação de vendas 
mostra que $\mathrm{EC}_{10}$ e $\mathrm{EC}_{19}$ possuem uma alta covariància positiva (US\$ 4,02), resultando num lucro líquido médio esperado de US\$38.111,00.

O grau de aversão ao risco por parte do produtor afeta diretamente a combinação de estratégias de comercialização dos planos ótimos (vide Tabela 12 e figura 9). Sendo assim, produtores com "alto grau de aversão ao risco" selecionarão estratégias diversificadas de vendas que proporcionam um menor lucro líquido médio esperado, com o objetivo básico de reduzir o risco de seu plano ótimo de vendas. Por outro lado, produtores com "baixa aversão ao risco", ou seja os que "objetivam maximização de renda", vão selecionar estratégias que normalmente concentrem suas vendas e que proporcionem um alto lucro líquido médio esperado, mesmo que com isto resulte um plano ótimo de vendas com alto risco associado.

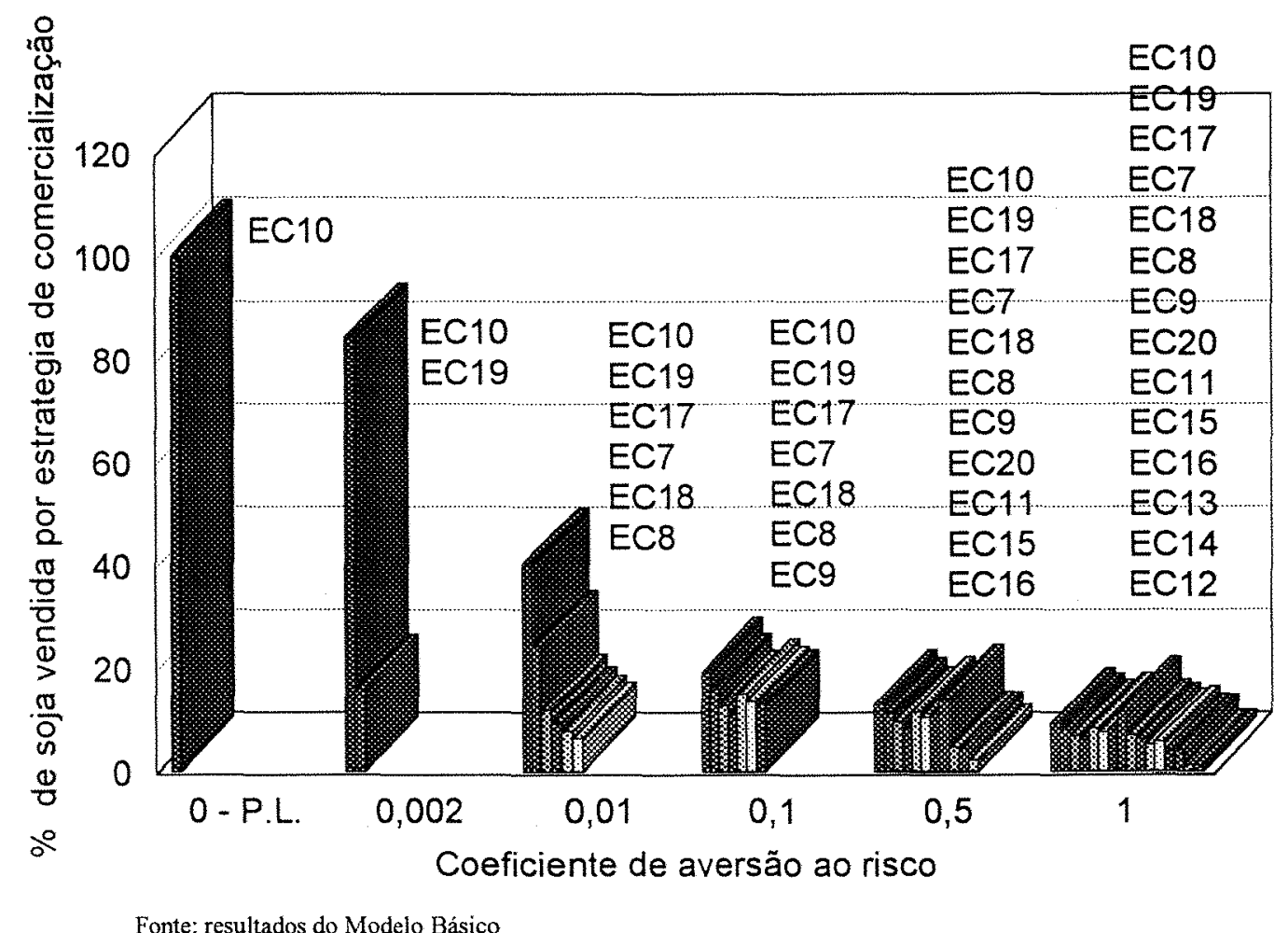

Figura 9 - Efeitos do coeficiente de aversão ao risco sobre a decisão de comercialização de soja - Modelo básico - PR, 1980-95. 


\section{2 - Efeitos da Aversão ao Risco sobre a Renda Líquida Média Esperada}

No caso do plano ótimo proporcionado pelo Modelo Básico para produtores com "média aversão ao risco" ( $\alpha$ entre 0,25 e 0,30$)$, foram selecionadas alternativas diversificadas de comercialização da produção, pois buscaram-se planos mais seguros ou seja, planos com menor risco associado, mas que mantivessem um certo nível de renda esperada. Assim, conforme apresentado na Tabela 14, foi proporcionada uma renda líquida média esperada de US $\$ 36.833,00$, com um risco associado de US $\$ 2.233,00$, coeficiente de variação de $0,13 \%$ e coeficiente de elasticidade Risco-Renda de 48,5\% (ou seja, uma redução de $1 \%$ na renda líquida média esperada vai proporcionar uma redução de 48,5\% no risco associado).

Tabela 14 - Renda Líquida Média Esperada, Coeficiente de Aversão ao Risco, Risco associado às Estratégias de Comercialização de Soja e Elasticidade Risco-Renda - Modelo Básico - PR, 1980-95.

\begin{tabular}{cccc}
\hline $\begin{array}{c}\text { Coeficiente de Aversão } \\
\text { ao Risco }(\alpha)\end{array}$ & $\begin{array}{c}\text { Renda Líquida Média } \\
\text { Esperada (US } \$)\end{array}$ & $\begin{array}{c}\text { Risco Associado } \\
\text { (US } \$)\end{array}$ & $\begin{array}{c}\text { Elasticidade Risco-Renda } \\
\mathcal{E}_{\mathrm{mr}\left({ }^{* *}\right)}\end{array}$ \\
\hline $0,0{\left.\text { P.L. }{ }^{*}\right)}_{0,002}$ & $38.169,00$ & $30.365,00$ & $\infty$ \\
0,003 & $38.111,00$ & $11.006,00$ & 618,42 \\
0,004 & $38.091,00$ & $8.469,00$ & 547,41 \\
0,005 & $38.073,00$ & $6.929,00$ & 500,40 \\
0,01 & $38.058,00$ & $6.098,00$ & 457,10 \\
0,02 & $38.006,00$ & $4.931,00$ & 336,73 \\
0,03 & $37.936,00$ & $4.463,00$ & 242,90 \\
0,1 & $37.878,00$ & $4.186,00$ & 197,98 \\
0,2 & $37.516,00$ & $3.265,00$ & 93,39 \\
0,25 & $37.045,00$ & $2.499,00$ & 56,75 \\
0,3 & $36.833,00$ & $2.233,00$ & 48,46 \\
0,4 & $36.624,00$ & $2.009,00$ & 42,40 \\
0,5 & $36.235,00$ & $1.683,00$ & 34,43 \\
0,6 & $35.883,00$ & $1.463,00$ & 29,41 \\
0,7 & $35.573,00$ & $1.315,00$ & 26,05 \\
0,8 & $35.297,00$ & $1.220,00$ & 23,60 \\
0,9 & $35.051,00$ & $1.163,00$ & 21,75 \\
1,0 & $34.825,00$ & $1.136,00$ & 20,26 \\
\hline
\end{tabular}

Fonte: resultados do Modelo Básico

(*) resultado obtido pela programação linear.

${ }^{(* *)}$ Genericamente o termo elasticidade é uma medida de resposta que compara a mudança percentual em uma variável dependente (risco) devido a uma mudança percentual em uma variável explicatória (renda). Matematicamente pode ser representado como: $\mathbf{g r r}=\left[\left(\mathbf{R i}_{2}-\mathbf{R i}_{1}\right) /\left(\mathbf{R i}_{2}+\mathbf{R i}_{1}\right)\right] \div\left[\left(\mathbf{R e}_{2}-\mathbf{R e}_{1}\right) /\left(\mathbf{R e}_{2}+\mathbf{R e}_{1}\right)\right]$, onde: $\mathbf{R i}_{\mathrm{j}}=$ risco no ponto j e $\mathbf{R} \mathbf{e}_{\mathrm{j}}=$ renda líquida esperada no ponto $\mathrm{j}$. 
Produtores "altamente avessos ao risco" $(\alpha=1)$, os quais selecionam alternativas mais diversificadas de comercialização da sua produção, notadamente, quando comparados com produtores "indiferentes ao risco" $(\alpha=0)$, vão obter uma renda líquida média menor, o que, é devido ao fato de desejarem planos mais seguros de comercialização da produção (planos mais seguros necessariamente indicam situações onde o risco associado a atividade de venda é menor). Nesta situação analisada, a renda líquida média esperada é de US\$ $34.615,00$, a qual apresenta um risco associado de US $\$ 1.125,00$, um coeficiente de variação de $0,10 \%$ e um coeficiente de elasticidade Risco-Renda de 19,0\%.

Produtores "indiferentes ao risco" $(\alpha=0)$, por outro lado, concentram a venda da sua produção em um plano ótimo de comercialização, cujo objetivo principal é a maximização de sua renda, obtendo com isto um lucro líquido médio esperado de US\$ $38.169,00$. Entretanto, para este nível de renda está associado um risco muito alto (US\$ $30.365,00$ ), um elevado coeficiente de variação de $0,46 \%$ e um coeficiente de Elasticidade Risco-Renda que tende para $\infty$.

Comparativamente com o produtor "avesso ao risco", o produtor "indiferente ao risco" obtém um lucro líquido 10,3\% maior, mas assume um risco 27 vezes maior (em termos percentuais, $2.599 \%$ a mais de risco na atividade). Teoricamente, esta situação é plausível, mas na vida real torna-se completamente inaceitável, dado que o produtor rural apresenta um comportamento intermediário entre as situações analisadas anteriormente, e como já demonstrado anteriormente, deve selecionar o plano que combine alta renda com baixo risco.

A Figura 10 mostra o comportamento do coeficiente de aversão ao risco em função da renda líquida média esperada pelos produtores. Nota-se que a renda líquida decresce à medida em que aumenta o coeficiente de aversão ao risco. Sendo assim, estes resultados demonstram que o produtor atribui importância ao risco, e que este valor não deve ficar próximo nem do coeficiente unitário, nem do coeficiente nulo de risco. 


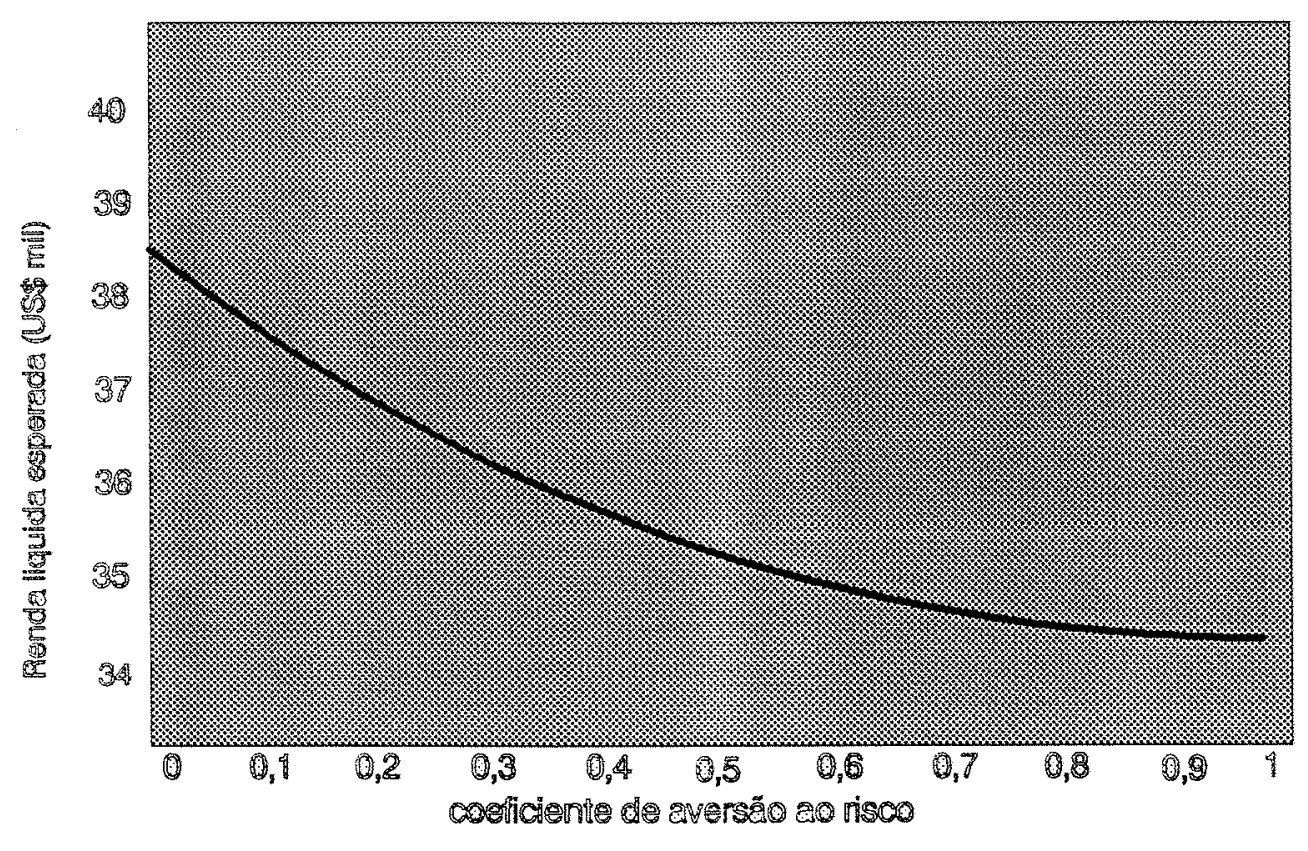

Fonte: resultados do Modelo Básico.

Figura 10 - Efeitos do Coeficiente de Aversão ao Risco sobre a Renda Líquida média Esperada pelos produtores - Modelo Básico - PR, 1980-95.

\section{3 - A Fronteira Eficiente da Média-Variância (fronteira E-V)}

A fronteira eficiente é um aspecto importante a ser considerado na análise de planos ótimos de comercialização. A fronteira é baseada na dominância de certos princípios, de tal forma que dentre todos os investimentos com uma dada taxa de retorno, o que oferece mínimo risco é o mais desejável; ou dentre todas as alternativas de uma dada classe de risco, a que oferece a mais alta taxa de retorno é a preferível. Como resultado, pontos sobre a fronteira E-V compreendem planos ótimos de estratégias de comercialização, locais estes onde o produtor seleciona um ponto que é capaz de maximizar sua utilidade esperada, para dado coeficiente de aversão ao risco (Conforme pode ser observado na Figura 11). 


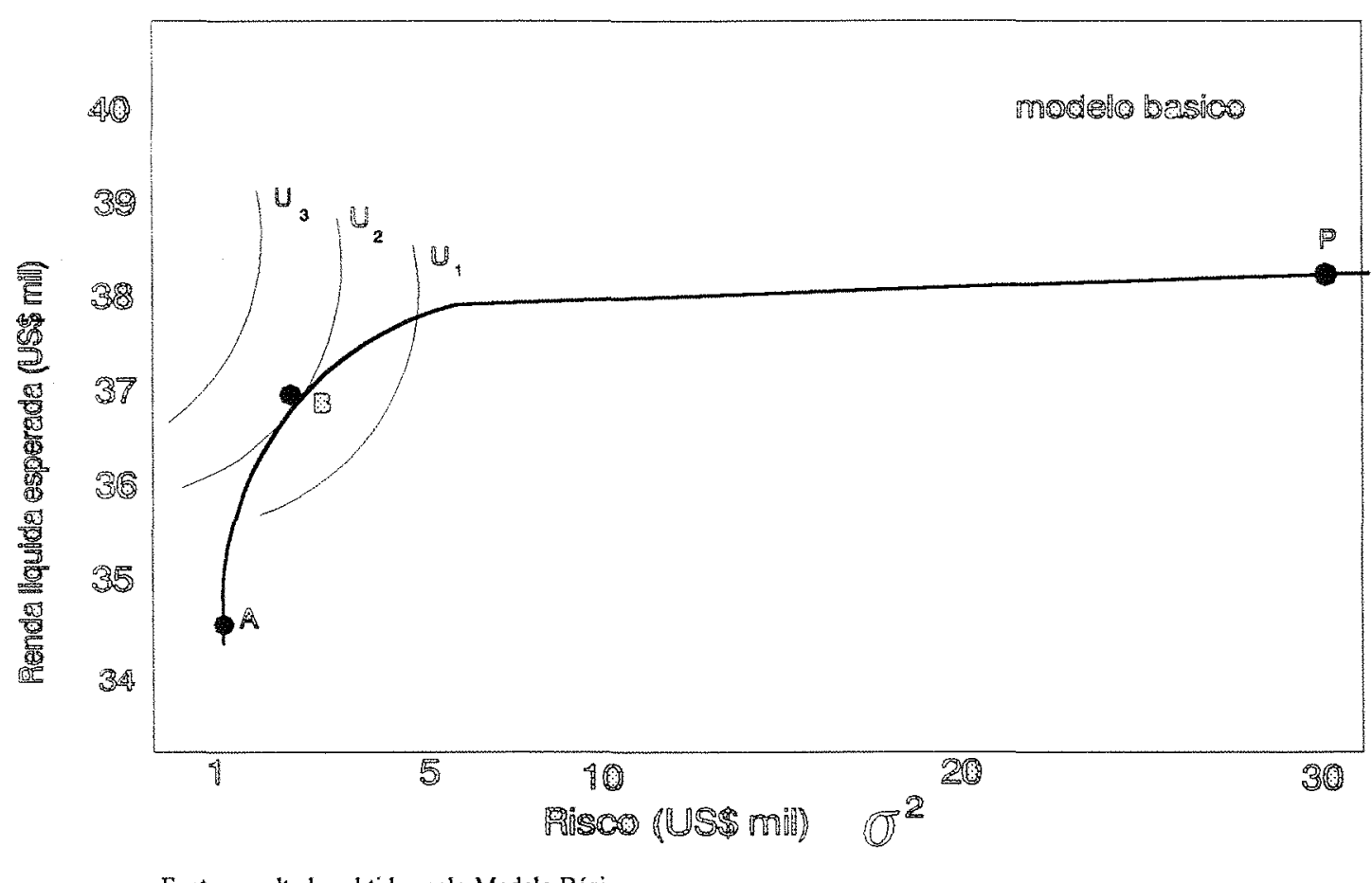

Fonte: resultados obtidos pelo Modelo Básico.

Figura 11 - Fronteira Eficiente da Média-Variância para o Modelo Básico - PR, 1980-95.

Analisando-se a Figura 11, é possível observar que a inclinação da fronteira eficiente tende a decrescer enquanto a renda líquida média esperada sofre incremento. Este aumento no risco ocorre devido ao fato de que com o incremento na renda, a seleção das estratégias de comercialização para a composição do plano ótimo sofre restrições para que se possa obter o nivel de renda desejado, proporcionando então uma redução na diversificação das estratégias.

O ponto P na Figura 11 representa o plano ótimo de comercialização do produtor "indiferente ao risco", que é proporcionado pela programação linear, cujo retorno líquido médio esperado é máximo, mas com um risco associado muito elevado, sendo descartado como o ideal.

O ponto A, por outro lado, representa uma situação completamente oposta, representando o produtor "altamente avesso ao risco", cujo retorno líquido médio esperado possui o menor risco associado dentre todos, mas que também não é a solução ideal de comercialização. 
$\mathrm{O}$ ponto $\mathrm{B}$, diferentemente dos anteriores, pode ser considerado como a solução ideal proporcionada pelo modelo básico pois, além de ser o ponto de tangência da curva de isoutilidade, tem na sua diversificação de vendas uma motivação para a redução de risco ao plano ótimo de $92,7 \%$. Por outro lado, conseguiu manter uma renda líquida média esperada apenas 3,5\% inferior à obtida pelo ponto $\mathrm{P}$ (programação linear).

Os resultados analisados anteriormente confirmam esta afirmação, dado que em planos ótimos com "alta aversão ao risco", os mesmos são constituídos por mais de 10 estratégias de comercialização, enquanto que em planos ótimos com "indiferença ao risco", o mesmo é composto por somente uma estratégia de comercialização, o que consiste basicamente no ponto de maximização de lucro fornecido pela programação linear.

\section{4 - Simulações do Modelo Básico}

O objetivo desta secção consiste em se parametrizar os valores do Modelo Básico, com o intuito de se avaliar a sensibilidade das condições de contorno do Modelo frente a possiveis variações em diversos parâmetros tais como: taxas de juros de mercado, custo de armazenagem e custo de transporte. É possível assim estimar mudanças nas soluções ótimas das estratégias de comercialização, na renda líquida média esperada frente ao risco, na Fronteira Eficiente da Média-Variância (fronteira E-V) e nas variações no Coeficiente de Elasticidade Risco-Renda.

\subsection{1 - O Efeito da Redução na Taxa de Juros}

A taxa de juros, sem dúvida, é um dos elementos que influencia na escolha de "quando" e "como" vender a produção, por parte dos produtores rurais. Um efeito imediato associado à redução na taxa de juros é o de que o produtor deve adiar a venda de sua produção, esperando um momento mais oportuno, dado que o custo do dinheiro no 
tempo tende a ser relativamente menor, incentivando-o assim a buscar um preço futuro melhor para vender a sua produção e obter melhor remuneração ao trabalho realizado.

Comparativamente aos resultados fornecidos pelo Modelo Básico, o efeito da redução da taxa de juros de $16 \%$ a.a. (1,24\% a.m.) (que foi utilizada para remunerar o crédito rural no último ano agrícola) para $6 \%$ a.a. $(0,48 \%$ a.m. $)$ ou seja uma taxa de juros praticada para poupança, teve como objetivo determinar qual seria o comportamento do modelo com relação às soluções de venda anteriormente encontradas dado que a atual tendência do mercado vislumbra reduções nas taxas de juros, principalmente para o setor agricola que carece bastante de recursos a baixo custo.

Os resultados mostram que o modelo foi menos sensivel no que tange ao aspecto do início do processo de diversificação das estratégias de comercialização. No Modelo Básico, a diversificação iniciou-se com um coeficiente de aversão ao risco $(\alpha)$ igual a 0,001 , enquanto que nesta simulação se inicia $\operatorname{com} \alpha=0,01$.

A melhor das soluções ótimas não modificou-se, tendo prevalecido o coeficiente de aversão ao risco $\alpha$ entre 0,25 e 0,3 , ou seja produtor com "média aversão ao risco". A composição ótima de vendas ficou composta pelas seguintes estratégias de vendas: $8,5 \% \mathrm{em}$ setembro, $12,1 \%$ em outubro, $14,2 \%$ em novembro, $18,7 \%$ em dezembro, $10,3 \%$ através da estratégia $\mathrm{EC}_{17}, 14,1 \%$ através da estratégia $\mathrm{EC}_{18}, 14,1 \%$ através da estratégia $\mathrm{EC}_{19}$ e $8,1 \%$ através da estratégia $\mathrm{EC}_{20}$ (vide Tabela 15).

A este plano ótimo de comercialização corresponderia a armazenagem da produção na época da colheita e venda futura através da seguinte composição de mensal de vendas: $2,7 \%$ em abril, $23,4 \%$ em setembro, $24,2 \%$ em outubro, $21,3 \%$ em novembro e $28,4 \%$ em dezembro (vide Tabela 16). Este plano ótimo de vendas mostrou-se similar à solução obtida no Modelo Básico, diferindo deste apenas com relação a pequenas variações percentuais na composição de cada estratégia. 
Tabela 15 - Percentagem de venda de soja, por Estratégia de Comercialização, segundo coeficiente de aversão ao risco - Simulação da Redução da Taxa de Juros - PR 1980-95.

\begin{tabular}{|c|c|c|c|c|c|c|c|c|c|c|c|c|c|c|c|}
\hline & & \multicolumn{14}{|c|}{ Estratégias de comercialização de soja (\%) } \\
\hline $\begin{array}{l}\text { Renda } \\
\text { Líquida }\end{array}$ & $\begin{array}{l}\text { Coeficiente } \\
\text { de Aversão }\end{array}$ & $\mathrm{EC}$ & $\mathrm{EC}$ & $\mathrm{EC}$ & $\mathrm{EC}$ & $\mathrm{EC}$ & $\mathrm{EC}$ & $\mathrm{EC}$ & $\mathrm{EC}$ & $\mathrm{EC}$ & $\mathrm{EC}$ & $\mathrm{EC}$ & $\mathrm{EC}$ & $\mathrm{EC}$ & $\mathrm{EC}$ \\
\hline $\begin{array}{c}\text { Esperada } \\
\text { (US\$) }\end{array}$ & $\begin{array}{c}\text { ao Risco } \\
(\alpha)\end{array}$ & 7 & 8 & 9 & 10 & 11 & 12 & 13 & 14 & 15 & 16 & 17 & 18 & 19 & 20 \\
\hline $42.798,00$ & $0,0\left(\right.$ p.1. $\left.{ }^{*}\right)$ & & & & 100 & & & & & & & & & & \\
\hline $42.768,00$ & 0,001 & & & & 100 & & & & & & & & & & \\
\hline $42.495,00$ & 0,01 & & & & 96,4 & & & & & & & & & 3,6 & \\
\hline $42,297,00$ & 0,02 & & & 10,6 & 64,7 & & & & & & & & 8,1 & 16,6 & \\
\hline $42.177,00$ & 0,03 & & 3,8 & 14,4 & 51,0 & & & & & & & & 12,7 & 18,1 & \\
\hline $42.085,00$ & 0,04 & & 7,0 & 15,3 & 43,0 & & & & & & & 2,8 & 14,0 & 17,9 & \\
\hline $42.007,00$ & 0,05 & 0,7 & 8,6 & 15,6 & 38,0 & & & & & & & 5,0 & 14,6 & 17,5 & \\
\hline $41.701,00$ & 0,1 & 5,9 & 11,4 & 15,5 & 27,2 & & & & & & & 8,8 & 15,0 & 16,2 & \\
\hline $41.172,00$ & 0,2 & 8,3 & 12,6 & 15,3 & 21,6 & & & & & & & 10,5 & 15,0 & 15,3 & 1,4 \\
\hline $40.707,00$ & 0,3 & 8,5 & 12,1 & 14,2 & 18,7 & & & & & & & 10,3 & 14,1 & 14,1 & 8,0 \\
\hline $40.279,00$ & 0,4 & 8,4 & 11,7 & 13,5 & 17,1 & & & & & 1,3 & & 10,1 & 13,4 & 13,3 & 11,2 \\
\hline $39.885,00$ & 0,5 & 8,1 & 11,1 & 12,8 & 15,8 & & & & & 4,0 & 0,2 & 9,6 & 12,7 & 12,5 & 12,4 \\
\hline $39.530,00$ & 0,6 & 7,7 & 10,4 & 11,9 & 14,5 & & & & & 5,3 & 2,2 & 9,1 & 11,8 & 11,6 & 12,6 \\
\hline $39.209,00$ & 0,7 & 7,3 & 9,8 & 11,2 & 13,5 & 4,2 & & 1,4 & & 6,1 & 3,5 & 8,6 & 11,1 & 10,9 & 12,5 \\
\hline $38.917,00$ & 0,8 & 6,9 & 9,3 & 10,5 & 12,6 & 5,0 & 0,4 & 3,0 & 0,8 & 6,4 & 4,2 & 8,1 & 10,4 & 10,2 & 12,2 \\
\hline $38.652,00$ & 0,9 & 6,5 & 8,7 & 9,9 & 11,8 & 5,5 & 1,6 & 4,1 & 1,9 & 6,6 & 4,6 & 7,6 & 9,8 & 9,6 & 11,8 \\
\hline $38.408,00$ & 1,0 & 6,2 & 8,3 & 9,4 & 11,1 & 5,8 & 2,5 & 4,9 & 2,8 & 6,7 & 4,9 & 7,3 & 9,3 & 9,1 & 11,5 \\
\hline
\end{tabular}

Fonte; resultado do modelo com redução na taxa de juros. $\left(p . .^{*}\right)=$ resultado obtido por programação linear.

Tabela 16 - Percentagem de venda de soja, Discriminação mensal, segundo coeficiente de Aversão ao Risco - Simulação da Redução da taxa de juros - PR, 1980-95.

\begin{tabular}{|c|c|c|c|c|c|c|c|c|c|c|}
\hline \multirow{2}{*}{$\begin{array}{l}\text { Coeficiente de } \\
\text { Aversão ao } \\
\text { Risco }(\alpha)\end{array}$} & \multicolumn{10}{|c|}{ Discriminação Mensal de vendas dos Planos Ótimos (\%) } \\
\hline & MAR & ABR & $\mathrm{MAI}$ & JUN & JL & $\mathrm{AGO}$ & SET & OUT & NOV & $\mathrm{DEZ}$ \\
\hline $0,0\left(\mathrm{p} .1^{*}\right)$ & & & & & & & & & & 100 \\
\hline 0,001 & & & & & & & & & & 100 \\
\hline 0,01 & & & & & & & 1,8 & & & 98,2 \\
\hline 0,02 & & & & & & & 8,3 & 4,0 & 14,7 & 73,0 \\
\hline 0,03 & & & & & & & 9,0 & 10,2 & 20,8 & 60,0 \\
\hline 0,04 & & & & & & & 10,3 & 15,4 & 22,3 & 52,0 \\
\hline 0,05 & & & & & & & 11,9 & 18,4 & 22,9 & 46,8 \\
\hline 0,1 & & & & & & & 18,4 & 23,3 & 23,0 & 35,3 \\
\hline 0,2 & & 0,47 & & & & & 21,7 & 25,4 & 22,8 & 29,6 \\
\hline 0,3 & & 2,7 & & & & & 23,4 & 24,2 & 21,3 & 28,4 \\
\hline 0,4 & & 3,7 & & & & 0,7 & 23,8 & 24,1 & 20,2 & 27,5 \\
\hline 0,5 & & 4,1 & & & 0,1 & 2,0 & 23,4 & 24,3 & 19,2 & 26,9 \\
\hline 0,6 & & 4,2 & & & 1,1 & 2,7 & 23,4 & 23,5 & 17,8 & 24,5 \\
\hline 0,7 & & 4,2 & 2,8 & & 1,8 & 3,8 & 25,1 & 22,7 & 16,5 & 23,1 \\
\hline 0,8 & & 4,3 & 3,6 & 0,2 & 2,2 & 4.6 & 24,9 & 227 & 157 & 21,8 \\
\hline 0,9 & & 4,4 & 4,7 & 0.5 & 2,8 & 5,2 & 24,6 & 22,5 & 14,8 & 20,5 \\
\hline 1,0 & & 4,5 & 5,4 & 0,8 & 3,3 & 5,7 & 24,4 & 22,3 & 14,1 & 19,5 \\
\hline
\end{tabular}

Fonte: resultado do modelo com redução na taxa de juros. $\left(\right.$ p..$\left.^{*}\right)=$ resultado fornecido pela programação linear 
Quanto ao produtor com "grande aversão ao risco" $(\alpha=1)$, igualmente ao que ocorreu no Modelo Básico, houve uma diversificação de estratégias de comercialização para a formação do plano ótimo de vendas, objetivando reduzir o risco associado à atividade de venda, o qual normalmente atua de maneira negativa, pois reduz a renda líquida média esperada pelo produtor.

Desta forma, obteve-se a seguinte composição de estratégias de comercialização da produção, vendendo-se: $0,09 \%$ em junho, $6,2 \%$ em setembro, $8,3 \%$ em outubro, $9,4 \% \mathrm{em}$ novembro, $11,1 \%$ em dezembro, $5,8 \%$ através da estratégia $\mathrm{EC}_{11}, 2,5 \%$ através da estratégia $\mathrm{EC}_{12}, 4,9 \%$ através da estratégia $\mathrm{EC}_{13}, 2,8 \%$ através da estratégia $\mathrm{EC}_{14}, 6,7 \%$ através da estratégia $\mathrm{EC}_{15}, 4,9 \%$ através da estratégia $\mathrm{EC}_{16}, 7,3 \%$ através da estratégia $\mathrm{EC}_{17}, 9,3 \%$ através da estratégia $\mathrm{EC}_{18}, 9,1 \%$ através da estratégia $\mathrm{EC}_{19}$ e $11,5 \%$ através da estratégia $\mathrm{EC}_{20}$.

O produtor "indiferente ao risco" $(\alpha=0)$, tal como no Modelo Básico, selecionaria como solução ótima uma única estratégia de comercialização na composição de seu plano ótimo de vendas, a qual maximiza a sua utilidade esperada. Neste caso, optaria pela estratégia $\mathrm{EC}_{10}$, ou seja, armazenaria a produção na época da colheita com posterior venda de toda a produção em dezembro.

Com relação aos efeitos da aversão ao risco sobre a renda líquida esperada pelos produtores, foram observados os seguintes resultados.

No caso do plano ótimo do produtor com "média aversão ao risco" ( $\alpha$ entre 0,25 e $0,3)$, foram selecionadas alternativas diversificadas de venda, seguindo o princípio de diversificação de Markowitz. Com isto, obteve-se uma renda líquida média esperada de US\$ $40.707,00$, a qual possui um risco associado da ordem de US\$ $2.299,00$, com um coeficiente de variação de $0,12 \%$ e um coeficiente de elasticidade Risco-Renda de 34,4.

Comparativamente ao Modelo Básico, devido à redução da taxa de juros, a renda cresceu cerca de 10,5\%, ou seja, proporcionou um incremento de US\$ $4.083,00$ ha renda anteriormente obtida. Quanto ao risco associado, este aumentou apenas $2,9 \%$ (US\$ 290,00), conforme representado na Tabela 17. 
Tabela 17 - Renda Líquida Média Esperada, Coeficiente de Aversão ao Risco, Risco associado às Estratégias de Comercialização de Soja e Elasticidade Risco-Renda - Simulação da Redução da taxa de juros - PR, 1980-95.

\begin{tabular}{ccccc}
\hline $\begin{array}{c}\text { Coeficiente } \\
\text { de Aversão } \\
\text { ao Risco }(\alpha)\end{array}$ & $\begin{array}{c}\text { Renda Líquida } \\
\text { Média Esperada } \\
\text { (US\$) }\end{array}$ & $\begin{array}{c}\text { Diferença de renda } \\
\text { em relação ao } \\
\text { Modelo Básico }\left(^{* *}\right)\end{array}$ & $\begin{array}{c}\text { Risco Associado } \\
\text { (US\$) }\end{array}$ & $\begin{array}{c}\text { Diferença de risco em } \\
\text { relação ao Modelo } \\
\left.\text { Básico } *^{* * *}\right)\end{array}$ \\
\hline $0,0\left(\mathrm{p} . .^{*}\right)$ & $42.798,00$ & $+4.629,00$ & $30.365,00$ & 0 \\
0,001 & $42.768,00$ & $+4.657,00$ & $27.300,00$ & $+12.294,00$ \\
0,01 & $42.495,00$ & $+4.489,00$ & $10.611,00$ & $+7.346,00$ \\
0,05 & $42.007,00$ & $+4.192,00$ & $4.337,00$ & $+451,00$ \\
0,1 & $41.701,00$ & $+4.185,00$ & $3.635,00$ & $+369,00$ \\
0,2 & $41.172,00$ & $+4.127,00$ & $2.819,00$ & $+320,00$ \\
0,3 & $40.707,00$ & $+4.083,00$ & $2.299,00$ & $+290,00$ \\
0,4 & $40.279,00$ & $+4.044,00$ & $1.938,00$ & $+255,00$ \\
0,5 & $39.885,00$ & $+4.002,00$ & $1.684,00$ & $+221,00$ \\
0,6 & $39.530,00$ & $+3.957,00$ & $1.499,00$ & $+184,00$ \\
0,7 & $39.209,00$ & $+3.930,00$ & $1.365,00$ & $+145,00$ \\
0,8 & $38.917,00$ & $+3.866,00$ & $1.269,00$ & $+106,00$ \\
0,9 & $38.652,00$ & $+3.827,00$ & $1.204,00$ & $+68,00$ \\
1,0 & $38.408,00$ & $+3.793,00$ & $1.163,00$ & $+38,00$ \\
\hline
\end{tabular}

Fonte: resultado fornecido pelo modelo com redução na taxa de juros.

(p.l.*) resultado obtido por programação linear.

${ }^{* *}$ ) Renda do modelo com redução de juros menos renda do Modelo Básico (Tabela 13).

$\left({ }^{* * *}\right)$ Risco do modelo com redução de juros menos o risco do Modelo Básico (Tabela 13).

No caso do produtor com "alta aversão ao risco" $(\alpha=1)$, na composição ótima de vendas houve uma grande diversificação, buscando uma redução no risco e obtendo com isto uma renda líquida média esperada de US\$38.408,00, com um risco associado da ordem de US\$ 1.163,00, coeficiente de variação de 0,09\% e coeficiente de elasticidade RiscoRenda de 17,1 .

Com relação aos resultados fornecidos pelo Modelo Básico, a renda líquida média esperada cresceu $10,9 \%$, ou seja, teve um incremento de US $\$ 3.793,00$ e o risco associado aumentou $3,4 \%$, ou seja, US $\$ 38,00$.

Finalmente, analisando-se o produtor "indiferente ao risco" $(\alpha=0)$, o qual busca apenas a maximização de sua utilidade esperada e que desconsidera os riscos do mercado, o mesmo obteria uma renda líquida média esperada da ordem de US\$42.798,00, com um risco associado de US $\$ 30.365,00$, com um coeficiente de variação de $0,4 \%$ e um 
coeficiente de elasticidade Risco-Renda $\infty$. Comparativamente ao Modelo Básico, haveria um incremento da ordem de $12,1 \%$ na renda esperada (US\$ 4.629,00), com o risco associado permanecendo constante.

Nesta simulação de redução de taxa de juros, comparando-se o produtor "indiferente ao risco" com o produtor "avesso ao risco", nota-se que o primeiro obtém um lucro líquido médio esperado $11,4 \%$ maior, mas assume um risco 26 vezes maior na atividade, tornando teoricamente inaceitáveis estas duas situações.

Com relação à fronteira eficiente de renda-risco desta simulação, constata-se que a mesma apresenta um comportamento similar à fronteira obtida inicialmente pelo Modelo Básico, ressaltando que a inclinação da curva tende a decrescer. Pode ocorrer assim um incremento na renda líquida média esperada, devido ao fato das estratégias que compõem o plano ótimo sofrerem restrição de uso para que se possa obter rendas mais elevadas (vide Figura 12). Comparativamente ao que se pode observar no Modelo Básico, devido à redução da taxa de juros, a fronteira eficiente desta simulação sofreu um deslocamento para cima, paralelamente à função gerada pelo Modelo Básico.

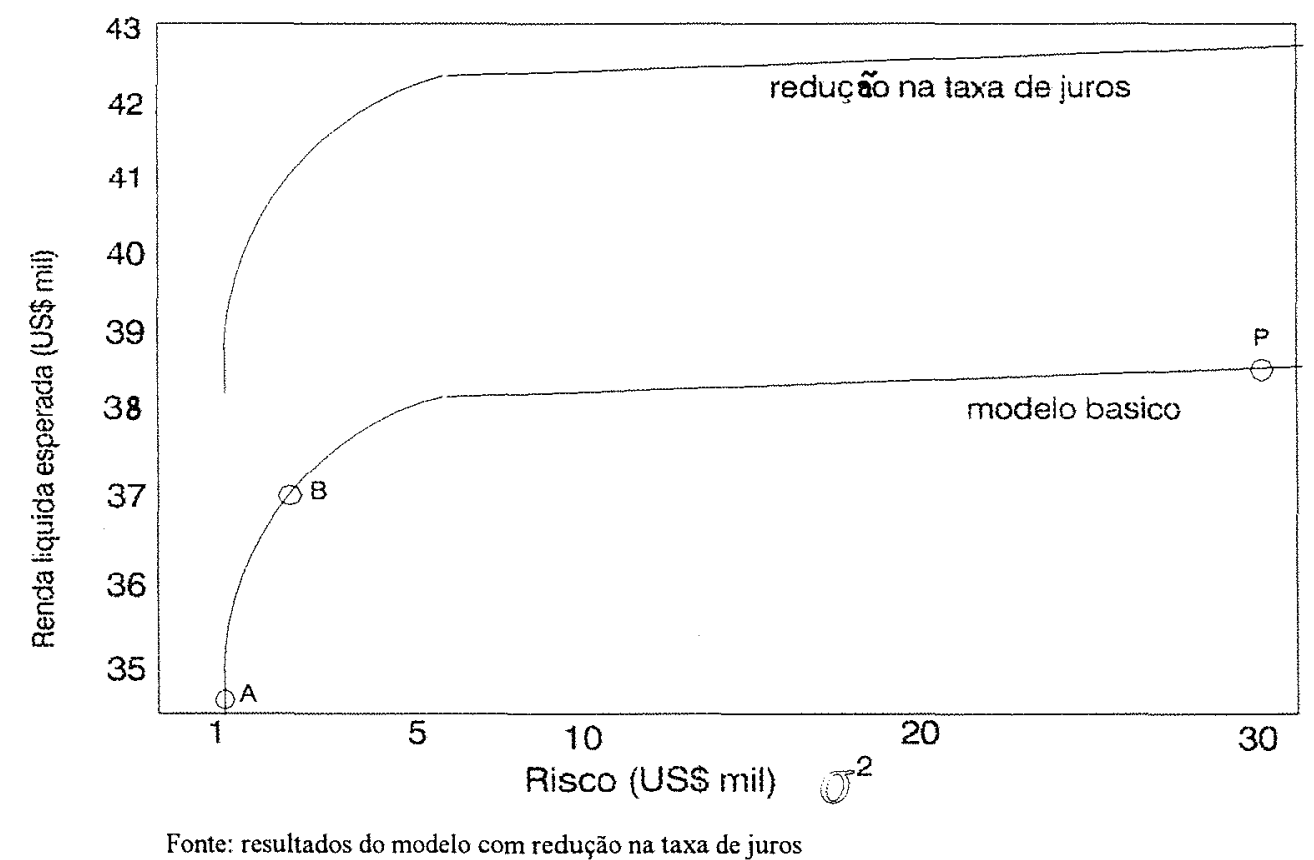

Figura 12 - Fronteira Eficiente da Média-Variância para a simulação da redução da taxa de juros - PR - 1980-95. 


\subsection{2 - O Efeito da elevação na taxa de juros}

De maneira diferente à análise anteriormente realizada, uma elevação na taxa de juros de mercado confere ao modelo um efeito de "antecipação" da venda da produção, dado que no tempo, o custo do dinheiro tende a ficar relativamente mais caro. Com isto, as possibilidades de obtenção de melhores retornos tornam-se pouco atrativas ao produtor, que notadamente prefere a segurança de retornos menores e mais seguros à incerteza de obter retornos futuros mais elevados.

Comparativamente ao Modelo Básico, o efeito da elevação na taxa de juros de 16\% a.a. (1,24\% a.m.) para $43 \%$ a.a. (3,0\% a.m.) teve como objetivo analisar como se comportaria o Modelo Básico frente a uma situação de mercado onde a taxa de juros pactuada fosse muito elevada em relação a taxa de juros atualmente utilizada pela agricultura. Com relação às soluções ótimas de vendas anteriormente encontradas, nota-se que o modelo foi um pouco menos sensível quanto ao aspecto do início do processo de diversificação das vendas para a composição do plano ótimo de estratégias de comercialização. No modelo básico, iniciou-se este processo com um coeficiente de aversão ao risco $(\alpha)$ igual a 0,001 , enquanto que na simulação, começou-se com $\alpha=0,0075$.

Nesta simulação de elevação na taxa de juros de mercado, a solução ótima sofreu uma alteração, tendo o modelo selecionado o coeficiente de aversão ao risco $\alpha=0,15$, ou seja produtor com "baixa aversão ao risco". A composição ótima de vendas ficou desta forma sendo composta pelas seguintes estratégias de vendas: $30,5 \%$ em março, $13,5 \%$ em setembro, $7,4 \%$ através da estratégia $\mathrm{EC}_{11}, 11,2 \%$ através da estratégia $\mathrm{EC}_{17}, 2,7 \%$ através da estratégia $\mathrm{EC}_{18}, 3,5 \%$ através da estratégia $\mathrm{EC}_{19}$ e $18,3 \%$ através da estratégia $\mathrm{EC}_{20}$. (vide Tabela 18).

A este plano ótimo de comercialização corresponderia, diferentemente das situações analisadas anteriormente, a venda mensal da produção através da seguinte distribuição: $30,5 \%$ em março, $6,1 \%$ em abril, 6,5\% em maio, 33,4\% em setembro, $14,4 \%$ em outubro, $1,4 \%$ em novembro e $7,7 \%$ em dezembro, onde cerca de $43,1 \%$ de todas as vendas estariam concentradas na época da colheita (vide Tabela 19). 
Tabela 18 - Percentagem de venda de soja, por Estratégia de Comercialização, segundo coeficiente de aversão ao risco - Simulação da elevação da taxa de juros - PR 1980-95

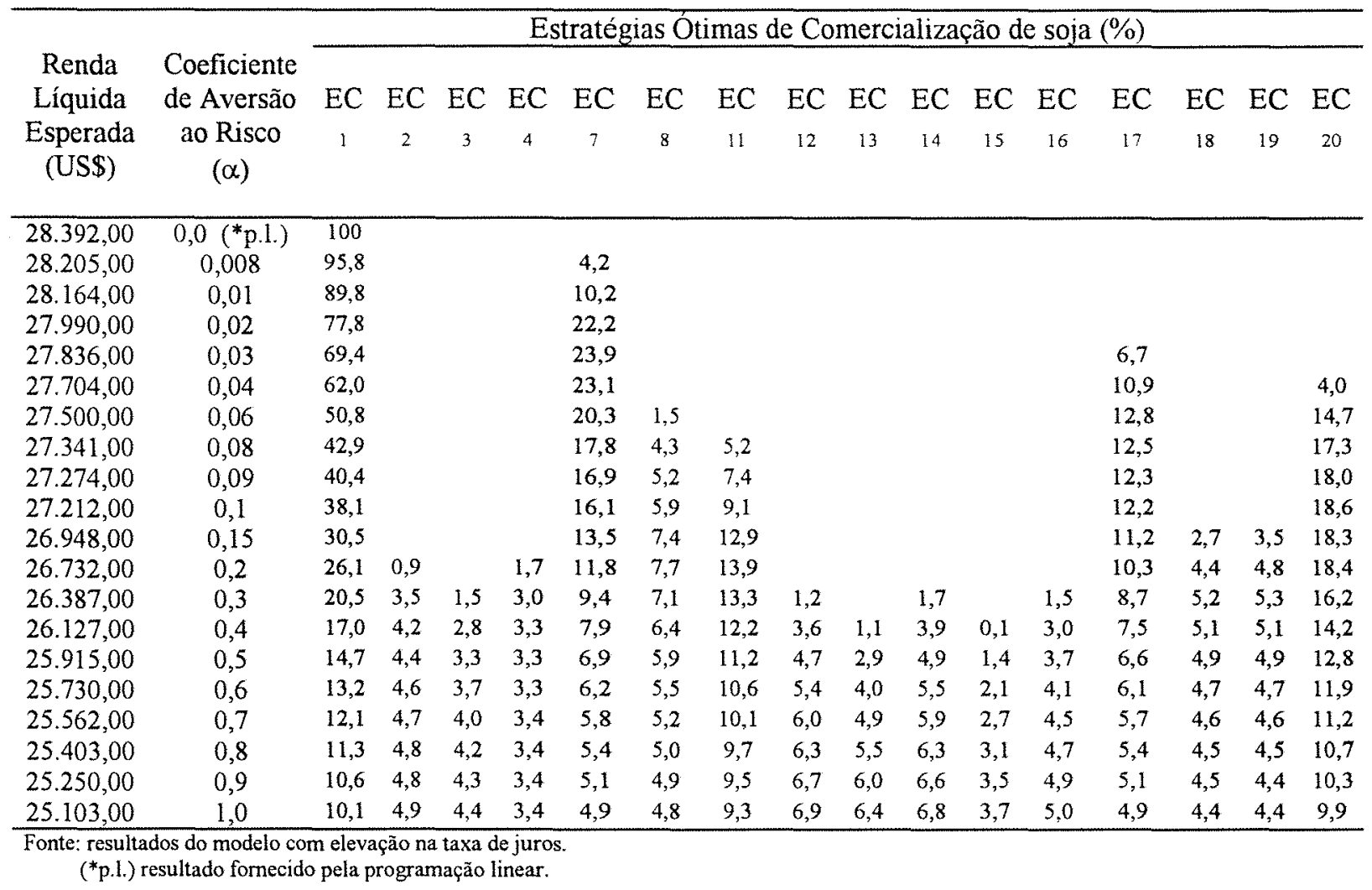

A composição dos planos ótimos de vendas mostrou-se diferente da solução obtida no Modelo Básico, já que uma elevação na taxa de juros proporciona uma antecipação de vendas.

O produtor com "grande aversão ao risco" $(\alpha=1)$, diferentemente ao que ocorreu no Modelo Básico, formulou planos ótimos de comercialização de sua produção com uma maior concentração das vendas no período pós-safra, mas mantendo ainda uma grande diversificação de estratégias, sempre com o objetivo de reduzir o risco de sua atividade de vendas. 
Tabela 19 - Percentagem de venda de soja, Discriminação mensal, segundo coeficiente de Aversão ao Risco - Simulação da elevação da taxa de juros - PR, 1980- 95.

\begin{tabular}{|c|c|c|c|c|c|c|c|c|c|c|}
\hline \multirow{2}{*}{$\begin{array}{l}\text { Coeficiente de } \\
\text { Aversão ao } \\
\text { Risco }(\alpha)\end{array}$} & \multicolumn{10}{|c|}{ Discriminação Mensal de vendas dos Planos Ótimos (\%) } \\
\hline & MAR & ABR & MAI & JUN & JUL & AGO & SET & OUT & NOV & DEZ \\
\hline $0,0\left({ }^{*}\right.$ p. 1.$)$ & 100 & & & & & & & & & \\
\hline 0,008 & 95,8 & & & & & & 4,2 & & & \\
\hline 0,01 & 89,8 & & & & & & 10,2 & & & \\
\hline 0,02 & 77,8 & & & & & & 22,2 & & & \\
\hline 0,03 & 69,4 & & & & & & 27,3 & 3,3 & & \\
\hline 0,04 & 62,0 & 1,3 & & & & & 29,9 & 5,5 & & 2,2 \\
\hline 0,06 & 50,8 & 4,9 & & & & & 31,6 & 7,9 & & 4,8 \\
\hline 0,08 & 42,9 & 5,8 & 2,6 & & & & 32,4 & 11,1 & & 5,2 \\
\hline 0,09 & 40,2 & 6,0 & 3,7 & & & & 32,8 & 11,4 & & 5,9 \\
\hline 0,1 & 38,1 & 6,2 & 3,0 & & & & 33,0 & 12,0 & & 7,7 \\
\hline 0,15 & 30,5 & 6,1 & 6,5 & & & & 33,4 & 14,4 & 1,4 & 7,7 \\
\hline 0,2 & 26,1 & 7,0 & 7,0 & 1,7 & & & 32,4 & 14,4 & 2,2 & 8,5 \\
\hline 0,3 & 20,5 & 9,3 & 8,6 & 3,4 & 1,2 & 0,4 & 29,6 & 14,5 & 4,5 & 8,0 \\
\hline 0,4 & 17,0 & 9,9 & 10,5 & 4,3 & 2,7 & 0,6 & 27,7 & 14,6 & 5,2 & 8,0 \\
\hline 0,5 & 14,7 & 9,9 & 11,4 & 4,5 & 3,4 & 2,9 & 25,9 & 14,6 & 5,4 & 7,9 \\
\hline 0,6 & 13,2 & 10,0 & 12,1 & 4,7 & 3,9 & 3,8 & 24,7 & 14,6 & 5,6 & 7,9 \\
\hline 0,7 & 12,1 & 9,9 & 12,7 & 4,9 & 4,3 & 4,5 & 24,0 & 14,8 & 5,6 & 7,9 \\
\hline 0,8 & 11,3 & 9,9 & 13,0 & 4,9 & $\begin{array}{l}4,3 \\
4,4\end{array}$ & 5,0 & 23,2 & $\begin{array}{l}14,9 \\
14,9\end{array}$ & 5,6 & 7,9 \\
\hline 0,9 & 10,6 & 9,9 & 13,2 & 5,0 & 4,6 & 5,4 & 22,8 & 15,0 & 5,6 & 7,9 \\
\hline 1,0 & 10,1 & 9,9 & 13,5 & 5,1 & 4,8 & 5,7 & 22,3 & 15,1 & 5,6 & 7,9 \\
\hline
\end{tabular}

Fonte: resultado do modelo com elevação na taxa de juros.

$\left({ }^{*}\right.$ p.l. $)=$ resultado obtido com a programação linear.

Desta forma, nesta simulação obteve-se a seguinte discriminação mensal de vendas: $10,1 \%$ em março, $9,9 \%$ em abril, 13,5\% em maio, $5,1 \%$ em junho, 4,8\% em julho, 5,75 em agosto, $22,3 \%$ em setembro, $15,1 \%$ em outubro, $5,6 \%$ em novembro e $7,9 \%$ em dezembro.

Quanto ao produtor "indiferente ao risco" $(\alpha=0)$, tal como no Modelo Básico, selecionou-se uma única estratégia de comercialização para a composição de seu plano ótimo de vendas, estratégia esta que maximiza a sua utilidade esperada. Nesta caso, foi selecionada a estratégia $\mathrm{EC}_{1}$, ou seja, vender toda a sua produção na época da colheita em março, dado que a taxa de juros é muito alta, não compensando uma armazenagem com venda posterior.

Com relação aos efeitos da aversão ao risco sobre a renda líquida esperada pelos produtores para o caso do produtor com "baixa aversão ao risco" $(\alpha=0,15)$, nota-se que o modelo selecionou um conjunto de alternativas diversificadas como sendo a solução ótima, seguindo o princípio estabelecido por Markowitz. Com isto, obteve-se uma renda líquida média esperada de US\$26.948,00, a qual possui um risco associado da ordem de US\$ 
2.069,00, com um coeficiente de variação de $0,17 \%$ e com um coeficiente de elasticidade Risco-Renda de 32,1 (vide Tabela 20).

Tabela 20 - Renda Líquida Média Esperada, Coeficiente de Aversão ao Risco, Risco associado às Estratégias de Comercialização de Soja e Elasticidade Risco-Renda - Simulação da elevação da taxa de juros - PR, 1980-95.

\begin{tabular}{ccccc}
\hline $\begin{array}{c}\text { Coeficiente } \\
\text { de Aversão } \\
\text { ao Risco }(\alpha)\end{array}$ & $\begin{array}{c}\text { Renda Líquida } \\
\text { Média } \\
\text { Esperada } \\
\text { (US\$) }\end{array}$ & $\begin{array}{c}\text { Diferença de } \\
\text { renda em relação } \\
\text { ao Modelo } \\
\text { Básico(**) }\end{array}$ & $\begin{array}{c}\text { Risco } \\
\text { Associado } \\
\text { (US } \$)\end{array}$ & $\begin{array}{c}\text { Diferença de risco } \\
\text { em relação ao } \\
\text { Modelo } \\
\text { Básico(***) }\end{array}$ \\
\hline $0,0\left({ }^{*}\right.$ p.1.) & $28.392,00$ & $-9.777,00$ & $23.483,00$ & $-14.686,00$ \\
0,008 & $28,205,00$ & $-9.829,00$ & $12.524,00$ & $-7.024,00$ \\
0,01 & $28.164,00$ & $-9.842,00$ & $11.495,00$ & $-6.564,00$ \\
0,02 & $27.990,00$ & $-9.946,00$ & $8.216,00$ & $-3.753,00$ \\
0,03 & $27.836,00$ & $-10.042,00$ & $6.251,00$ & $-2.065,00$ \\
0,04 & $27.704,00$ & - & $5.069,00$ & - \\
0,06 & $27.500,00$ & - & $3.840,00$ & - \\
0,08 & $27.341,00$ & - & $3.191,00$ & - \\
0,09 & $27.274,00$ & - & $2.956,00$ & - \\
0,1 & $27.212,00$ & $-10.304,00$ & $2.756,00$ & $-509,00$ \\
0,15 & $26.948,00$ & $-10.322,00$ & $2.069,00$ & $-781,00$ \\
0,2 & $26.732,00$ & $-10.313,00$ & $1.673,00$ & $-826,00$ \\
0,3 & $26.387,00$ & $-10.237,00$ & $1.316,00$ & $-693,00$ \\
0,4 & $26.127,00$ & $-10.108,00$ & $1.179,00$ & $-504,00$ \\
0,5 & $25.915,00$ & $-9.968,00$ & $1.133,00$ & $-330,00$ \\
0,6 & $25.730,00$ & $-9.843,00$ & $1.121,00$ & $-194,00$ \\
0,7 & $25.562,00$ & $-9.735,00$ & $1.109,00$ & $-111,00$ \\
0,8 & $25.403,00$ & $-9.648,00$ & $1.098,00$ & $-65,00$ \\
0,9 & $25.250,00$ & $-9.575,00$ & $1.087,00$ & $-49,00$ \\
1,0 & $25.103,00$ & $-9.722,00$ & $1.077,00$ & $-48,00$ \\
\hline
\end{tabular}

Fonte: resultado obtido pelo modelo com elevação na taxa de juros.

(p.l.*) resultado obtido por programação linear.

$\left.{ }^{(* *}\right)$ Renda do modelo com elevação da taxa de juros menos a renda do Modelo Básico (Tabela 13).

(***) Risco do modelo com elevação da taxa de juros menos o risco do Modelo Básico (Tabela 13).

Analisando-se comparativamente esta solução obtida pelo modelo com elevação na taxa de juros com a melhor solução ótima proporcionada pelo Modelo Básico, nota-se que a renda líquida média esperada foi reduzida em cerca de $26,8 \%$, ou seja, sofreu uma queda de US\$ $10.304,00$. O risco associado foi diminuído em $7,3 \%$, o que corresponde a uma redução de US\$ 781,00 . 
Quanto ao caso do produtor "altamente avesso ao risco" $(\alpha=1)$, o modelo selecionou a maior diversificação de vendas para o formação do plano ótimo até aqui analisada, mostrando nitidamente que o mesmo busca uma redução de risco na comercialização da produção, obtendo com isto uma renda líquida média esperada de US\$ $25.103,00$, com um risco associado da ordem de US\$1.077,00, um coeficiente de variação de $0,13 \%$ e um coeficiente de elasticidade Risco-Renda de 14,8 .

Com relação à mesma situação analisada no Modelo Básico, a renda líquida média esperada caiu 27,5\% (o que corresponde a uma redução de US\$ 9.722,00) e o risco associado caiu em $4,3 \%$ (o que significa uma redução de US $\$ 48,00$ ).

Finalmente, quanto ao produtor "indiferente ao risco" $(\alpha=0)$, o qual busca somente a maximização de sua utilidade esperada e que ignora os riscos de mercado, obteve-se uma renda líquida média esperada de US\$ $28.392,00$, com um risco associado de US\$23.483,00, um coeficiente de variação de 0,54\% e um coeficiente de elasticidade Risco-Renda tendendo a $\infty$.

Analisando-se esta situação obtida pela simulação de elevação da taxa de juros, de forma comparativa com a mesma situação proporcionada pelo Modelo Básico, nota-se que houve uma redução da ordem de $26,6 \%$ na renda líquida média esperada, ou seja, a mesma foi reduzida em US\$ 9.829,00. Quanto ao risco associado, o mesmo foi diminuído em $22,7 \%$ (em termos monetários, US\$ 7.024,00).

Nesta situação de elevação da taxa de juros, comparando-se na mesma simulação o produtor "indiferente ao risco" com o produtor "avesso ao risco", nota-se que o primeiro obtém uma renda líquida média esperada $11,6 \%$ maior, mas assume um risco 21,8 vezes maior na atividade, mostrando mais uma vez que a solução ideal seria uma situação intermediária entre estes dois casos.

Analisando-se, finalmente, a fronteira eficiente de renda-risco desta simulação, observa-se um comportamento similar à fronteira obtida anteriormente pelo Modelo Básico, ou seja, a inclinação da fronteira tende a decrescer com incremento na renda líquida média esperada. Note-se pela Figura 13 que devido ao efeito do aumento da taxa de juros de 
mercado, a mesma sofreu um deslocamento para baixo, paralelamente à fronteira gerada na situação inicial.

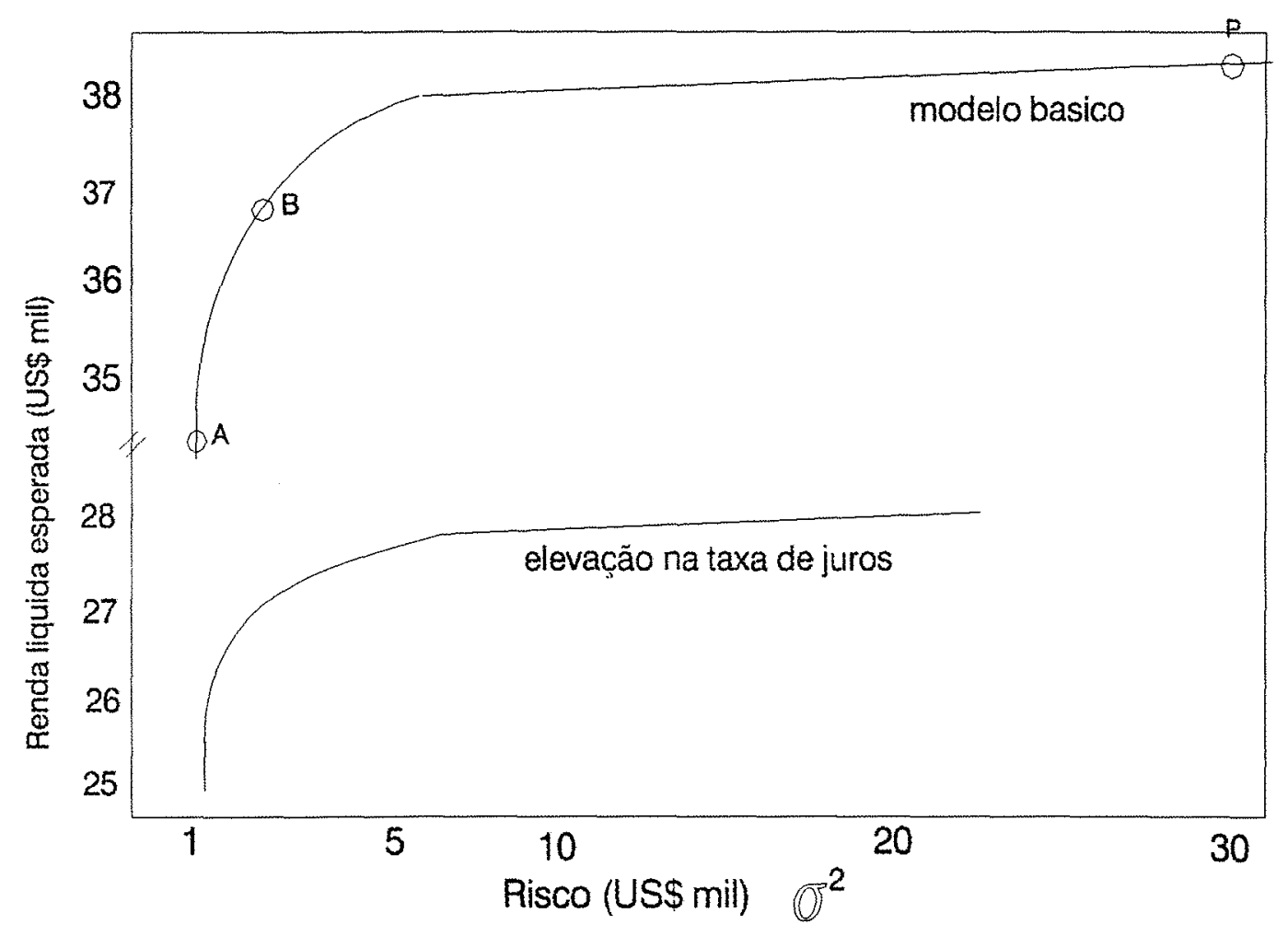

Fonte: resultado obtido pelo modelo com elevação da taxa de juros.

Figura 13 - Fronteira Eficiente da Média-Variância para a simulação da elevação da taxa de juros - PR - 1980-95.

\subsection{3 - O Efeito da Elevação no Custo de Armazenagem}

O custo de armazenagem é um dos elementos determinantes na tomada de decisão sobre "quando", "quanto" e "como" vender a produção por parte dos produtores rurais.

Desta forma, os sojicultores só devem armazenar sua safra se a receita bruta proveniente da venda da produção depois de algum tempo, descontados os custos de armazenagem e perdas, for superior à receita obtida pela venda da produção na época da colheita. Assim, um efeito imediato associado à elevação dos custos de armazenagem, consistiria na antecipação da venda da produção, dado que manter o produto armazenado para se buscar 
um preço futuro melhor acarretaria necessariamente em uma redução da renda líquida média esperada.

Em relação ao Modelo Básico, este efeito da elevação no custo de armazenagem de $25 \%$, ou seja, de US\$ 0,08 por saca de $60 \mathrm{~kg}$ por mês (preço praticado atualmente pelo mercado) para US\$ 0,10 por saca de $60 \mathrm{~kg}$ por mês, com relação às soluções de venda anteriormente encontradas, mostram que o modelo não sofreu alteração com relação ao aspecto de início do processo de diversificação das estratégias, evidenciando o mesmo comportamento apresentado pelo Modelo Básico.

Nesta simulação de elevação do custo de armazenagem, a melhor das soluções ótima sofreu um deslocamento, sendo escolhido pelo modelo o coeficiente de aversão ao risco $\alpha=0,2$, ou seja, produtor com "baixa aversão ao risco". Desta forma, para a composição ótima de vendas foram selecionadas as seguintes estratégias de comercialização: $11,0 \% \mathrm{em}$ setembro, $12,7 \%$ em outubro, $11,7 \%$ em novembro, $14,0 \%$ em dezembro, $12,1 \%$ através da estratégia $\mathrm{EC}_{17}, 13,3 \%$ através da estratégia $\mathrm{EC}_{18}, 13,6 \%$ através da estratégia $\mathrm{EC}_{19} \mathrm{e}$ $11,7 \%$ através da estratégia $\mathrm{EC}_{20}$ (vide Tabela 21 ).

Este plano ótimo de comercialização consistiria na armazenagem da produção com posterior venda mensal da produção através da seguinte composição: $3,9 \%$ em abril, 27,8\% em setembro, $25,4 \%$ em outubro, $18,2 \%$ em novembro e $24,7 \%$ em dezembro, onde cerca de $96,1 \%$ das vendas estariam concentradas nos últimos quatro meses do ano (vide Tabela 22). A composição do plano ótimo de vendas mostrou-se similar à solução obtida pelo Modelo Básico, já que esta elevação no custo de armazenagem não foi suficiente para causar um grande impacto na composição das estratégias que formam o plano ótimo de vendas.

Quanto ao produtor com "grande aversão ao risco" $(\alpha=1)$, da mesma maneira que ocorreu ao Modelo Básico, foram formulados planos ótimos de comercialização de sua produção com uma maior concentração de vendas no final do ano, mas mantendo ainda assim uma grande diversificação de estratégias, objetivando-se com isto redução de risco de sua atividade de venda. 
Tabela 21 - Percentagem de venda de soja, por Estratégia de Comercialização, segundo coeficiente de aversão ao risco - Simulação da Elevação do custo de armazenagem - PR - 1980-95.

\begin{tabular}{|c|c|c|c|c|c|c|c|c|c|c|c|c|c|c|c|c|}
\hline & & \multicolumn{15}{|c|}{ Estratégias de comercialização de soja (\%) } \\
\hline $\begin{array}{l}\text { Renda } \\
\text { Líquida }\end{array}$ & $\begin{array}{l}\text { Coeficiente } \\
\text { de Aversão }\end{array}$ & $\mathrm{EC}$ & $\mathrm{EC}$ & $\mathrm{EC}$ & $\mathrm{EC}$ & $\mathrm{EC}$ & $\mathrm{EC}$ & $\mathrm{EC}$ & $\mathrm{EC}$ & $\mathrm{EC}$ & $\mathrm{EC}$ & $\mathrm{EC}$ & $\mathrm{EC}$ & $\mathrm{EC}$ & $\mathrm{EC}$ & $\mathrm{EC}$ \\
\hline $\begin{array}{c}\text { Esperada } \\
\text { (US\$) }\end{array}$ & $\begin{array}{c}\text { ao Risco } \\
(\alpha)\end{array}$ & 4 & 7 & 8 & 9 & 10 & 11 & 12 & 13 & 14 & 15 & 16 & 17 & 18 & 19 & 20 \\
\hline $37.259,00$ & $0,0\left(^{*}\right.$ p.1.) & & 100 & & & & & & & & & & & & & \\
\hline $37.216,00$ & 0,001 & & 85,2 & & & & & & & & & & 14,8 & & & \\
\hline $37.189,00$ & 0,002 & & 66,0 & & & & & & & & & & 34,0 & & & \\
\hline $37.166,00$ & 0,003 & & 57,4 & & & & & & & & & & 37,9 & & 4,7 & \\
\hline $37.147,00$ & 0,004 & & 50,3 & & & & & & & & & & 36,6 & & 13,1 & \\
\hline $37.104,00$ & 0,007 & & 38,1 & 10,3 & & & & & & & & & 31,5 & & 20,0 & \\
\hline $37.081,00$ & 0,009 & & 33,8 & 13,3 & & & & & & & & & 29,3 & 2,5 & 21,1 & \\
\hline $37.070,00$ & 0,01 & & 32,0 & 14,1 & & & & & & & & & 28,2 & 4,5 & 21,2 & \\
\hline $36.991,00$ & 0,02 & & 22,6 & 15,4 & & 9,7 & & & & & & & 21,5 & 11,4 & 19,4 & \\
\hline $36.924,00$ & 0,03 & & 19,1 & 15,4 & 2,7 & 12,5 & & & & & & & 18,9 & 13,2 & 18,3 & \\
\hline $36.812,00$ & 0,05 & & 15,9 & 14,9 & 7,8 & 14,1 & & & & & & & 16,4 & 14,1 & 16,9 & \\
\hline $36.654,00$ & 0,08 & & 14,1 & 14,6 & 10,7 & 15,0 & & & & & & & 15,0 & 14,6 & 16,4 & \\
\hline $36.552,00$ & 0,1 & & 13,3 & 14,2 & 11,3 & 15,0 & & & & & & & 14,3 & 14,5 & 15,6 & 1,8 \\
\hline $36.109,00$ & 0,2 & & 11,0 & 12,7 & 11,7 & 14,0 & & & & & & & 12,1 & 13,3 & 13,6 & 11,7 \\
\hline $35.700,00$ & 0,3 & & 10,1 & 12,0 & 11,7 & 13,5 & & & & & & & 11,2 & 12,8 & 12,8 & 14,7 \\
\hline $35.330,00$ & 0,4 & & 9,1 & 11,0 & 10,9 & 12,4 & 4,6 & & & & 2,8 & 0,8 & 10,2 & 11,7 & 11,7 & 14,8 \\
\hline $35.013,00$ & 0,5 & & 8,2 & 10,0 & 10,1 & 11,3 & 6,1 & 2,6 & & & 4,3 & 2,8 & 9,2 & 10,7 & 10,6 & 14,2 \\
\hline $34.737,00$ & 0,6 & & 7,5 & 9,1 & 9,3 & 10,4 & 6,7 & 4,2 & 2,1 & 1,0 & 4,9 & 3,7 & 8,4 & 9,8 & 9,7 & 13,3 \\
\hline $34.494,00$ & 0,7 & 0,3 & 6,9 & 8,4 & 8,6 & 9,6 & 6,9 & 5,1 & 3,5 & 2,3 & 5,2 & 4,2 & 7,7 & 9,0 & 8,9 & 12,6 \\
\hline $34.276,00$ & 0,8 & 0,8 & 6,4 & 7,9 & 8,1 & 9,0 & 7,1 & 5,7 & 4,4 & 3,2 & 5,5 & 4,6 & 7,2 & 8,5 & 8,3 & 12,0 \\
\hline $34.073,00$ & 0,9 & 1,1 & 6,1 & 7,5 & 7,7 & 8,5 & 7,2 & 6,2 & 5,1 & 3,9 & 5,6 & 4,9 & 6,8 & 8,0 & 7,9 & 11,6 \\
\hline $33.883,00$ & 1,0 & 1,4 & 5,8 & 7,1 & 7,4 & 8,1 & 7,3 & 6,6 & 5,7 & 4,5 & 5,7 & 5,1 & 6,5 & 7,7 & 7,5 & 11,2 \\
\hline
\end{tabular}

Fonte: resultado fornecido pela simulação de elevaçăo no custo de armazenagem. $\left({ }^{*}\right.$ p.l. $)=$ resultado obtido pela programação linear.

Desta forma, obteve-se a seguinte composição de estratégias de comercialização de sua produção: $2,3 \%$ em março, $1,4 \%$ em junho, $5,8 \%$ em setembro, $7,1 \%$ em outubro, $7,4 \%$ em novembro, $8,1 \%$ em dezembro, $7,3 \%$ através da estratégia $\mathrm{EC}_{11}, 6,6 \%$ através da estratégia $\mathrm{EC}_{12}, 5,7 \%$ através da estratégia $\mathrm{EC}_{13}, 4,5 \%$ através da estratégia $\mathrm{EC}_{14}, 5,7 \%$ através da estratégia $\mathrm{EC}_{15}, 5,1 \%$ através da estratégia $\mathrm{EC}_{16}, 6,5 \%$ através da estratégia $\mathrm{EC}_{17}, 7,7 \%$ através da estratégia $\mathrm{EC}_{18}, 7,5 \%$ através da estratégia $\mathrm{EC}_{19}$ e $11,2 \%$ através da estratégia $\mathrm{EC}_{20}$.

Quanto à discriminação mensal de vendas, comercializaria-se: 2,3\% em março, 4,7\% em abril, $7,8 \%$ em maio, $2,5 \%$ em junho, $4,8 \%$ em julho, $5,9 \%$ em agosto, $24,9 \%$ em setembro, $20,1 \%$ em outubro, $11,3 \%$ em novembro e $15,4 \%$ em dezembro. 
Tabela 22 - Percentagem de venda de soja, Discriminação mensal, segundo coeficiente de Aversão ao Risco - Simulação da elevação do custo de armazenagem - PR, 1980-95.

\begin{tabular}{|c|c|c|c|c|c|c|c|c|c|c|}
\hline \multirow{2}{*}{$\begin{array}{c}\text { Coeficiente de } \\
\text { Aversão ao } \\
\text { Risco }(\alpha)\end{array}$} & \multicolumn{10}{|c|}{ Discriminação Mensal de vendas dos Planos Otimos (\%) } \\
\hline & MAR & $\mathrm{ABR}$ & MAI & JUN & JUL & AGO & SET & OUT & NOV & DEZ \\
\hline $0,0($ p.l. $*)$ & & & & & & & 100 & & & \\
\hline 0,001 & & & & & & & 92,6 & 7,4 & & \\
\hline 0,002 & & & & & & & 83,0 & 17,0 & & \\
\hline 0,003 & & & & & & & 78,7 & 19,0 & & 2,3 \\
\hline 0,004 & & & & & & & 75,2 & 18,3 & & 6,5 \\
\hline 0,007 & & & & & & & 63,9 & 26,1 & & 10,0 \\
\hline 0,009 & & & & & & & 59,0 & 29,2 & 1,3 & 10,5 \\
\hline 0,01 & & & & & & & 56,7 & 30,5 & 2,3 & 10,5 \\
\hline 0,02 & & & & & & & 43,1 & 31,9 & 5,7 & 19,3 \\
\hline 0,03 & & & & & & & 37,7 & 31,5 & 9,3 & 21,5 \\
\hline 0,05 & & & & & & & 32,6 & 30,2 & 14,9 & 22,3 \\
\hline 0,08 & & & & & & & 29,8 & 29,4 & 18,0 & 22,8 \\
\hline 0,1 & & & & & & & 29,2 & 28,6 & 18,6 & 23,6 \\
\hline 0,2 & & 3,9 & & & & & 27,8 & 25,4 & 18,2 & 24,7 \\
\hline 0,3 & & 4,9 & & & & & 27,6 & 24,0 & 18,1 & 26,0 \\
\hline 0,4 & & 4,9 & 2,3 & & 0,4 & 1,4 & 27,0 & 23,4 & 16,8 & 23,2 \\
\hline 0,5 & & 4,7 & 3,9 & & 2,3 & 2,2 & 27,0 & 22,1 & 15,5 & 21,3 \\
\hline 0,6 & & 4,7 & 5,5 & 0,25 & 3,3 & 3,4 & 27,0 & 21,6 & 14,2 & 19,7 \\
\hline 0,7 & 0,7 & 4,7 & 6,3 & 0,9 & 3,8 & 4,3 & 26,7 & 21,1 & 13,1 & 18,2 \\
\hline 0,8 & 1,3 &,+ 7 & 6,9 & 1,6 & 4,2 & 5,0 & 25,9 & 20,8 & 12,4 & 17,0 \\
\hline 0,9 & 1,9 & 4,7 & 7,4 & 2,1 & 4,5 & 5,5 & 25,4 & 20,4 & 11,7 & 16,2 \\
\hline 1,0 & 2,3 &,+ 7 & 7,8 & 2,5 & 4,8 & 5,9 & 24,9 & 21,1 & 11,3 & 15,4 \\
\hline
\end{tabular}

O produtor "avesso ao risco" $(\alpha=0)$, similarmente ao que ocorreu no Modelo Básico, selecionaria uma única estratégia de comercialização para a composição de seu plano ótimo de vendas, buscando uma estratégia que maximizasse sua utilidade esperada. Neste caso, foi selecionada a estratégia $\mathrm{EC}_{7}$, ou seja, armazenar a produção na época da colheita, com posterior venda de $100 \%$ em setembro.

Com relação aos efeitos da aversão ao risco sobre a renda líquida esperada pelos produtores, para o produtor com "baixa aversão ao risco" $(\alpha=0,2)$, o modelo selecionou um conjunto de alternativas diversificadas como sendo a solução ótima, seguindo o princípio de diversificação (Markowitz). Com isto, obteve-se uma renda líquida média esperada de US\$ $36.109,00$, a qual possui um risco associado da ordem de US\$2.303,00, cujo 
coeficiente de variação é de $0,13 \%$ e com um coeficiente de elasticidade Risco-Renda de 57,6 (vide Tabela 23).

Tabela 23 - Renda Líquida Média Esperada, Coeficiente de Aversão ao Risco, Risco associado às Estratégias de Comercialização de Soja e Elasticidade Risco-Renda da Simulação da elevação do custo de armazenagem - PR, 1980-95.

\begin{tabular}{|c|c|c|c|c|}
\hline $\begin{array}{l}\text { Coeficiente de } \\
\text { Aversão ao } \\
\text { Risco }(\alpha)\end{array}$ & $\begin{array}{l}\text { Renda Líquida } \\
\text { Média } \\
\text { Esperada } \\
\text { (US\$) }\end{array}$ & $\begin{array}{l}\text { Diferença de } \\
\text { renda em } \\
\text { relação ao } \\
\text { Modelo } \\
\text { Básico }\left(^{* *}\right) \\
\end{array}$ & $\begin{array}{l}\text { Risco } \\
\text { Associado } \\
\text { (US\$) }\end{array}$ & $\begin{array}{l}\text { Diferença de } \\
\text { risco em relação } \\
\text { ao Modelo } \\
\text { Básico }\left(^{* * *}\right)\end{array}$ \\
\hline $0,0\left(\mathrm{p} .1^{*}\right)$ & $37.259,00$ & $-910,00$ & $44.773,00$ & $+14.408,00$ \\
\hline 0,001 & $37.216,00$ & - & $17.288,00$ & - \\
\hline 0,002 & $37.189,00$ & $-895,00$ & $12.143,00$ & $+1.137,00$ \\
\hline 0,003 & $37.166,00$ & $-925,00$ & $9.560,00$ & $+1.091,00$ \\
\hline 0,004 & $37.147,00$ & $-926,00$ & $8.006,00$ & $+1.077,00$ \\
\hline 0,007 & $37.104,00$ & - & $5.969,00$ & - \\
\hline 0,01 & $37.070,00$ & $-936,00$ & $5.199,00$ & $+268,00$ \\
\hline 0,03 & $36.924,00$ & $-954,00$ & $4.075,00$ & $-111,00$ \\
\hline 0,08 & $36.654,00$ & - & $3.305,00$ & - \\
\hline 0,1 & $36.552,00$ & $-964,00$ & $3.076,00$ & $-189,00$ \\
\hline 0,2 & $36.109,00$ & $-936,00$ & $2.303,00$ & $-196,00$ \\
\hline 0,3 & $35.700,00$ & $-924,00$ & $1.816,00$ & $-193,00$ \\
\hline 0,4 & $35.330,00$ & $-905,00$ & $1.521,00$ & $-162,00$ \\
\hline 0,5 & $35.013,00$ & $-870,00$ & $1.338,00$ & $-125,00$ \\
\hline 0,6 & $34.737,00$ & $-836,00$ & $1.226,00$ & $-89,00$ \\
\hline 0,7 & $34.494,00$ & $-803,00$ & $1.163,00$ & $-57,00$ \\
\hline 0,8 & $34.276,00$ & $-775,00$ & $1.135,00$ & $-28,00$ \\
\hline 0,9 & $34.073,00$ & $-752,00$ & $1.123,00$ & $-13,00$ \\
\hline 1,0 & $33.883,00$ & $-732,00$ & $1.113,00$ & $-12,00$ \\
\hline
\end{tabular}

Comparativamente ao Modelo Básico, nota-se que devido a esta elevação do custo de armazenagem, a renda líquida média esperada foi reduzida em cerca de $1,9 \%$ ou seja, menos US $\$ 936,00$ de renda, com um risco associado diminuído $7,8 \%$, ou seja, US $\$ 196,00$ a menos de risco. 
Quanto ao produtor "altamente avesso ao risco" $(\alpha=1)$, o mesmo tende a proporcionar uma diversificação de vendas, de maneira semelhante ao Modelo Básico, mostrando mais uma vez seu desejo de redução do risco associado a sua atividade de vendas. Obteve-se assim uma renda líquida média esperada de US $\$ 33.883,00$, com um risco associado da ordem de US $\$ 1.113,00$, que possui um coeficiente de variação de $0,10 \%$ e um coeficiente de elasticidade Risco-Renda de 20,1.

Esta mesma situação, quando comparada com a solução fornecida pelo Modelo Básico, mostra que a renda líquida média esperada foi reduzida em US\$732,00, e que o risco teve uma redução de US\$12,00.

Finalmente, para o produtor "indiferente ao risco" $(\alpha=0)$, o qual busca apenas a maximização de sua utilidade e que desconhece de certa maneira os riscos de mercado, obteve-se uma renda líquida média esperada de US\$37.259,00, com um risco associado da ordem de US\$ 44.773,00, um coeficiente de variação de 0,57\% e um coeficiente de elasticidade Risco-Renda tendendo a $\infty$. Comparando-se, esta situação com a proporcionada pelo Modelo Básico, nota-se que houve uma redução de $2,4 \%$ na renda líquida média esperada (US\$ 910,00), com o risco associado, aumentando em $47,4 \%$, ou seja, um incremento da ordem de US\$14.408,00.

Isto ocorreu devido ao fato de que o modelo selecionou uma estratégia que possui uma elevada variância de preços (alto risco associado). Nesta situação de elevação do custo de armazenagem, comparando-se na mesma simulação o produtor "indiferente ao risco" com o produtor "avesso ao risco", constata-se que o primeiro obtém uma renda líquida média esperada $10 \%$ superior, mas com isto assume um risco 40,2 vezes maior na atividade, mostrando novamente que a solução ideal seria uma situação intermediária entre estes dois casos, tal como aquela representada por $\alpha=0,2$.

Analisando-se a fronteira eficiente de renda-risco desta simulação, observa-se um comportamento semelhante ao do Modelo Básico, mas que devido ao aumento no custo de armazenagem sofreu um deslocamento para baixo, paralelamente à fronteira gerada na situação inicial (vide Figura 14). 


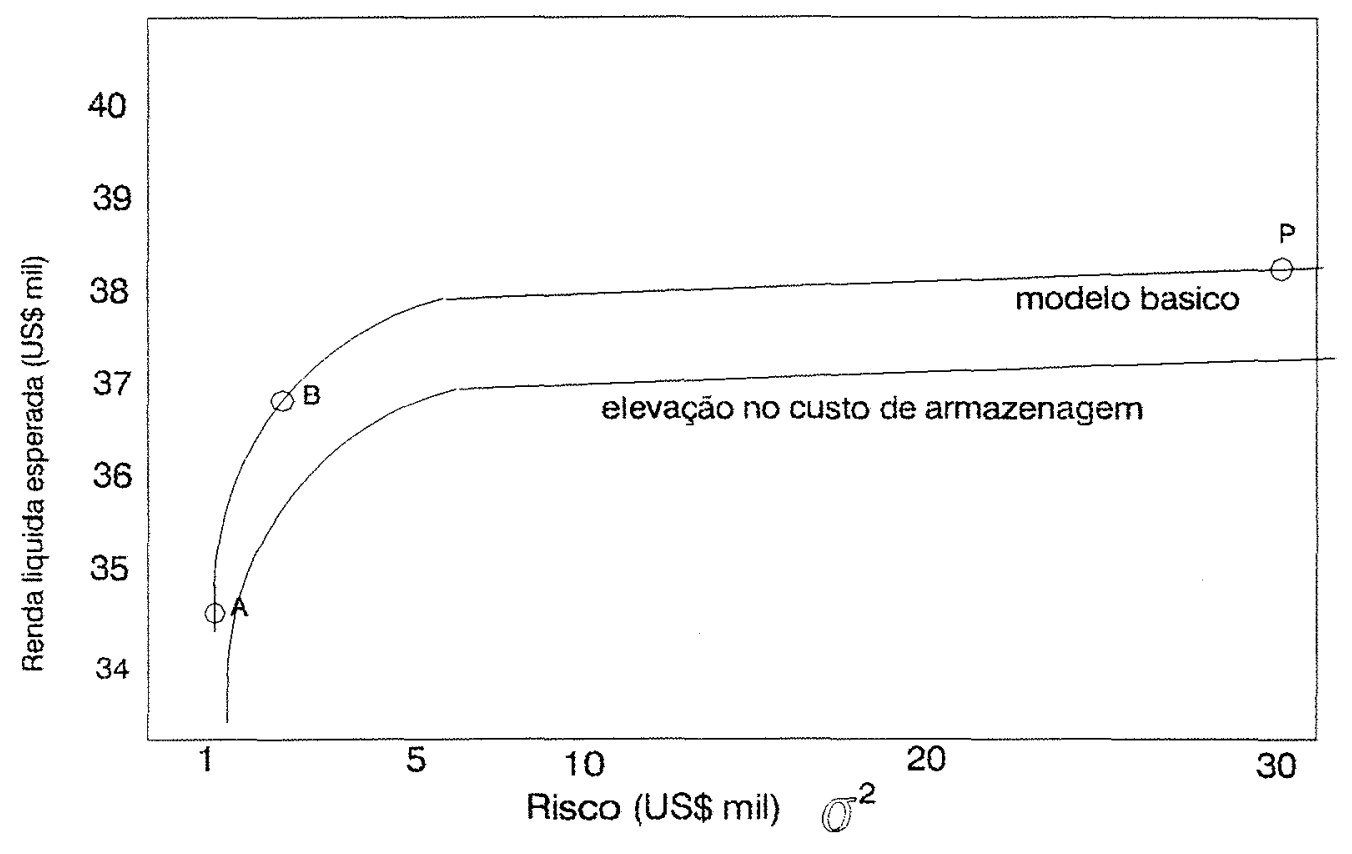

Fonte: resultado obtido pela simulação da elevação do custo de armazenagem.

Figura 14 - Fronteira Eficiente da Média-Variância para a Simulação da elevação custo de armazenagem - PR, 1980-95.

\subsection{4 - O Efeito da Redução no Custo de Armazenagem}

O custo de armazenagem, como já analisado na secção anterior, é um elemento decisório importante na escolha do momento mais adequado para a venda da produção. Um efeito imediato associado com a redução neste custo consistiria inicialmente em se "atrasar" a venda da produção, dado que no tempo este custo torna-se relativamente menor, possibilitanto com isto a busca de um preço futuro melhor.

Comparativamente ao Modelo Básico, o efeito da redução no custo de armazenagem em $25 \%$, ou seja, de US\$ 0,08 por saca de $60 \mathrm{~kg}$ por mês para US\$ 0,06 por saca de $60 \mathrm{~kg}$ por mês com relação às soluções de venda anteriormente encontradas, mostram que o modelo foi menos sensível no aspecto de início do processo de seleção de estratégias diversificadas para a composição dos planos ótimos de comercialização, pois no Modelo Básico a diversificação se iniciou $\operatorname{com} \alpha=0,001$, enquanto que na simulação com $\alpha=0,0051$. 
Nesta simulação de redução do custo de armazenagem, a melhor solução obtida pelo modelo foi a combinação de estratégias de comercialização que possui o coeficiente de aversão ao risco $(\alpha)$ igual a 0,25 , o que corresponde ao produtor com "média aversão ao risco". Esta composição ótima de vendas ficou sendo composta pelas seguintes estratégias de vendas: $9,2 \%$ em setembro, $12,4 \%$ em outubro, $13,6 \%$ em novembro, $17,9 \%$ em dezembro, $10,9 \%$ através da estratégia $\mathrm{EC}_{17}, 14,1 \%$ através da estratégia $\mathrm{EC}_{18}, 14,2 \%$ através da estratégia $\mathrm{EC}_{19}$ e 7,6\% através da estratégia $\mathrm{EC}_{20}$ (vide Tabela 24).

Tabela 24 - Percentagem de venda de soja, por Estratégia de Comercialização, segundo coeficiente de aversão ao risco - Simulação da Redução do custo de armazenagem - PR -1980-95.

\begin{tabular}{|c|c|c|c|c|c|c|c|c|c|c|c|c|c|c|c|}
\hline & & \multicolumn{14}{|c|}{ Estratégias de comercialização de soja (\%) } \\
\hline $\begin{array}{l}\text { Renda } \\
\text { Líquida }\end{array}$ & $\begin{array}{l}\text { Coeficiente } \\
\text { de aversão }\end{array}$ & $\mathrm{EC}$ & $\mathrm{EC}$ & $\mathrm{EC}$ & $\mathrm{EC}$ & $\mathrm{EC}$ & $\mathrm{EC}$ & $\mathrm{EC}$ & $\mathrm{EC}$ & $\mathrm{EC}$ & $\mathrm{EC}$ & $\mathrm{EC}$ & $\mathrm{EC}$ & $\mathrm{EC}$ & $\mathrm{EC}$ \\
\hline $\begin{array}{l}\text { Esperada } \\
\text { (US\$) }\end{array}$ & $\begin{array}{c}\text { ao risco } \\
(\alpha)\end{array}$ & 7 & 8 & 9 & 10 & 11 & 12 & 13 & 14. & 15 & 16 & 17 & 18 & 19 & 20 \\
\hline $39.369,00$ & $0,0\left(\mathrm{p} . \mathrm{l}^{*}\right)$ & & & & 100 & & & & & & & & & & \\
\hline $39.215,00$ & 0,0051 & & & & 99,4 & & & & & & & & & 0,6 & \\
\hline $39.189,00$ & 0,006 & & & & 92,4 & & & & & & & & & 7,6 & \\
\hline $39.142,00$ & 0,008 & & & & 82,5 & & & & & & & & & 17,5 & \\
\hline $39,121,00$ & 0,009 & & & & 78,4 & & & & & & & & 1,5 & 20,1 & \\
\hline $39.102,00$ & 0,01 & & & & 74,1 & & & & & & & & 4,6 & 21,3 & \\
\hline $38.972,00$ & 0,02 & & 6,1 & 8,6 & 48,2 & & & & & & & 3,8 & 12,7 & 20,6 & \\
\hline $38.892,00$ & 0,03 & 2,9 & 8,9 & 11,0 & 37,8 & & & & & & & 6,8 & 13,8 & 18,8 & \\
\hline $38,827,00$ & 0,04 & 4,9 & 10,2 & 12,1 & 32,5 & & & & & & & 8,3 & 14,2 & 17,8 & \\
\hline $38.768,00$ & 0,05 & 6,2 & 11,0 & 12,8 & 29,3 & & & & & & & 9,1 & 14,4 & 17,2 & \\
\hline $38.711,00$ & 0,06 & 7,0 & 11,5 & 13,2 & 27,1 & & & & & & & 9,7 & 14,6 & 16,8 & \\
\hline $38.657,00$ & 0,07 & 7,6 & 11,9 & 13,5 & 25,6 & & & & & & & 10,1 & 14,7 & 16,5 & \\
\hline $38.603,00$ & 0,08 & 8,0 & 12,2 & 13,8 & 24,5 & & & & & & & 10,4 & 14,8 & 16,3 & \\
\hline $38.551,00$ & 0,09 & 8,4 & 12,4 & 14,0 & 23,6 & & & & & & & 10,7 & 14,9 & 16,1 & \\
\hline $38.498,00$ & 0,1 & 8,6 & 12,6 & 14,1 & 22,9 & & & & & & & 10,9 & 14,9 & 16,0 & \\
\hline $37.999,00$ & 0,2 & 9,3 & 12,7 & 14,0 & 18,9 & & & & & & & 11,1 & 14,5 & 14,7 & 4,8 \\
\hline $37.779,00$ & 0,25 & 9,2 & 12,4 & 13,7 & 17,9 & & & & & & & 10,9 & 14,1 & 14,2 & 7,6 \\
\hline $37.559,00$ & 0,3 & 9,1 & 12,1 & 13,4 & 16,9 & & & & & & & 10,7 & 13,7 & 13,7 & 10,4 \\
\hline $37.148,00$ & 0,4 & 8,8 & 11,6 & 12,8 & 15,6 & & & & & 2,2 & & 10,3 & 13,0 & 12,9 & 12,7 \\
\hline $36.776,00$ & 0,5 & 8,2 & 10,8 & 11,9 & 14,3 & & & & & 4,3 & 1,3 & 9,6 & 12,1 & 11,9 & 13,0 \\
\hline $36.446,00$ & 0,6 & 7,8 & 10,1 & 11,1 & 13,2 & 4,5 & & 0,4 & & 5,5 & 3,0 & 9,0 & 11,3 & 11,1 & 13,0 \\
\hline $36.146,00$ & 0,7 & 7,3 & 9,5 & 10,4 & 12,3 & 5,5 & & 2,5 & 0,5 & 6,0 & 4,0 & 8,4 & 10,5 & 10,4 & 12,7 \\
\hline $35.878,00$ & 0,8 & 6,8 & 8,9 & 9,7 & 11,4 & 5,9 & 1,5 & 3,7 & 1,8 & 6,2 & 4,5 & 7,9 & 9,8 & 9,7 & 12,2 \\
\hline $35.633,00$ & 0,9 & 6,4 & 8,4 & 9,2 & 10,7 & 6,2 & 2,5 & 4,6 & 2,8 & 6,4 & 4,8 & 7,4 & 9,3 & 9,1 & 11,8 \\
\hline $35.407,00$ & 1,0 & 6,1 & 8,0 & 8,8 & 10,1 & 6,5 & 3,4 & 5,3 & 3,5 & 6,5 & 5,1 & 7,1 & 8,8 & 8,6 & 11,5 \\
\hline $\begin{array}{r}\text { Fonte: resultac } \\
\left(\text { p. } .^{*}\right) r\end{array}$ & $\begin{array}{l}\text { otido pelo mod } \\
\text { tado obtido cor }\end{array}$ & o con & eduçà & $\mathrm{gocus}$ & $\overline{\text { ode a }}$ & & agem. & & & & & & & & \\
\hline
\end{tabular}


composição mensal de vendas: $3,0 \%$ em abril, $21,7 \%$ em setembro, $24,9 \%$ em outubro, $20,8 \%$ em novembro e $28,0 \%$ em dezembro (vide Tabela 25 ).

Tabela 25 - Percentagem de venda de soja, Discriminação mensal, segundo coeficiente de Aversão ao Risco - Simulação da redução do custo de armazenagem - PR, 1980-95.

\begin{tabular}{|c|c|c|c|c|c|c|c|c|c|c|}
\hline \multirow{2}{*}{$\begin{array}{c}\text { Coeficiente de } \\
\text { Aversão ao } \\
\text { Risco }(\alpha)\end{array}$} & \multicolumn{10}{|c|}{ Discriminação Mensal de vendas dos Planos Otimos (\%) } \\
\hline & MAR & $\mathrm{ABR}$ & MAI & $\pi N$ & JUL & AGO & SET & OUT & NOV & DEZ \\
\hline $0,0\left(\right.$ p. $\left..1^{*}\right)$ & & & & & & & & & & 100 \\
\hline 0,0051 & & & & & & & 0,3 & & & 99,7 \\
\hline 0,006 & & & & & & & 3,8 & & & 96,2 \\
\hline 0,008 & & & & & & & 8,8 & & & 91,3 \\
\hline 0,009 & & & & & & & 10,1 & 0,8 & & 89,1 \\
\hline 0,01 & & & & & & & 10,7 & 2,3 & 2,3 & 84,8 \\
\hline 0,02 & & & & & & & 12,2 & 14,4 & 15,0 & 58,8 \\
\hline 0,03 & & & & & & & 15,7 & 19,2 & 17,9 & 47,2 \\
\hline 0,04 & & & & & & & 18,0 & 21,5 & 19,2 & 41,4 \\
\hline 0,05 & & & & & & & 19,4 & 22,8 & 20,0 & 37,9 \\
\hline 0,06 & & & & & & & 20,3 & 23,7 & 20,5 & 35,5 \\
\hline 0,07 & & & & & & & 20,9 & 24,3 & 20,9 & 33,9 \\
\hline 0,08 & & & & & & & 21,4 & 24,8 & 21,2 & 32,7 \\
\hline 0,09 & & & & & & & 21,8 & 25,2 & 21,5 & 31,7 \\
\hline 0,1 & & & & & & & 22,1 & 25,5 & 21,6 & 30,9 \\
\hline 0,2 & & 2,4 & & & & & 24,6 & 25,5 & 21,3 & 28,7 \\
\hline 0,25 & & 2,9 & & & & & 21,7 & 24,9 & 20,8 & 27,9 \\
\hline 0,3 & & 3,5 & & & & & 18,8 & 24,3 & 20,3 & 27,2 \\
\hline 0,4 & & 4,2 & & & & 1,1 & 24,6 & 24,4 & 19,3 & 26,3 \\
\hline 0,5 & & 4,3 & & & 0,7 & 2,2 & 23,9 & 23,8 & 18,0 & 24,6 \\
\hline 0,6 & & 4,3 & 2,4 & & 1,5 & 2,9 & 25,9 & 23,1 & 16,8 & 23,1 \\
\hline 0,7 & & 4,4 & 3,6 & 0,1 & 2,0 & 4,0 & 25,7 & 22,9 & 15,7 & 21,7 \\
\hline 0,8 & & 4,5 & 4,7 & 0,5 & 2,8 & 4,8 & 25,4 & 22,5 & 14,6 & 20,3 \\
\hline 0,9 & & 4,6 & 5,5 & 1,0 & 3,2 & 5,4 & 24,9 & 22,2 & 13,9 & 19,2 \\
\hline 1,0 & & 4,7 & 6,1 & 1,2 & 3,7 & 5,9 & 24,7 & 21,8 & 13,2 & 18,2 \\
\hline
\end{tabular}

Este plano ótimo de comercialização se mostrou muito semelhante ao obtido pelo Modelo Básico, diferindo deste apenas com relação a pequenas variações percentuais na composição de cada estratégia.

Quanto ao produtor com "grande aversão ao risco" $(\alpha=1)$, nota-se que o modelo proporcionou uma composição diversificada de estratégias de comercialização para a formação de seu plano ótimo de vendas, tendo em vista a amenização dos riscos de mercado. 
Desta forma, obteve-se a seguinte composição ótima de estratégias de vendas: $0,6 \%$ em junho, $6,1 \%$ em setembro, $8,0 \%$ em outubro, $8,8 \%$ em novembro, $10,1 \%$ em dezembro, $6,5 \%$ através da estratégia $\mathrm{EC}_{11}, 3,4 \%$ através da estratégia $\mathrm{EC}_{12}, 5,3 \%$ através da estratégia $\mathrm{EC}_{13}, 3,5 \%$ através da estratégia $\mathrm{EC}_{14}, 6,5 \%$ através da estratégia $\mathrm{EC}_{15}, 5,1 \%$ através da estratégia $\mathrm{EC}_{16}, 7,1 \%$ através da estratégia $\mathrm{EC}_{17}, 8,8 \%$ através da estratégia $\mathrm{EC}_{18}, 8,6 \%$ através da estratégia $\mathrm{EC}_{19}$ e $11,5 \%$ através da estratégia $\mathrm{EC}_{20}$.

A este plano ótimo de comercialização corresponda a seguinte composição mensal de vendas: $4,7 \%$ em abril, $6,1 \%$ em maio, $1,2 \%$ em junho, $3,7 \%$ em julho, $5,9 \%$ em agosto, $24,7 \%$ em setembro, $21,8 \%$ em outubro, $13,2 \%$ em novembro e $18,2 \%$ em dezembro.

No caso do produtor "indiferente ao risco" $(\alpha=0)$, tal como no Modelo Básico, foi selecionada apenas uma estratégia de comercialização para a composição de seu plano ótimo de vendas, estratégia esta considerada suficiente para maximizar a utilidade esperada do produtor. Sendo assim, selecionou-se a estratégia $\mathrm{EC}_{10}$, ou seja, armazenar a produção na época da colheita com posterior venda de toda a produção no mês de dezembro.

Analisando-se os efeitos da aversão de risco sobre a renda líquida esperada pelos produtores, percebe-se que no caso da seleção do melhor plano ótimo de vendas para o produtor com "média aversão ao risco" $(\alpha=0,25)$, foram combinadas alternativas diversificadas de vendas, objetivando-se reduzir o risco, mas mantendo um certo nível de renda esperado, segundo o princípio proposto por Markowitz. Com isto obteve-se uma renda líquida média esperada de US\$37.779,00, com um risco associado de US\$2.404,00, coeficiente de variação de 0,13\% e um coeficiente de elasticidade Renda-Risco de 41,4.

Comparando-se ao Modelo Básico, devido a esta redução no custo de armazenagem a renda cresceu $2,6 \%$, ou seja, teve um incremento de US $\$ 954,00$. Quanto ao risco associado cresceu 7,6\%, ou seja, US\$155,00 (vide Tabela 26).

No caso do produtor com "alta aversão ao risco" $(\alpha=1)$, novamente houve uma grande diversificação de vendas, buscando claramente com isto uma redução drástica no risco associado à atividade de venda. Com isto, houve também uma redução na renda líquida média esperada, obtendo com isto US\$ $35.407,00$, com um risco associado de US\$ $1.137,00$, um coeficiente de variação de $0,10 \%$ e um coeficiente de elasticidade Risco- 
Renda de 17,5. Com relação ao Modelo Básico, a renda líquida média esperada cresceu $2,28 \%$, com o risco associado aumentando apenas $1,06 \%$.

Finalmente, para o produtor "indiferente ao risco" $(\alpha=0)$, o qual desconsidera de certa maneira os riscos de mercado e que busca na comercialização de sua produção apenas a maximização de sua utilidade esperada, obteve com esta escolha uma renda líquida média esperada de US\$39.369,00, com um risco associado de US\$30.365,00, um coeficiente de variação de $0,44 \%$ e um coeficiente de elasticidade Risco-Renda tendendo a $\infty$. Com relação ao Modelo Básico, houve um incremento de 3,1\% na renda líquida média esperada, com o risco permanecendo inalterado.

Tabela 26 - Renda Líquida Média Esperada, Coeficiente de Aversão ao Risco, Risco associado às Estratégias de Comercialização de Soja e Elasticidade Risco-Renda da Simulação da redução do custo de armazenagem - PR, 1980-95.

\begin{tabular}{|c|c|c|c|c|}
\hline $\begin{array}{c}\text { Coeficiente de } \\
\text { Aversão ao Risco }(\alpha)\end{array}$ & $\begin{array}{l}\text { Renda Líquida Média } \\
\text { Esperada (US\$) }\end{array}$ & $\begin{array}{l}\text { Diferença de renda em } \\
\text { relação ao Modelo } \\
\text { Básico(**) }\end{array}$ & $\begin{array}{c}\text { Risco Associado } \\
\text { (US\$) }\end{array}$ & $\begin{array}{l}\text { Diferença de risco em } \\
\text { relação ao Modelo } \\
\text { Básico }\left(^{* * *}\right)\end{array}$ \\
\hline $0,0\left(\right.$ p..$\left.^{*}\right)$ & $39.369,00$ & $+1.200,00$ & $30.365,00$ & 0 \\
\hline 0,0051 & $39.215,00$ & $+1.157,00$ & $12.587,00$ & $+6.489,00$ \\
\hline 0,006 & $39.189,00$ & - & $10.945,00$ & - \\
\hline 0,008 & $39.142,00$ & - & $8.532,00$ & - \\
\hline 0,009 & $39.121,00$ & - & $7.671,00$ & - \\
\hline 0,01 & $39.102,00$ & $+1.586,00$ & $6.998,00$ & $+2.067,00$ \\
\hline 0,02 & $38.972,00$ & $+1.036,00$ & $4.884,00$ & $+421,00$ \\
\hline 0,03 & $38.892,00$ & $+1.014,00$ & $4.475,00$ & $+289,00$ \\
\hline 0,04 & $38.827,00$ & - & $4.226,00$ & - \\
\hline 0,05 & $38.768,00$ & - & $4.055,00$ & * \\
\hline 0,06 & $38.711,00$ & $=$ & $3.910,00$ & $=$ \\
\hline 0,07 & $38.657,00$ & - & $3.781,00$ & - \\
\hline 0,08 & $38.603,00$ & - & $3.662,00$ & - \\
\hline 0,09 & $38.551,00$ & - & $3.551,00$ & - \\
\hline 0,1 & $38.498,00$ & $+982,00$ & $3.443,00$ & $+178,00$ \\
\hline 0,2 & $37.999,00$ & $+954,00$ & $2.654,00$ & $+155,00$ \\
\hline 0,25 & $37.779,00$ & - & $2.404,00$ & + \\
\hline 0,3 & $37.559,00$ & $+935,00$ & $2.153,00$ & $+144,00$ \\
\hline 0,4 & $37.148,00$ & $+913,00$ & $1.807,00$ & $+124,00$ \\
\hline 0,5 & $36.776,00$ & $+893,00$ & $1.568,00$ & $+105,00$ \\
\hline 0,6 & $36.446,00$ & $+873,00$ & $1.401,00$ & $+86,00$ \\
\hline 0,7 & $36.146,00$ & $+849,00$ & $1.284,00$ & $+64,00$ \\
\hline 0,8 & $35.878,00$ & $+827,00$ & $1.207,00$ & $+44,00$ \\
\hline 0,9 & $35.633,00$ & $+808,00$ & $1.160,00$ & $+24,00$ \\
\hline 1,0 & $35.407,00$ & $+792,00$ & $1.137,00$ & $+12,00$ \\
\hline 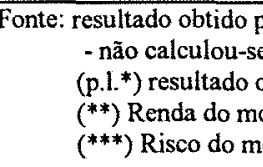 & $\begin{array}{l}\text { a simulação com reduc } \\
\text { s valores pois os interv } \\
\text { tido com a programaçã } \\
\text { elo com redução no cu } \\
\text { lelo com redução no cu }\end{array}$ & $\begin{array}{l}\text { custo de armazenage } \\
\text { entre o modelo básico } \\
\text { ar. }\end{array}$ & $\begin{array}{l}\text { lação foram dife } \\
\text { delo Básico (Ta } \\
\text { delo Básico (Ta }\end{array}$ & \\
\hline
\end{tabular}

Nesta simulação de redução no custo de armazenagem, comparando-se o produtor "indiferente ao risco" com o produtor "avesso ao risco", observa-se que o primeiro obtém 
uma renda líquida média esperada $11,2 \%$ superior, mas assume um risco 26,7 vezes maior na atividade, tornando do ponto de vista prático inaceitáveis estas duas situações. Confirmase assim mais uma vez que a solução ideal ao problema consiste numa combinação intermediária entre elas, tal como $\alpha=0,25$.

Por fim, analisando-se a fronteira eficiente de renda-risco desta simulação, pode-se notar um comportamento idêntico ao obtido pelo Modelo Básico, ressaltando mais uma vez que a inclinação da curva tende a decrescer, a partir de um incremento por parte da renda líquida média esperada. Isto basicamente se deve ao fato da seleção de estratégias que compõem o plano ótimo sofrerem uma série de restrições para conseguirem obter um nível de renda maior, reduzindo-se assim a diversificação das estratégias.

Comparando-se com o Modelo Básico, esta redução no custo de armazenagem faz com que a fronteira eficiente sofra um deslocamento para cima, paralelamente a fronteira originalmente gerada (vide Figura 15), uma vez que a utilização do tempo na armazenagem foi facilitada, gerando possibilidade de obtenção de rendas líquidas maiores (é possível estocar por mais tempo a produção para a busca de um preço futuro melhor)

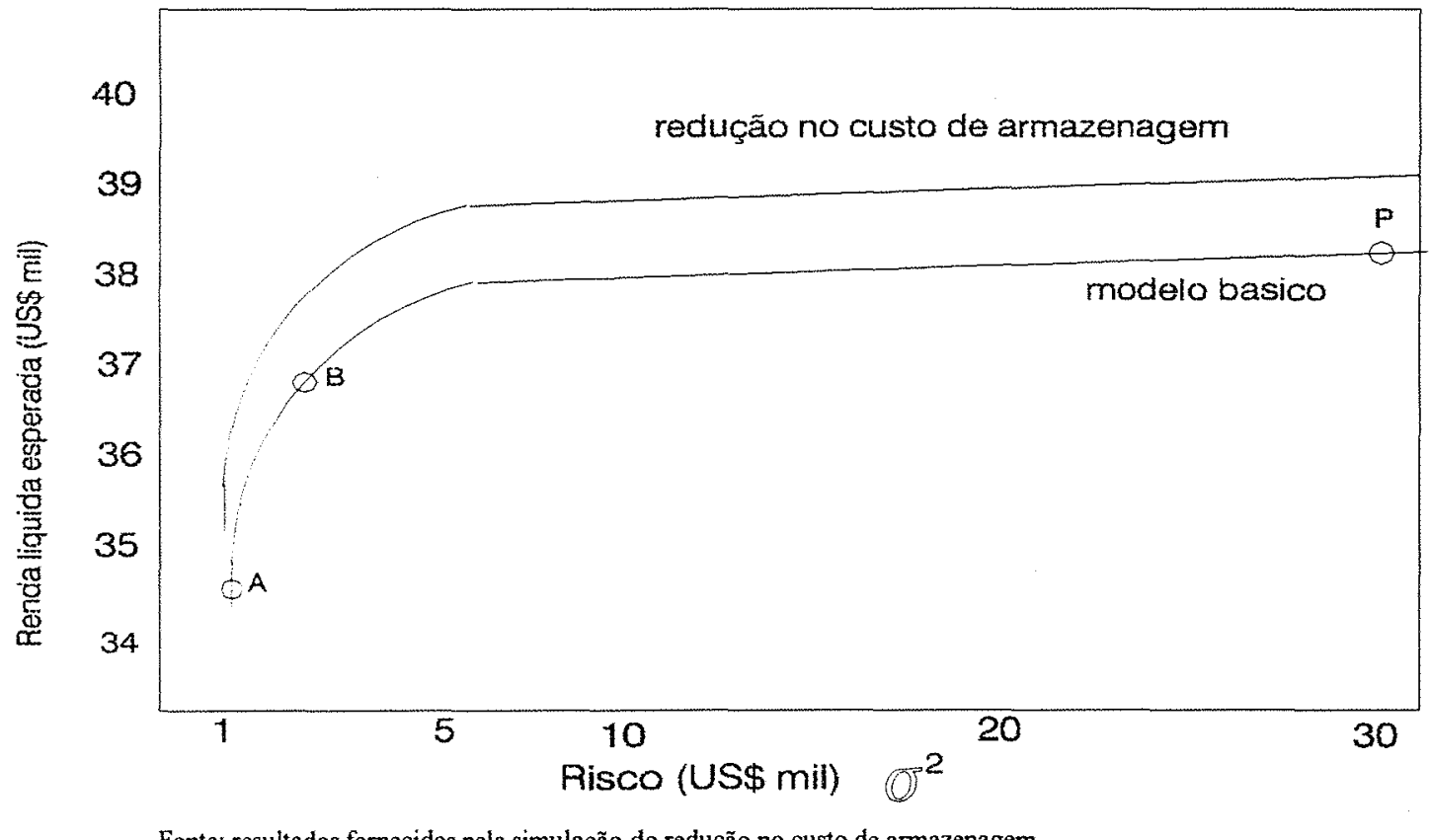

Fonte: resuitados fornecidos pela simulação de redução no custo de armazenagem.

Figura 15 - Fronteira Eficiente da Média-Variância para a Simulação da redução do custo de armazenagem - PR, 1980-95. 


\subsection{5 - O Efeito da Elevação no Custo de Transporte}

O custo de transporte é um outro elemento de decisão no momento de venda da produção agrícola. Com relação a este fato, há geralmente necessidades diversas de transporte durante o ano, havendo sobrecarga nas safras. Com isto, cria-se uma certa sozonalidade de preços durante o ano (na época da colheita existe uma maior demanda por transporte, encarecendo com isto o seu custo). Este eventual custo de transporte mais alto incorrerá em uma maior redução na renda líquida média esperada pelo produtor.

Com relação ao Modelo Básico, o efeito da elevação no custo de transporte em $25 \%$, mostra que o modelo foi pouco sensível para captar este efeito, mantendo praticamente o mesmo comportamento de seleção de alternativas ótimas de comercialização. Nesta simulação de elevação no custo de transporte, a melhor solução ótima consistiu no ponto de tangência do coeficiente de aversão ao risco $\alpha=0,25$, (ou seja, correspondendo ao produtor com "media aversão ao risco") com a curva de isoutilidade. Desta forma a composição ótima de vendas ficou sendo composta pelas seguintes estratégias: $10,4 \% \mathrm{em}$ setembro, $13,5 \%$ em outubro, $14,6 \%$ em novembro, $17,7 \%$ em dezembro, $12,1 \%$ através da estratégia $\mathrm{EC}_{17}, 15,1 \%$ através da estratégia $\mathrm{EC}_{18}, 14,8 \%$ através da estratégia $\mathrm{EC}_{19} \mathrm{e} 1,9 \%$ através da estratégia $\mathrm{EC}_{20}$ (vide Tabela 27)

A este plano ótimo de comercialização corresponde a armazenagem da produção na época da colheita, com venda futura através da seguinte composição mensal de vendas: $0,6 \%$ em abril, $24,5 \%$ em setembro, $27,1 \%$ em outubro, $22,1 \%$ em novembro e 25,7 em dezembro, com grande concentração de vendas nos últimos quatro meses do ano (vide Tabela 28).

Quanto ao produtor com "grande aversão ao risco" $(\alpha=1)$, similarmente ao que ocorreu no Modelo Básico, o modelo com maior custo de transporte proporcionou uma grande diversificação de estratégias de comercialização para a formação de seu plano ótimo de vendas, visando com isto uma redução no risco associado a esta atividade de venda.

Desta forma, obteve-se a seguinte composição ótima de vendas: 0,4\% em março, $0,8 \%$ em junho, $6,2 \%$ em setembro, $8,0 \%$ em outubro, $8,7 \%$ em novembro, $9,9 \%$ em 
dezembro, $6,8 \%$ através da estratégia $\mathrm{EC}_{11}, 3,7 \%$ através da estratégia $\mathrm{EC}_{12}, 5,6 \%$ através da estratégia $\mathrm{EC}_{13}, 5,6 \%$ através da estratégia $\mathrm{EC13}, 3,9 \%$ através da estratégia $\mathrm{EC}_{14}, 6,6 \%$ através da estratégia $\mathrm{EC} 15,5,4 \%$ através da estratégia $\mathrm{EC}_{16}, 7,2 \%$ através da estratégia $\mathrm{EC}_{17}, 8,8 \%$ através da estratégia $\mathrm{EC}_{18}, 8,6 \%$ através da estratégia $\mathrm{EC}_{19}$ e $9,5 \%$ através da estratégia $\mathrm{EC}_{20}$.

Tabela 27 - Percentagem de venda de soja, por Estratégia de comercialização, segundo o coeficiente de aversão ao risco - Simulação da Elevação no custo de transporte - PR - 1980-95.

\begin{tabular}{|c|c|c|c|c|c|c|c|c|c|c|c|c|c|c|}
\hline & & \multicolumn{13}{|c|}{ Estratégias de comercialização de soja (\%) } \\
\hline $\begin{array}{l}\text { Renda } \\
\text { Liquida }\end{array}$ & $\begin{array}{l}\text { Coeficiente } \\
\text { de Aversão }\end{array}$ & $\mathrm{EC}$ & $\mathrm{EC}$ & $\mathrm{EC}$ & $\mathrm{EC}$ & $\mathrm{EC}$ & $\mathrm{EC}$ & $\mathrm{EC}$ & $\mathrm{EC}$ & $\mathrm{EC}$ & $\mathrm{EC}$ & $\mathrm{EC}$ & $\mathrm{EC}$ & $\mathrm{EC}$ \\
\hline $\begin{array}{c}\text { Esperada } \\
\text { (US\$) }\end{array}$ & $\begin{array}{c}\text { ao Risco } \\
(\alpha)\end{array}$ & 7 & 8 & 9 & 10 & II & 13 & 14 & 15 & 16 & 17 & 18 & 19 & 20 \\
\hline $38.169,00$ & $0,0\left(\right.$ p..$\left.^{*}\right)$ & & & & 100 & & & & & & & & & \\
\hline $38.078,00$ & 0,003 & & & & 99,0 & & & & & & & & 1,0 & \\
\hline $38.051,00$ & 0,004 & & & & 87,5 & & & & & & & & 12,5 & \\
\hline $38.030,00$ & 0,005 & & & & 80,0 & & & & & & & 0,9 & 19,1 & \\
\hline $38.011,00$ & 0,006 & & & & 72,6 & & & & & & & 6,3 & 21,2 & \\
\hline $37,979,00$ & 0,008 & & 0,8 & & 62,1 & & & & & & 2,6 & 11,8 & 22,7 & \\
\hline $37.954,00$ & 0,01 & & 4,4 & 0,6 & 54,0 & & & & & & 5,4 & 11,8 & 22,7 & \\
\hline $37.811,00$ & 0,03 & 6,8 & 11,0 & 10,6 & 29,1 & & & & & & 10,3 & 14,9 & 17,3 & \\
\hline $37.702,00$ & 0,05 & 8,5 & 12,2 & 12,5 & 24,1 & & & & & & 11,2 & 15,1 & 16,3 & \\
\hline $37.547,00$ & 0,08 & 9,5 & 12,9 & 13,6 & 21,2 & & & & & & 11,7 & 15,2 & 15,8 & \\
\hline $37.445,00$ & 0,1 & 9,8 & 13,2 & 14,0 & 20,3 & & & & & & 11,9 & 15,3 & 156 & \\
\hline $36.941,00$ & 0,2 & 10,4 & 13,7 & 14,7 & 18,4 & & & & & & 12,2 & 15,4 & 15,2 & \\
\hline $36.692,00$ & 0,25 & 10,4 & 13,15 & 14,6 & 17,7 & & & & & & 12,1 & 15,1 & 14,8 & 4,9 \\
\hline $36.457,00$ & 0,3 & 10,1 & 13,1 & 14,2 & 16,9 & & & & & & 11,7 & 14,6 & 14,3 & 5,2 \\
\hline $36.028,00$ & 0,4 & 9,4 & 12,1 & 13,1 & 15,4 & 1,1 & & & 3,1 & & 10,8 & 13,5 & 13,1 & 8,3 \\
\hline $35.659,00$ & 0,5 & 8,6 & 11,1 & 12,0 & 13,9 & 3,7 & & & 4,8 & 2,2 & 9,9 & 12,3 & 12,0 & 9,4 \\
\hline $35.332,00$ & 0,6 & 8,0 & 10,3 & 11,2 & 12,9 & 5,2 & 1,1 & & 5,9 & 3,7 & 9,2 & 11,4 & 11,1 & 9,9 \\
\hline $35.039,00$ & 0,7 & 7,4 & 9,6 & 10,4 & 11,9 & 5,9 & 2,9 & 1,2 & 6,2 & 4,4 & 8,6 & 10,6 & 10,3 & 9,9 \\
\hline $34.779,00$ & 0,8 & 7,0 & 9,0 & 9,7 & 11,1 & 6,3 & 4,1 & 2,4 & 6,4 & 4,9 & 8,0 & 9,9 & 9,6 & 9,8 \\
\hline $34.541,00$ & 0,9 & 6,6 & 8,4 & 9,2 & 10,4 & 6,6 & 5,0 & 3,3 & 6,5 & 5,2 & 7,5 & 9,3 & 9,0 & 9,6 \\
\hline $34.320,00$ & 1,0 & 6,2 & 8,0 & 8,7 & 9,9 & 6,8 & 5,6 & 3,9 & 6,6 & 5,4 & 7,2 & 8,8 & 8,6 & 9,5 \\
\hline
\end{tabular}

Fonte: resultado obtido pela simulação de elevação no custo de transporte.

$($ p.I.*) resultado obtido pela programaçăo linear.

A este plano ótimo de comercialização corresponde a seguinte composição mensal de vendas: 0,4\% em março, 4,0\% em abril, 6,5\% em maio, 1,8\% em junho, 4,0\% em julho, $6,2 \%$ em agosto, $24,6 \%$ em setembro, $22,2 \%$ em outubro, $13,1 \%$ em novembro e $17,4 \%$ em dezembro.

Para o produtor "indiferente ao risco" $(\alpha=0)$, com elevação no custo de transporte, foi selecionada pelo modelo uma única estratégia de comercialização para a formação de seu 
plano ótimo de vendas da produção. Neste caso, foi selecionada a estratégia $\mathrm{EC}_{10}$, ou seja, armazenar a produção na época da colheita para posterior venda de toda a produção em dezembro.

Tabela 28 - Percentagem de venda de soja, Discriminação mensal, segundo coeficiente de Aversão ao Risco - Simulação da elevação do custo de transporte - PR, 1980-95.

\begin{tabular}{|c|c|c|c|c|c|c|c|c|c|c|}
\hline \multirow[b]{2}{*}{$\begin{array}{c}\text { Coeficiente de } \\
\text { Aversão ao } \\
\text { Risco }(\alpha)\end{array}$} & \multicolumn{10}{|c|}{ Discriminação Mensal de vendas dos Planos Otimos (\%) } \\
\hline & MAR & ABR & MAI & JUN & JUL & $\mathrm{AGO}$ & SET & OUT & NOV & DEZ \\
\hline $0,0\left(\mathrm{p.l}^{*}\right)$ & & & & & & & & & & 100 \\
\hline 0,003 & & & & & & & 0,5 & & & 99,5 \\
\hline 0,004 & & & & & & & 6,3 & & & 93,8 \\
\hline 0,005 & & & & & & & 9,6 & 0,5 & 0,5 & 89,6 \\
\hline 0,006 & & & & & & & 10,6 & 3,2 & 3,2 & 83,0 \\
\hline 0,008 & & & & & & & 13,0 & 8,0 & 6,0 & 73,5 \\
\hline 0,01 & & & & & & & 13,8 & 14,0 & 7,0 & 65,1 \\
\hline 0,03 & & & & & & & 21,0 & 24,0 & 18,1 & 38,0 \\
\hline 0,05 & & & & & & & 22,0 & 25,0 & 20,1 & 32,0 \\
\hline 0,08 & & & & & & & 23,0 & 26,0 & 21,0 & 29,0 \\
\hline 0,1 & & & & & & & 23,6 & 27,0 & 21,7 & 28,0 \\
\hline 0,2 & & & & & & & 24,0 & 28,0 & 22,0 & 26,0 \\
\hline 0.25 & & & & & & & 24,5 & 27,1 & 22,1 & 257 \\
\hline 0,3 & & 1,7 & & & & & 25,0 & 26,0 & 22,0 & 25,8 \\
\hline 0,4 & & 2,8 & 0,6 & & & 1,6 & 24,7 & 26,0 & 19,9 & 24,7 \\
\hline 0.5 & & 3,1 & 1,9 & & 1,1 & 2,4 & 25,6 & 24,6 & 18,2 & 23,0 \\
\hline 0,6 & & 3,3 & 3,0 & & 2,0 & 3,3 & 26,0 & 24,0 & 17,0 & 20,9 \\
\hline 0,7 & & 3,6 & 4,1 & 0,3 & 2,4 & 4,4 & 25,5 & 23,6 & 16,0 & 20,4 \\
\hline 0,8 & & 4,0 & 5,3 & 0,6 & 3,2 & 5.2 & 25,0 & 23,2 & 14,7 & 19,2 \\
\hline 0,9 & & 4,0 & 6,0 & 1,3 & 3,6 & 5,8 & 25,0 & 22,6 & 13,1 & 17,4 \\
\hline 1.0 & 0,4 & 4,0 & 6,5 & 1,8 & 4,0 & 6,2 & 24,6 & 22,2 & 13,1 & 17,4 \\
\hline
\end{tabular}

Fonte: resultado obtido pelo modelo com elevação no custo de transporte.

(p.l.*) resultado obtido por programação linear.

No caso da melhor solução ótima encontrada ou produtor com "média aversão ao risco" $(\alpha=0,25)$, o modelo selecionou um conjunto de alternativas diversificadas como sendo a solução ótima. Com isto, obteve-se uma renda líquida média esperada de US\$ $36.693,00$, com um risco associado de US\$2.393,00, com um coeficiente de variação de 0,13\% e um coeficiente de elasticidade Risco-Renda de 43,3 (vide Tabela 29).

Comparando-se os resultados da simulação com elevação do custo de transporte com a melhor solução obtida pelo Modelo Básico, pode-se observar que a renda líquida média esperada foi reduzida em cerca de $0,38 \%$, com o risco associado crescendo $7,2 \%$.

No caso do produtor "altamente avesso ao risco" $(\alpha=1)$, novamente o modelo proporcionou uma acentuada diversificação, mostrando que o mesmo busca uma redução no 
risco associado a sua atividade de vendas, obtendo desta forma uma renda líquida média esperada de US\$ $34.320,00$, com um risco associado de US\$ $1.132,00$, um coeficiente de variação $0,10 \%$ e um coeficiente de elasticidade Risco-Renda tendendo a $\infty$.

Tabela 29- Renda Líquida Média Esperada, Coeficiente de Aversão ao Risco, Risco associado às Estratégias de Comercialização de Soja e Elasticidade Risco-Renda da Simulação da elevação do custo de transporte - PR, 1980-95.

\begin{tabular}{|c|c|c|c|c|}
\hline $\begin{array}{l}\text { Coeficiente de } \\
\text { Aversão ao Risco } \\
(\alpha)\end{array}$ & $\begin{array}{c}\text { Renda Líquida } \\
\text { Média Esperada } \\
\text { (US\$) }\end{array}$ & $\begin{array}{l}\text { Diferença de renda em } \\
\text { relação ao Modelo } \\
\left.\text { Básico( }{ }^{* *}\right)\end{array}$ & $\begin{array}{c}\text { Risco Associado } \\
\text { (US\$) }\end{array}$ & $\begin{array}{l}\text { Diferença de risco em } \\
\text { relação ao Modelo } \\
\text { Básico(***) }\end{array}$ \\
\hline $0,0\left(\mathrm{p} .1 .^{*}\right)$ & $38.169,00$ & 0 & $30.365,00$ & 0 \\
\hline 0,003 & $38.078,00$ & $-13,00$ & $12.465,00$ & $+3.996,00$ \\
\hline 0,004 & $38.051,00$ & $-22,00$ & $9.841,00$ & $+2.912,00$ \\
\hline 0,005 & $38.030,00$ & $-28,00$ & $8.180,00$ & $+2.082,00$ \\
\hline 0,006 & $38.011,00$ & - & $6.994,00$ & - \\
\hline 0,008 & $37.979,00$ & - & $5.620,00$ & - \\
\hline 0,03 & $37.811,00$ & $-67,00$ & $4.515,00$ & $+329,00$ \\
\hline 0,05 & $37.702,00$ & - & $4.194,00$ & + \\
\hline 0,08 & $37.547,00$ & - & $3.805,00$ & - \\
\hline 0,1 & $37.445,00$ & $-71,00$ & $3.578,00$ & $+313,00$ \\
\hline 0,2 & $36.941,00$ & $-104,00$ & $2.717,00$ & $+218,00$ \\
\hline 0,25 & $36.693,00$ & - & $2.393,00$ & - \\
\hline 0,3 & $36.457,00$ & $-167,00$ & $2.137,00$ & $+128,00$ \\
\hline 0,4 & $36.028,00$ & $-207,00$ & $1.769,00$ & $+86,00$ \\
\hline 0,5 & $35.659,00$ & $-224,00$ & $1.532,00$ & $+69,00$ \\
\hline 0,6 & $35.332,00$ & $-241,00$ & $1.368,00$ & $+53,00$ \\
\hline 0,7 & $35.039,00$ & $-258,00$ & $1.258,00$ & $+38,00$ \\
\hline 0,8 & $34.779,00$ & $-272,00$ & $1.189,00$ & $+26,00$ \\
\hline 0,9 & $34.541,00$ & $-284,00$ & $1.149,00$ & $+13,00$ \\
\hline 1,0 & $34.320,00$ & $-295,00$ & $1.132,00$ & $+7,00$ \\
\hline $\begin{array}{l}\text { onte: resultado obtid } \\
\text { - não calculou } \\
\left.\text { (p.l. }{ }^{*}\right) \text { resultad } \\
\left({ }^{* *}\right) \text { renda do } \\
\left({ }^{* * *}\right) \text { risco do }\end{array}$ & Ho modelo com elev & $\begin{array}{l}\text { o no custo de transporte. } \\
\text { alos entre o Modelo Básic }\end{array}$ & imulac̃̃o foram dif & es. \\
\hline
\end{tabular}

Esta situação de elevação no custo de transporte, se comparada à mesma situação apresentada pelo Modelo Básico, observa uma renda líquida média esperada $0,8 \%$ inferior, ou seja, foi reduzida em US\$295,00. Quanto ao risco associado, o mesmo aumentou em $0,6 \%$, o que corresponde a um aumento de US $\$ 7,00$.

Finalmente, analisando-se o comportamento do produtor "indiferente ao risco" $(\alpha=0)$, o qual busca somente a maximização de sua utilidade esperada e desconsidera de suas análises os riscos de mercado, obteve-se uma renda líquida média esperada de US\$ $38.169,00$, um risco associado de US\$ $30.365,00$, um coeficiente de variação de $0,46 \%$ e 
um coeficiente de elasticidade Risco-Renda tendendo a $\infty$. Comparando-se esta situação com a mesma obtida pelo Modelo Básico, a renda líquida média esperada e o risco associado não sofreram alterações, mantendo-se renda e risco no mesmo nível obtido anteriormente. Isto mostra que esta elevação no custo de transporte não foi suficiente para alterar as combinações ótimas de vendas proporcionadas pelo modelo.

Analisando-se a fronteira eficiente de renda-risco obtida nesta simulação, nota-se que a mesma novamente apresenta um comportamento semelhante ao proporcionado pelo Modelo Básico; e que devido ao aumento de $25 \%$ no custo de transporte tal fronteira sofreu um pequeno deslocamento para baixo, paralelamente a fronteira gerada na situação inicial (vide Figura 16).

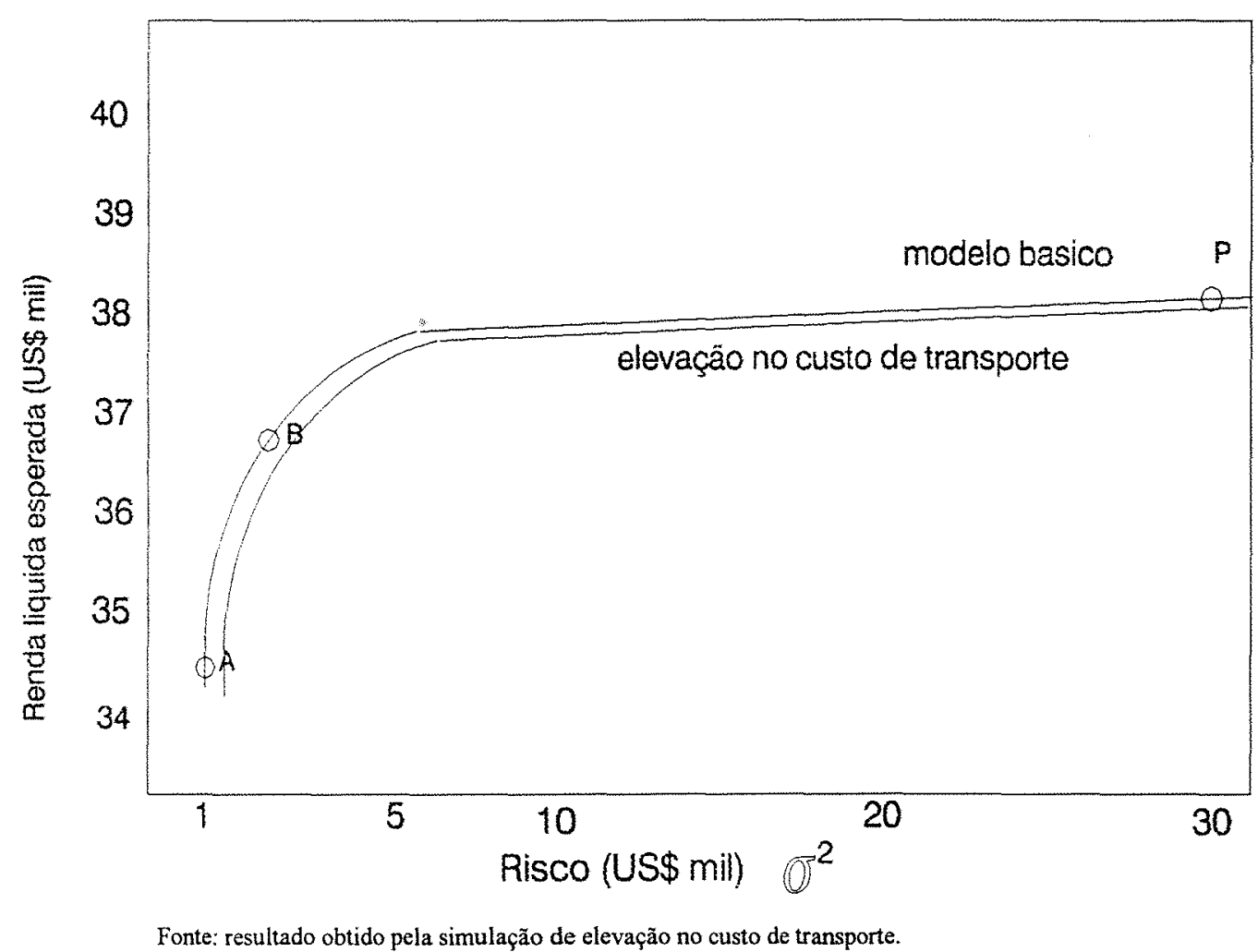

Figura 16 - Fronteira Eficiente da Média-Variância para a Simulação da Elevação no custo de transporte - PR - 1980-95. 


\subsection{6 - O Efeito da Redução no Custo de Transporte}

Diferentemente da situação discutida na secção anterior, uma redução no custo de transporte proporciona uma maior competitividade ao produto, dado que seu custo torna-se mais baixo, aumentando com isto a possibilidade de obtenção de maiores rendas esperadas para os produtores.

Analisando-se os resultados da simulação do modelo com redução no custo de transporte, nota-se que a redução no custo em $65 \%$, com relação às soluções ótimas anteriormente encontradas pelo Modelo Básico, não alterou sensivelmente o início do processo de diversificação para a formação de planos ótimos de comercialização. Tal processo se iniciou em um patamar idêntico ao do Modelo Básico $(\alpha=0,001)$, sendo que a melhor combinação de estratégias de vendas obtidas nesta simulação esteve associado ao coeficiente de aversão ao risco ou $(\alpha)$ igual a 0,2 , o que caracteriza o produtor de "baixa aversão ao risco". A composição ótima de vendas ficou sendo composta pelas seguintes estratégias de vendas: $11,6 \%$ em setembro, $12,9 \%$ em outubro, $11,4 \%$ em novembro, $14,8 \%$ em dezembro, $12,6 \%$ através da estratégia $\mathrm{EC}_{17}, 13,2 \%$ através da estratégia $\mathrm{EC}_{18}, 14,4 \%$ através da estratégia $\mathrm{EC}_{19}$ e 9,3\% através da estratégia $\mathrm{EC}_{20}$ (vide Tabela 30 ).

A este plano ótimo de comercialização corresponde uma venda mensal da produção através da seguinte distribuição: $3,1 \%$ em abril, 28,2\% em setembro, 25,8\% em outubro, $18,0 \%$ em novembro e $25,1 \%$ em dezembro, onde cerca de $97,1 \%$ das vendas estariam concentradas nos últimos quatro meses do ano (vide Tabela 31).

No caso do produtor com "grande aversão ao risco" $(\alpha=1)$, da mesma maneira ao ocorrido no Modelo Básico, foram selecionadas combinações de estratégias de comercialização com grande diversificação para a formação de seu plano ótimo de vendas, concorrendo desta maneira para uma redução do risco associado à atividade de venda.

Desta forma, obteve-se a seguinte combinação de estratégias de comercialização: $3,5 \%$ em março, $0,1 \%$ em abril, $1,2 \%$ em maio, $1,7 \%$ em junho, $5,6 \%$ em setembro, $6,7 \%$ em outubro, 6,8\% em novembro, 7,8\% em dezembro, $8,0 \%$ através da estratégia $\mathrm{EC}_{11}$, $5,3 \%$ através da estratégia $\mathrm{EC}_{12}, 6,5 \%$ através da estratégia $\mathrm{EC}_{13}, 5,2 \%$ através da estratégia 
$\mathrm{EC}_{14}, 5,6 \%$ através da estratégia $\mathrm{EC}_{15}, 5,2 \%$ através da estratégia $\mathrm{EC}_{16}, 6,2 \%$ através da estratégia $\mathrm{EC}_{17}, 7,2 \%$ através da estratégia $\mathrm{EC}_{18}, 7,2 \%$ através da estratégia $\mathrm{EC}_{19}$ e $9,9 \%$ através da estratégia $\mathrm{EC}_{20}$.

Tabela 30 - Percentagem de venda de soja, por Estratégia de comercialização, segundo o coeficiente de aversão ao risco - Simulação da Redução no custo de transporte - PR - 1980-95.

\begin{tabular}{|c|c|c|c|c|c|c|c|c|c|c|c|c|c|c|c|}
\hline & & \multicolumn{14}{|c|}{ Estratégias de comercialização de soja (\%) } \\
\hline $\begin{array}{c}\text { Renda } \\
\text { Líquida }\end{array}$ & $\begin{array}{l}\text { Coeficiente } \\
\text { de Aversão }\end{array}$ & $\mathrm{EC}$ & $\mathrm{EC}$ & $\mathrm{EC}$ & $\mathrm{EC}$ & $\mathrm{EC}$ & $\mathrm{EC}$ & $\mathrm{EC}$ & $\mathrm{EC}$ & $\mathrm{EC}$ & $\mathrm{EC}$ & $\mathrm{EC}$ & $\mathrm{EC}$ & $\mathrm{EC}$ & $\mathrm{EC}$ \\
\hline $\begin{array}{c}\text { Esperada } \\
\text { (US\$) }\end{array}$ & $\begin{array}{c}\text { ao Risco } \\
(\alpha)\end{array}$ & 7 & 8 & 9 & 10 & 11 & 12 & 13 & 14 & 15 & 16 & 17 & 18 & 19 & 20 \\
\hline $43.409,00$ & $0,0\left(\right.$ p.1. $\left.{ }^{*}\right)$ & 100 & & & & & & & & & & & & & \\
\hline $43.364,00$ & 0,001 & 98,5 & & & & & & & & & & 1,5 & & & \\
\hline $43.331,00$ & 0,002 & 72,6 & & & & & & & & & & 27,4 & & & \\
\hline $43.308,00$ & 0,003 & 60,2 & & & & & & & & & & 31,5 & & 8,3 & \\
\hline $43.289,00$ & 0,004 & 52,3 & & & & & & & & & & 31,8 & & 15,8 & \\
\hline $43.258,00$ & 0,006 & 44,5 & & & & & & & & & & 32,1 & & 23,4 & \\
\hline $43.229,00$ & 0,008 & 39,5 & 3,7 & & & & & & & & & 31,1 & & 25,7 & \\
\hline $43.205,00$ & 0,01 & 34,9 & 7,2 & & 4,2 & & & & & & & 28,6 & & 25,0 & \\
\hline $43.115,00$ & 0,02 & 24,7 & 12,8 & & 12,8 & & & & & & & 22,5 & 5,1 & 22,1 & \\
\hline $42.981,00$ & 0,04 & 18,6 & 14,4 & 2,2 & 15,7 & & & & & & & 18,4 & 11,3 & 19,4 & \\
\hline $42.866,00$ & 0,06 & 16,1 & 14,3 & 6,6 & 16,0 & & & & & & & 16,4 & 12,7 & 17,9 & \\
\hline $42.758,00$ & 0,08 & 14,8 & 14,3 & 8,8 & 16,1 & & & & & & & 15,5 & 13,3 & 17,1 & \\
\hline $42.654,00$ & 0,1 & 14,1 & 14,2 & 10,2 & 16,2 & & & & & & & 14,9 & 13,8 & 16,7 & \\
\hline $42.185,00$ & 0,2 & 11,6 & 12,9 & 11,4 & 14,8 & & & & & & & 12,6 & 13,2 & 14,4 & 9,3 \\
\hline $41.783,00$ & 0,3 & 10,1 & 11,6 & 10,9 & 13,5 & 5,1 & & & & 0,6 & & 11,1 & 12,1 & 12,8 & 12,1 \\
\hline $41.438,00$ & 0,4 & 9,0 & 10,5 & 10,2 & 12,2 & & 7,5 & & & 3,5 & 2,1 & 9,9 & 11,1 & 11,5 & 12,6 \\
\hline $41.140,00$ & 0,5 & 8,0 & 9,5 & 9,3 & 11,0 & 8,1 & 0,6 & 2,2 & 0,9 & 4,6 & 3,5 & 8,9 & 10,0 & 10,3 & 12,1 \\
\hline $40.888,00$ & 0,6 & 7,2 & 8,6 & 8,5 & 10,0 & 8,1 & 2,2 & 3,7 & 2,4 & 5,0 & 4,1 & 8,0 & 9,1 & 9,3 & 11,4 \\
\hline $40.667,00$ & 0,7 & 6,7 & 8,0 & 7,9 & 9,2 & 8,1 & 3,4 & 4,7 & 3,4 & 5,2 & 4,6 & 7,4 & 8,4 & 8,6 & 10,9 \\
\hline $40.465,00$ & 0,8 & 6,2 & 7,5 & 7,5 & 8,7 & 8,1 & 4,2 & 5,5 & 4,2 & 5,4 & 4,9 & 6,9 & 7,9 & 8,0 & 10,6 \\
\hline $40.276,00$ & 0,9 & 5,9 & 7,1 & 7,1 & 8,2 & 8,1 & 4,8 & 6,0 & 4,7 & 5,6 & 5,1 & 6,5 & 7,5 & 7,6 & 10,2 \\
\hline $40.098,00$ & 1,0 & 5,6 & 6,7 & 6,8 & 7,8 & 8,0 & 5,3 & 6,5 & 5,2 & 5,6 & 5,2 & 6,2 & 7,2 & 7,2 & 9,9 \\
\hline
\end{tabular}

Esta composição ótima de estratégias de venda observa a seguinte discriminação mensal de vendas: $3,1 \%$ em abril, $28,2 \%$ em setembro, $25,8 \%$ em outubro, $18,0 \%$ em novembro e $25,1 \%$ em dezembro.

Quanto ao produtor "indiferente ao risco" $(\alpha=0)$, igualmente ao que ocorreu no Modelo Básico, selecionou-se uma única estratégia de comercialização para a composição de seu plano ótimo de vendas, plano este que maximiza sua utilidade esperada. Neste caso, 
foi selecionada a estratégia $\mathrm{EC}_{10}$, ou seja, armazenar a produção na época da colheita com posterior venda de toda a produção em dezembro.

Tabela 31 - Percentagem de venda de soja, Discriminação mensal, segundo coeficiente de Aversão ao Risco - Simulação da Redução do custo de transporte - PR, 198095 .

\begin{tabular}{|c|c|c|c|c|c|c|c|c|c|c|}
\hline \multirow{2}{*}{$\begin{array}{c}\text { Coeficiente } \\
\text { de Aversão } \\
\text { ao Risco }(\alpha)\end{array}$} & \multicolumn{10}{|c|}{ Discriminação Mensal de vendas dos Planos Ótimos (\%) } \\
\hline & MAR & $\mathrm{ABR}$ & MAI & JUN & JUL & AGO & SET & OUT & NOV & DEZ \\
\hline $0,0\left(\mathrm{p} .1^{*}\right)$ & & & & & & & 100 & & & \\
\hline 0,001 & & & & & & & 99,3 & 0,8 & & \\
\hline 0,002 & & & & & & & 86,3 & 13,7 & & \\
\hline 0,003 & & & & & & & 80,1 & 15,8 & & 4,2 \\
\hline 0,004 & & & & & & & 76,1 & 15,9 & & 7,9 \\
\hline 0,006 & & & & & & & 72,5 & 16,1 & & 11,7 \\
\hline 0,008 & & & & & & & 68,1 & 19,3 & & 12,9 \\
\hline 0,01 & & & & & & & 61,7 & 21,5 & & 16,7 \\
\hline 0,02 & & & & & & & 47,0 & 26,6 & 2,6 & 23,9 \\
\hline 0,04 & & & & & & & 37,5 & 29,3 & 7,9 & 25,4 \\
\hline 0,06 & & & & & & & 32,8 & 28,9 & 13,0 & 25,0 \\
\hline 0,08 & & & & & & & 31,1 & 28,7 & 15,5 & 24,7 \\
\hline 0,1 & & & & & & & 29,9 & 28,6 & 17,1 & 24,6 \\
\hline 0,2 & & 3,1 & & & & & 28,2 & 25,8 & 18,0 & 25,1 \\
\hline 0,3 & & 4,0 & 2,6 & & & 0,3 & 28,6 & 23,5 & 17,0 & 23,9 \\
\hline 0,4 & & 4,2 & 3,8 & & 1,0 & 1,8 & 28,7 & 22,8 & 15,8 & 17,5 \\
\hline 0,5 & 1,0 & 4,3 & 5,0 & 0,2 & 2,0 & 3,3 & 27,6 & 22,2 & 14,3 & 20,2 \\
\hline 0,6 & 1,9 & 4,4 & 6,0 & 1,0 & 2,8 & 4,3 & 26,5 & 21,5 & 13,1 & 18,5 \\
\hline 0,7 & 2,5 & 4,5 & 6,7 & 1,8 & 3,4 & 5,0 & 25,8 & 20,9 & 12,1 & 17,1 \\
\hline 0,8 & 2,9 & 4,6 & 7,3 & 2,4 & 3,9 & 5,6 & 25,1 & 20,5 & 11,5 & 16,2 \\
\hline 0,9 & 3,3 & 4,6 & 8,4 & 2,7 & 4,2 & 6,0 & 24,6 & 20,1 & 10,9 & 15,4 \\
\hline 1,0 & 3,5 & 4,7 & 9,1 & 3,0 & 4,4 & 6,3 & 24,0 & 19,7 & 10,6 & 14,7 \\
\hline
\end{tabular}

Fonte: resultado obtido pelo modelo com redução no custo de transporte.

(p.l.*) resultado obtido pela programação linear.

No caso do plano ótimo para o "produtor com baixa aversão ao risco" $(\alpha=0,2)$, foram selecionadas alternativas diversificadas de venda, obtendo-se uma renda líquida média esperada de US\$ $42.185,00$, com um risco associado da ordem de US\$2.170,00, um 
coeficiente de variação de $0,11 \%$ e um coeficiente de elasticidade Risco-Renda de 63,5 (Vide Tabela 32).

Tabela 32 - Renda Líquida Média Esperada, Coeficiente de Aversão ao Risco, Risco associado às Estratégias de Comercialização de Soja e Elasticidade RiscoRenda da Simulação da Redução do custo de transporte - PR, 1980-95.

\begin{tabular}{|c|c|c|c|c|}
\hline $\begin{array}{l}\text { Coeficiente de } \\
\text { Aversão ao } \\
\text { Risco }(\alpha)\end{array}$ & $\begin{array}{l}\text { Renda Líquida } \\
\text { Média Esperada } \\
\text { (US\$) }\end{array}$ & $\begin{array}{c}\text { Diferença de } \\
\text { renda em relação } \\
\text { ao Modelo } \\
\text { Básico }(* *)\end{array}$ & $\begin{array}{l}\text { Risco } \\
\text { Associado } \\
\text { (US\$) }\end{array}$ & $\begin{array}{c}\text { Diferença de } \\
\text { risco em relação } \\
\text { ao Modelo } \\
\text { Básico }(* * *) \\
\end{array}$ \\
\hline $0,0\left(\right.$ p. $\left.^{*}\right)$ & $43.409,00$ & $+5.240,00$ & $44.879,00$ & $+14514,00$ \\
\hline 0,001 & $43.364,00$ & - & $18.830,00$ & - \\
\hline 0,002 & $43.331,00$ & $+5.220,00$ & $12.743,00$ & $+1.737,00$ \\
\hline 0,003 & $43.308,00$ & $+5.217,00$ & $10.394,00$ & $+1.925,00$ \\
\hline 0,004 & $43.289,00$ & $+5.216,00$ & $8.882,00$ & $+1.953,00$ \\
\hline 0,006 & $43.258,00$ & - & $7.178,00$ & - \\
\hline 0,008 & $43.229,00$ & - & $6.211,00$ & - \\
\hline 0,01 & $43.205,00$ & $+5.199,00$ & $5.662,00$ & $+731,00$ \\
\hline 0,02 & $43.115,00$ & $+5.179,00$ & $4.721,00$ & $+258,00$ \\
\hline 0,04 & $42.981,00$ & - & $4.021,00$ & - \\
\hline 0,06 & $42.866,00$ & - & $3.614,00$ & - \\
\hline 0,08 & $42.758,00$ & - & $3.302,00$ & - \\
\hline 0,1 & $42.654,00$ & $+5.138,00$ & $3.048,00$ & $-218,00$ \\
\hline 0,2 & $42.185,00$ & $+5.140,00$ & $2.170,00$ & $-329,00$ \\
\hline 0,3 & $41.783,00$ & $+5.159,00$ & $1.686,00$ & $-323,00$ \\
\hline 0,4 & $41.438,00$ & $+5.203,00$ & $1.415,00$ & $-268,00$ \\
\hline 0,5 & $41.140,00$ & $+5.257,00$ & $1.255,00$ & $-208,00$ \\
\hline 0,6 & $40.888,00$ & $+5.315,00$ & $1.171,00$ & $-144,00$ \\
\hline 0,7 & $40.667,00$ & $+5.370,00$ & $1.136,00$ & $-84,00$ \\
\hline 0,8 & $40.465,00$ & $+5.414,00$ & $1.117,00$ & $-46,00$ \\
\hline 0,9 & $40.276,00$ & $+5.451,00$ & $1.113,00$ & $-23,00$ \\
\hline 1,0 & $40.098,00$ & $+5.483,00$ & $1.103,00$ & $-22,00$ \\
\hline
\end{tabular}

Analisando-se esta situação de redução no custo de transporte, nota-se que a renda líquida média esperada aumentou $14,5 \%$, ou seja, teve um incremento da ordem de US\$ 
5.140,00; quanto ao risco associado, o mesmo decresceu $2,8 \%$ o que representa uma redução de US $\$ 329,00$.

Quanto ao produtor "avesso ao risco" $(\alpha=1)$, o modelo selecionou um plano ótimo composto por uma grande diversificação de estratégias de vendas, buscando com isto numa redução do risco associado à atividade de vendas e obtendo desta forma uma renda líquida média esperada de US $\$ 40.098,00$, com um risco associado da ordem de US $\$ 1.103,00$, um coeficiente de variação de $0,08 \%$ e um coeficiente de elasticidade Risco-Renda de 24,0 . Este resultado obtido, mostra que a renda líquida média esperada cresceu $15,8 \%$, ou seja, observou-se um aumento de US\$ $5.483,00$; já o risco associado foi reduziu em $1,9 \%$, o que corresponde a uma diminuição de US $\$ 22,00$.

Finalmente, para o produtor "indiferente ao risco" $(\alpha=0)$, obteve-se uma renda líquida média esperada de US $\$ 43.409,00$, com um risco associado de US $\$ 44.879,00$, um coeficiente de variação de $0,49 \%$ e um coeficiente de elasticidade Risco-Renda tendendo $\infty$. Nota-se assim que houve um incremento na renda líquida média esperada de $13,7 \%$, o que corresponderia a um aumento de US $\$ 5.240,00$, com o risco associado aumentando em $47,8 \%$, o que significaria uma elevação de US $\$ 14.514,00$ no risco.

Nesta mesma simulação de redução do custo de transporte, comparando-se o produtor "indiferente ao risco" com o produtor "avesso ao risco", nota-se que o primeiro obtém um lucro líquido médio esperado 8,3\% maior, mas assume um risco 40,7 vezes maior também, caracterizando como bastante improváveis estas duas situações citadas como condições reais de comportamento.

Analisando-se a fronteira eficiente de Renda-Risco desta simulação, nota-se um comportamento similar à fronteira eficiente obtida pelo Modelo Básico, ressaltando uma vez mais que a inclinação da curva tende a decrescer enquanto ocorre um incremento na renda líquida média esperada (vide Figura 17). Comparativamente ao Modelo Básico, uma redução do custo de transporte proporciona um deslocamento da fronteira para cima, paralelamente à fronteira originalmente gerada. 


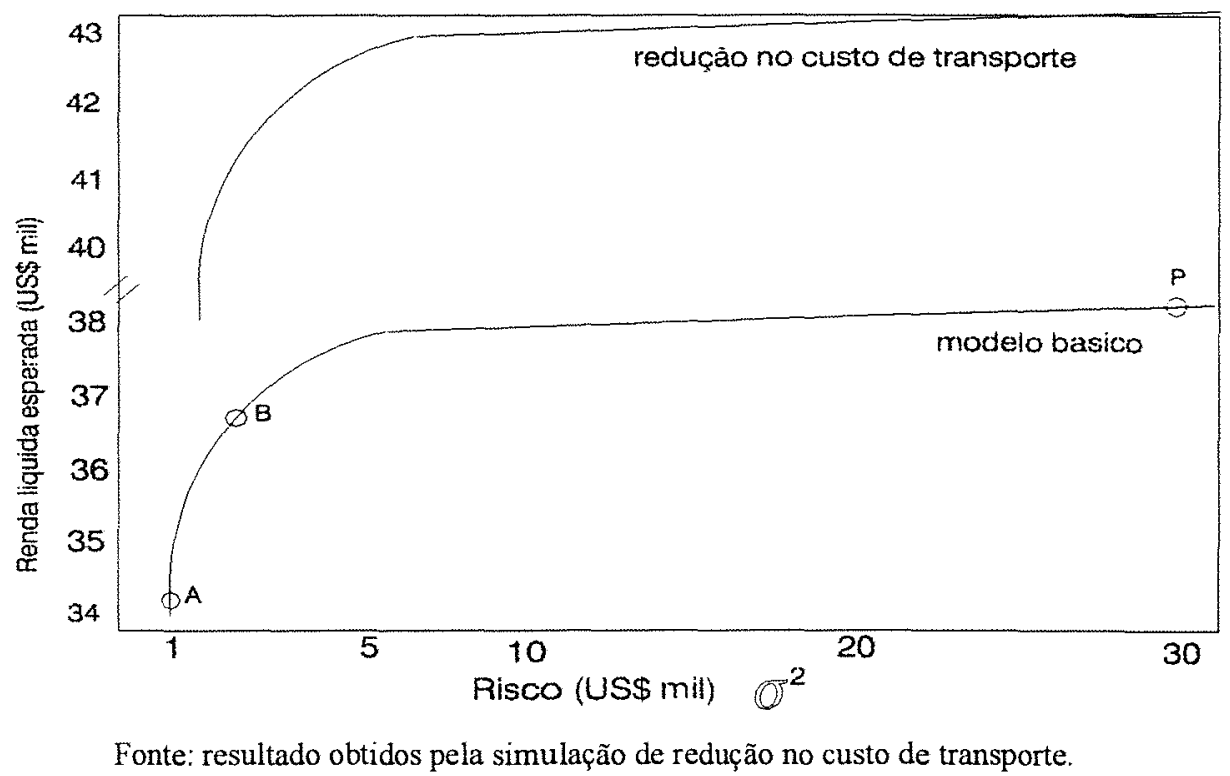

Figura 17 - Fronteira Eficiente da Média-Variância para a Simulação da Redução no custo de transporte - PR - 1980-95.

\section{5 - CONCLUSÕES}

A agropecuária direta ou indiretamente influencia o processo de desenvolvimento econômico do Brasil, e o complexo soja neste contexto destaca-se por ser o principal produto na pauta de exportações do país, além de permitir que outros setores da economia experimentem grande desenvolvimento. A sojicultura nacional pode ser caracterizada por apresentar alto grau de especialização, uso intensivo de tecnologiasavançadas, bons níveis de eficiência produtiva e excelente desempenho externo.

Dentre os principais problemas comuns ao setor destacam-se os fretes, as despesas portuárias e os impostos, que constituem parte do chamado "Custo Brasil", além de uma capacidade ociosa das indústrias de esmagamento e políticas instáveis de financiamento ao produtor. Além destes problemas estruturais, a produção agrícola normalmente é realizada em condições de risco e incerteza e é de dificil planejamento e controle.

Desta forma, a tendência mundial da agricultura vem trazendo à tona uma demanda cada vez maior para que o agricultor torne-se um empresário rural preocupado não somente 
com o aumento de sua eficiência produtiva, mas com toda a gestão da propriedade rural. Além de saber produzir, minimizando os riscos desta atividade, é necessário que se saiba comercializar adequadamente a sua produção para que sejam compensados todos os esforços despendidos com a produção.

A determinação de estratégias eficientes de comercialização de soja frente ao risco de mercado vem de encontro à esta necessidade dos sojicultores, como uma forma de auxílio à tomada de decisão, buscando combinações de melhores preços de venda durante o ano e possibilitando com isto a obtenção de rendas agrícolas maiores, mais estáveis e com menor risco associado.

Os resultados fornecidos pelo Modelo Básico deixam claro que o comportamento dos produtores de soja varia significativamente conforme se altera o coeficiente de aversão ao risco, resultando em conjuntos diferentes de estratégias de comercialização para a formação de seu plano ótimo de vendas.

Para produtores indiferentes ao risco, o modelo quadrático transforma-se em um modelo linear, selecionando uma única estatégia para compor seu plano ótimo, devido ao fato do produtor buscar somente a maximização de seu lucro, não importando o nivel de risco associado.

No caso de produtores altamente aversos ao risco, de maneira diferente, a solução ótima obtida, para manter um determinado nível de renda esperada com risco mínimo, faz uso de várias estratégias para compor seu plano de vendas.

Desta forma, a melhor combinação de estratégias de comercialização de soja frente ao risco de mercado para o período de 1980-95 (ou seja, o ponto de tangência entre a Fronteira Eficiente de Renda-Risco e as Curvas de Isoutildade dos produtores) constitui-se na seleção realizada por produtores com "média aversão ao risco" ( $\alpha$ entre 0,25 e 0,3 ). Tal situação pode ser explicada pela combinação diversificada de vendas implicar uma redução de $92,7 \%$ no risco associado ao plano ótimo de vendas, conseguindo ainda manter uma renda líquida média apenas 3,5\% inferior à solução obtida pela programação linear.

Assim sendo, a maneira mais apropriada de comercializar a soja tendo em vista a redução de risco e da variabilidade na comercialização, seria através da armazenagem da 
produção na época da colheita e a venda em lotes parcelados no mercado disponivel através da seguinte composição mensal de vendas: $3,6 \%$ em abril, $26,1 \%$ em setembro, $24,7 \% \mathrm{em}$ outubro, $19,5 \%$ em novembro e $26,1 \%$ em dezembro, onde $96,4 \%$ das vendas totais estariam concentradas nos últimos quatro meses do ano.

As simulações realizadas com algumas variaveis exógenas do Modelo Básico (taxa de juros, custo de armazenagem e custo de transporte), demonstraram a versatilidade do mesmo, uma vez que foi capaz de fornecer soluções diferenciadas para cada caso, sempre mantendo elevado nivel de retorno esperado com mínimo risco associado.

Finalmente, deve-se enfatizar que os resultados obtidos neste estudo possuem certas limitações oriundas tanto do modelo utilizado quanto das hipóteses simplificadoras que foram utilizadas para representar a realidade e que são válidas exclusivamente para a região analisada. Desta forma, é necessário evitar generalizações que possam ser derivadas da presente análise empírica.

Para estudos futuros, propõem-se a atualização deste trabalho através da utilização da Dominância Estocástica, que vem a ser um ferramental semelhante ao da análise E-V, e comparação dos resultados para a determinação da eficiência de ambos diante de situações de tomada de decisões frente ao risco de mercado. 


\section{REFERÊNCIAS BIBLIOGRÁFICAS}

AGRIANUAL 96 - Anuário Estatístico da Agricultura Brasileira. São Paulo, SP. Editora Argos Comunicação, 1996. 392p.

ASSOCIAÇÃO BRASILEIRA DE AGRIBUSINESS - ABAG - Segurança alimentar, uma abordagem de agribusiness. São Paulo, SP.edições ABAG, 1993. 162p.

BRANCO, A. Isenção eleva preços internos. Gazeta Mercantil, 5 de setembro de 1996. Custo Brasil, p.B-15.

CHIANG, A. Matemática para Economistas, 2a. edição, São Paulo, SP. McGraw-Hill do Brasil, 1982. 684p.

CONTINI, E., ARAÚJO, J.D. \& GARRIDO, W.E. Instrumental econômico para a decisão na propriedade agrícola. Brasília, DF, EMBRAPA-DEP, 1986.

CUTLER, L. \& PASS, D.S. A computer program for quadratic mathematical models to be used for aircrafts design and other applications involving linear constraints. Santa Monica, CA, a report prepared for U.S. Air Force, june 1971. $34 \mathrm{p}$.

CRUZ, E.R. da. Aspectos teóricos sobre a incorporação de risco em modelos de decisão. Brasília, DF, EMBRAPA-DEP, 1986.

DILLON, J.L. An expository review of Bernoullian decision theory. R. Marketing Agric. Econ., 39(1):1-80, mar. 1971.

DOSSA, D. \& DIAS, S.V. Perfil sócio-econômico e tecnológico dos produtores de soja no Paraná. Londrina, PR, CNPso/EMBRAPA, 1987. 19p.

EMPRESA BRASILEIRA DE PESQUISA AGROPECUÁRIA. Departamento de difusão de tecnologia, Brasília, DF. Planejamento da Propriedade Agrícola Modelos de decisão, EMBRAPA-DDT, 1986. 300p.

HENDERSON, J.M. \& QUANDT, R.E. Teoria Microeconômica - uma abordagem matemática, 2a. edição, São Paulo, SP. Livraria Pioneira editora, 1976. 417p. 
INSTITUTO BRASILEIRO DE ECONOMIA. Centro de estudos agrícolas.

Agroanalisys, 3, vol. 14, São Paulo, SP. 15 de Novembro de 1994. 48p.

IPARDES - Paraná - Algumas Informações. Instituto Paranaense de Desenvolvimento Econômico e Social, Curitiba, PR. 1994. 30p.

JANK, M.S. A inserção do Brasil e do setor cooperativo no mercado mundial de produtos agroindustrializados. Piracicaba, ESALQ/USP/FEALQ, 1990, 196p.

LARSON, D.W. Competitiveness in world soybeans markets. In: V seminário sobre problemas e perspectivas. Piracicaba, 9 a 21 de Setembro de 1989, Anais, p.73-100.

LOPES, M.de.R. Os novos sistemas de financiamento das safras. Agroanalysis, Rio de janeiro,v. 14, n.3, p.10-12, nov. 1994.

LOPEZ, R.E. An evaluation of quadratic programming and the MOTAD model as aplied to farm planning under uncertainty. British Columbia, University of British Columbia, 1977, 118p. (tese de Master of Science)

MANCHETE RURAL. Corredores tornam a soja mais competitiva no mercado externo. Rio de janeiro: Bloch, ano 11, n. 7, jul. 1996.

MARKOWITZ, $\mathrm{H}$. Portfolio selection; efficient diversification of investments. New York, John Wiley, 1959.

MARQUES, P.V. Riscos na Comercialização e Mercado Futuro. Piracicaba,SP. Série Didática n ${ }^{\circ}$ 71. DESR/ESALQ/USP. 1992, 9 p.

MATLAB with simulink. User's guide. Natick, MA. The Mathworks, Inc. 1993.

MENDES, J.T.G. The selection of marketing strategies under price risk: the case of brasilian soybeans. Columbus, Ohio, The Ohio State University, 1980.(Tese de Ph.D.).

MENDES, J.T.G. \& GUIMARÃES, V.D.A. Perspectivas para a Safra 1995-96 Curitiba, PR. julho/1995. Documento técnico, 55p.

MINISTÉRIO DA AGRICULTURA. A soja no Brasil: História e Estatística. Londrina, CNPSo/EMBRAPA, 1987, 61p.

NORONHA, J.F. Projetos Agropecuários, Administração Financeira, Orçamentação e Avaliação Econômica. FEALQ, Piracicaba, SP, 1981. 
ORGANIZAÇÃO DAS COOPERATIVAS DO ESTADO DO PARANÁ. Cooperativas: caminhos macroeconômicos para as cooperativas paranaenses - desafios e oportunidades. Curitiba, PR, OCEPAR, 1996.172p.

PEIXOTO, H. Períodos ótimos de venda de soja face ao risco de mercado. Porto Alegre, RS, Universidade Federal do Rio Grande do Sul, 1976. (Dissertação de mestrado)

PEREIRA, E.N.C. Bolsa de commodities: mercado futuro. Rio de Janeiro, Ed da Fundação Getúlio Vargas, 1985, 69p.

SERVIÇO NACIONAL DE APRENDIZAGEM RURAL - Produtor na administração rural. Curitiba, PR, SENAR, 1996. 76p.

SOUZA, F.D.B. de. Dominância Estocástica Versus Estabilidade na Seleção de Genótipos. Piracicaba, SP, Universidade de São Paulo - ESALQ, 1990. 115 p. (Dissertação de mestrado)

TAHA, H. A. Operations Research: An Introduction, 2nd edition, MacMillan Publishing Co., Inc., New York, 1976.

TAKAYAMA, T. \& BATterhaM, R.L. Portfolio Selection and Resource Allocation for Financial and Agricultural Firms With the Rand QP360 Quadratic Programming Code. Ilinois, DAE - University of Ilinois at UrbanaChampaign, 1972 19p.

VASCONCELOS, M de F.S.de Competitividade do Comercio Internacional de Soja. Piracicaba, SP, Universidade de São Paulo - ESALQ, 1994.92 p. (Dissertação de mestrado) 
A pêndices 


\section{APÊNDICE 1}

\section{A Função Quadrática de Utilidade e e Análise E-V.}

A função de utilidade de forma quadrática, expressa em termos de valores de $\{x\}, o$ conjunto dos possiveis resultados, pode assumir a seguinte forma,

$$
\mathrm{U}(\mathrm{x})=\mathrm{x}+\mathrm{bx}^{2}
$$

Devido às condições de incerteza de resultados, o que existe de fato é uma função de utilidade esperada, que pode ser obtida pela aplicação das propriedades de esperança matemática, ou seja

$$
\mathrm{E}[\mathrm{U}(\mathrm{x})]=\mathrm{E}(\mathrm{x})+\mathrm{b} \cdot \mathrm{E}\left(\mathrm{x}^{2}\right)
$$

Esta nova função gerada pode passar a ser expressa em termos dos momentos das distribuições, bastando para isso que se verifique que a variância é definida como

$$
\begin{gathered}
\mathrm{V}(\mathrm{x})=\mathrm{E}[\mathrm{x}-\mathrm{E}(\mathrm{x})]^{2} \\
\mathrm{~V}(\mathrm{x})=\mathrm{E}\left\{\mathrm{x}^{2}-2 \cdot \mathrm{x} \cdot \mathrm{E}(\mathrm{x})+\left[\mathrm{E}(\mathrm{x})^{2}\right\}\right. \\
\mathrm{V}(\mathrm{x})=\mathrm{E}\left(\mathrm{x}^{2}\right)-2 \cdot \mathrm{E}(\mathrm{x}) \cdot \mathrm{E}(\mathrm{x})+[\mathrm{E}(\mathrm{x})]^{2} \\
\mathrm{~V}(\mathrm{x})=\mathrm{E}\left(\mathrm{x}^{2}\right)-[\mathrm{E}(\mathrm{x})]^{2}
\end{gathered}
$$

que reordenada resulta em

$$
E\left(x^{2}\right)=[E(x)]^{2}+V(x)
$$

Substituindo em (24), chega-se a

$$
E[U(x)]=E(x)+b \cdot[E(x)]^{2}+b \cdot V(x)
$$

que corresponde a forma final da função de utilidade esperada, onde a utilidade é uma função da média, $\mathrm{E}(\mathrm{x})$, e da variância, $\mathrm{V}(\mathrm{x})$, dos possíveis resultados. 


\section{APÊNDICE 2 \\ CONTRATOS DE PRODUÇÃO ANTES DA COLHEITA ${ }^{1}$}

\section{1) Soja verde}

É um contrato de compra e venda de soja verde, e tratado como contrato mercantil dentro dos códigos comercial e civil para entrega futura, com preços fixos ou a fixar, mas que também admite um sistema de negociação de preços das cooperativas, cuja finalidade principal é a obtenção de recursos financeiros para o plantio da safra. Há modalidades de escambo (troca de produtos) para a obtenção de insumos, substituindo o custeio tradicional. Para operar, o produtor procura uma cooperativa ou uma empresa que esteja financiando "ha folha" e assina um contrato de adiantamento de recursos para o custeio. Definida a quantidade a ser entregue, as características do produto - maturação, teores de umidade, impureza e percentual de quebrados - o prazo (data) e o armazém da entrega podem ser fixados. O preço é fixado na época do plantio correspondente à quantidade acordada, procurando antecipar o preço futuro na safra. Pode também haver a modalidade preço a fixar, e mesmo desconto de encargos financeiros, "por dentro" dos preços fixados antecipadamente.

\section{2) CM-G - Certificado de Mercadoria com Emissão Garantida}

É um contrato mercantil de venda e compra de produtos agrícolas e agro-industriais. Existem basicamente duas modalidades disponíveis: o CMDG, Certificado de Mercadoria com Emissão Garantida - Entrega Física Disponivel, para quem tem o produto e para venda à vista, e entrega fisica da mercadoria no ato; e o CMFG, Certificado de Mercadoria com Emissão Garantida - Entrega Futura Garantida, para entrega efetiva da mercadoria em data no futuro, com pagamento à vista. O CMDG é um certificado para venda (e ampla negociação) de mercadorias disponíveis. O CMFG, certificado para venda antecipada da mercadoria a ser produzida, destina-se a levantar recursos, seja para o plantio das safras (substitui o custeio), seja para o aproveitamento dos preços remunerados na entressafra.

\footnotetext{
${ }^{1}$ LOPES, M.R. Os novos sistemas de financiamento das safras. Agroanalysys, Rio de Janeiro, 1994.
} 
estabelecimento rural, ou admitir a entrega do produto no armazém credenciado, para depois o classificar. De posse do Certificado de classificação, procura um banco credenciado, que faz a fiança bancária, contra garantia real, com base em cadastro e na tradição do produtor. $\mathrm{O}$ banco registra $\mathrm{O} \mathrm{CMDG}$ na central de registros e custodia 0 contrato, estando o produtor livre para negociar com o corretor a venda do produto (uma vez que a central emite o boleto de venda). Pelo CMFG o produtor faz o seu cadastro no banco e com base em um limite operacional, emitindo o documento em si, no qual declara a classificação compromissada da mercadoria, a quantidade a ser vendida, a data e o armazém de entrega do produto, por ocasião da safra.

De qualquer forma, de uma maneira geral, o CM-G, CMDG ou CMFG, é livremente negociado no mercado, com base na qualidade da mercadoria, quantidade, local e prazo de entrega.

\section{3) CPR - Cédula de Produto Rural}

É um ativo financeiro, sem incidência de impostos sobre operações de crédito, câmbio e seguro, ou relativas a títulos ou valores mobiliários, com promessa de entrega futura de produtos rurais. Destina-se, portanto, a viabilizar ao setor produtivo a alavancagem de recursos para custear os empreendimentos, através de venda antecipada, à vista, de parte da produção própria, substituindo o tradicional custeio. Para poder operar, o produtor/emitente deve procurar um banco que opere com a CPR e declarar seu interesse em operar com 0 título.

Os compradores podem ser agroindústrias, exportadores, fornecedores de máquinas e insumos agropecuários e demais investidores, inclusive pessoas físicas. O título é de operacionalidade simples, sendo a CPR, enquanto vincenda, considerada como ativo financeiro, sem incidência de ICMS e requer a realização de seguro contra frustração de safra.

O valor é livremente pactuado entre as partes, de acordo com os preços antecipados de mercado na data da entrega da mercadoria ao armazém. O preço pode ser, portanto, 
livremente ajustado entre as partes, de acordo com o preço praticado nas vendas antecipadas à vista, para entrega futura da mercadoria.

\section{4) CLB - Commodity Linked Bond (Título Mercantil lastreado por Commodities).}

É um contrato mercantil de compra e venda de commodity, isto é, com emissão lastreada por commodity, de recebimento à vista e compromisso contratual de entrega fisica. O CLB é específico para cada emitente, ou para grupos de emitentes.

A finalidade básica deste título é a obtenção de recursos de capital de giro para empresários/fazendeiros, mediante a venda a valores pré-fixados de qualquer commodity com entrega futura. Há possibilidade da contratação da operação por quatro anos, com comprometimento de entrega de $25 \%$ do volume total pactuado em cada ano, substituindo o custeio tradicional. A operação pode contar com grupos de cinco a vinte produtores que reunam tradição, tecnologia e elevada produtividade formando, as chamadas "parcerias em tecnologia e comercialização".

O grupo normalmente faz contato com uma empresa local associada à ARB (Ativos Reais do Brasil), ao nivel local. Definidos o valor de transação, os volumes e as garantias, o grupo realiza uma emissão de títulos e a ARB procura colocá-los junto ao mercado secundário.

No vencimento dos títulos, o detentor dos mesmos pode optar ou pelo recebimento de produto fisico, ou pelo recebimento do valor líquido de custos ou impostos, mandando vender o produto; ou ainda pelo recebimento do principal, mais correção, juros e taxas, de acordo com o que foi pactuado. 


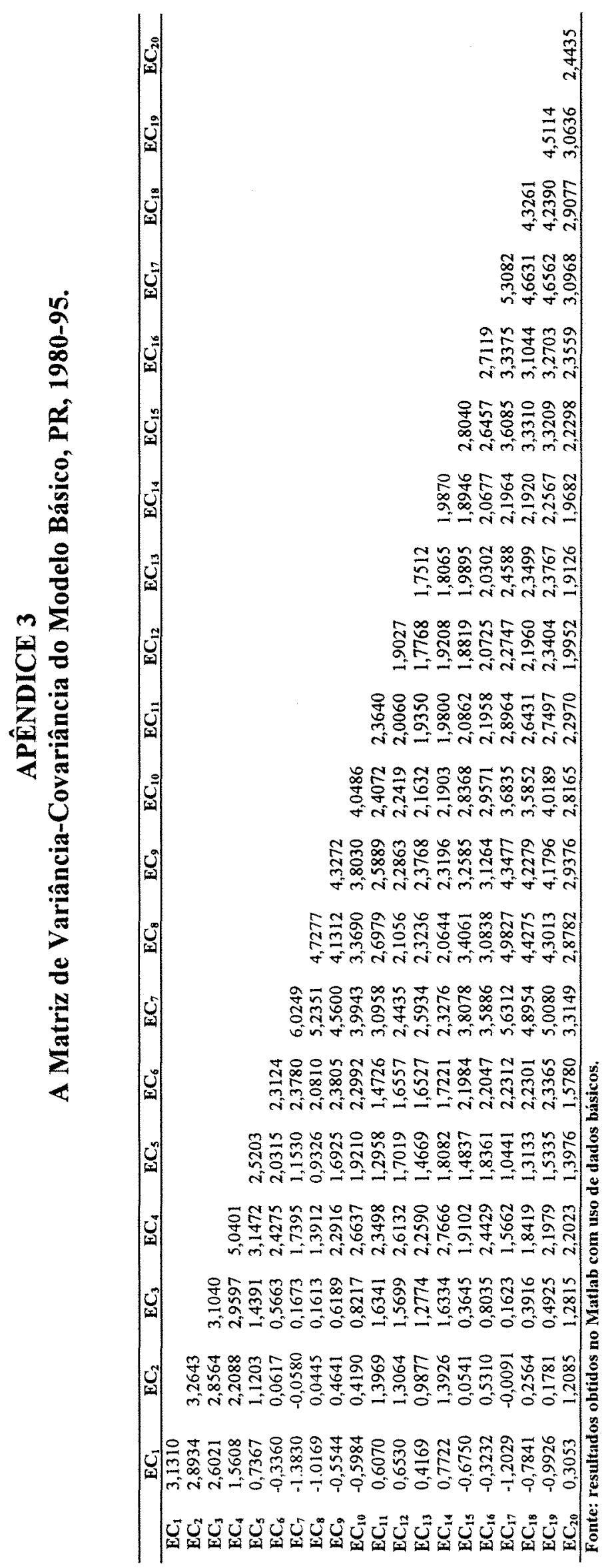




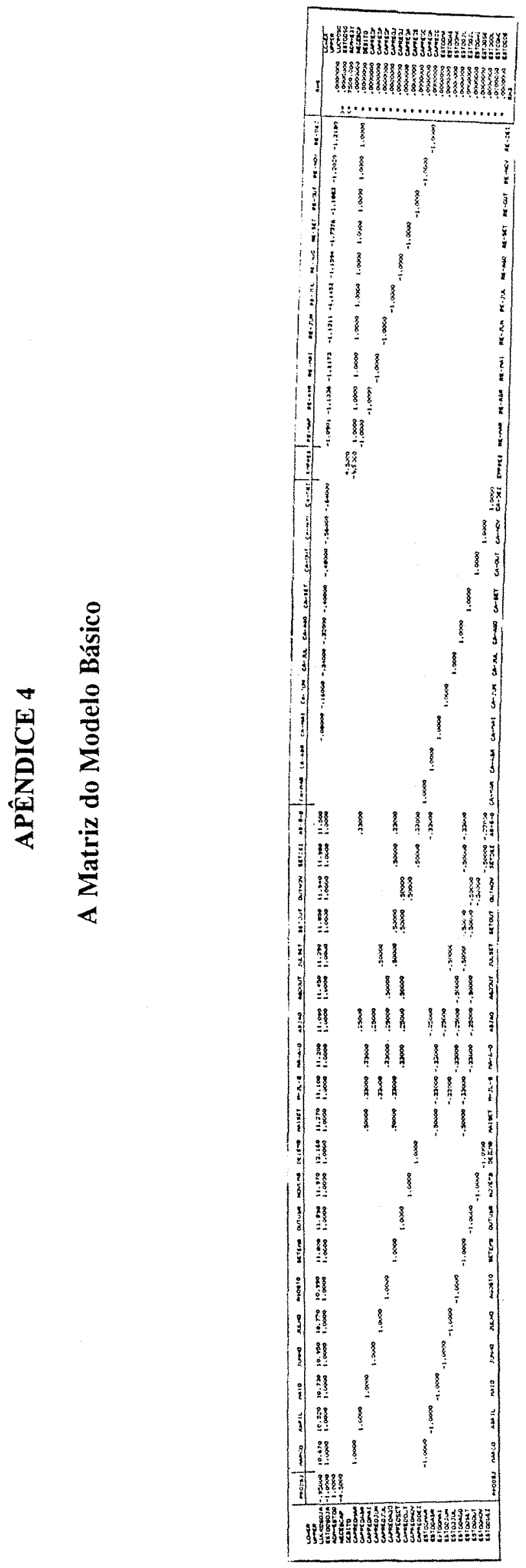




\section{APÊNDICE 5}

\section{A Rotina do Modelo Básico utilizada pelo GAMS}

\$TITLE PORTFOLIO OTIMO

*Estrategias de comercializacao de soja - MODElo QUADRATICO.

SETS I estrategias /E ${ }^{\star} E 20 /$

$\mathrm{J}$ despesas mensais $/ \mathrm{M} 1 * \mathrm{M} 2 \mathrm{O} /$;

TABLE $P(I, J)$ precos medios recebidos por estraregia por mes

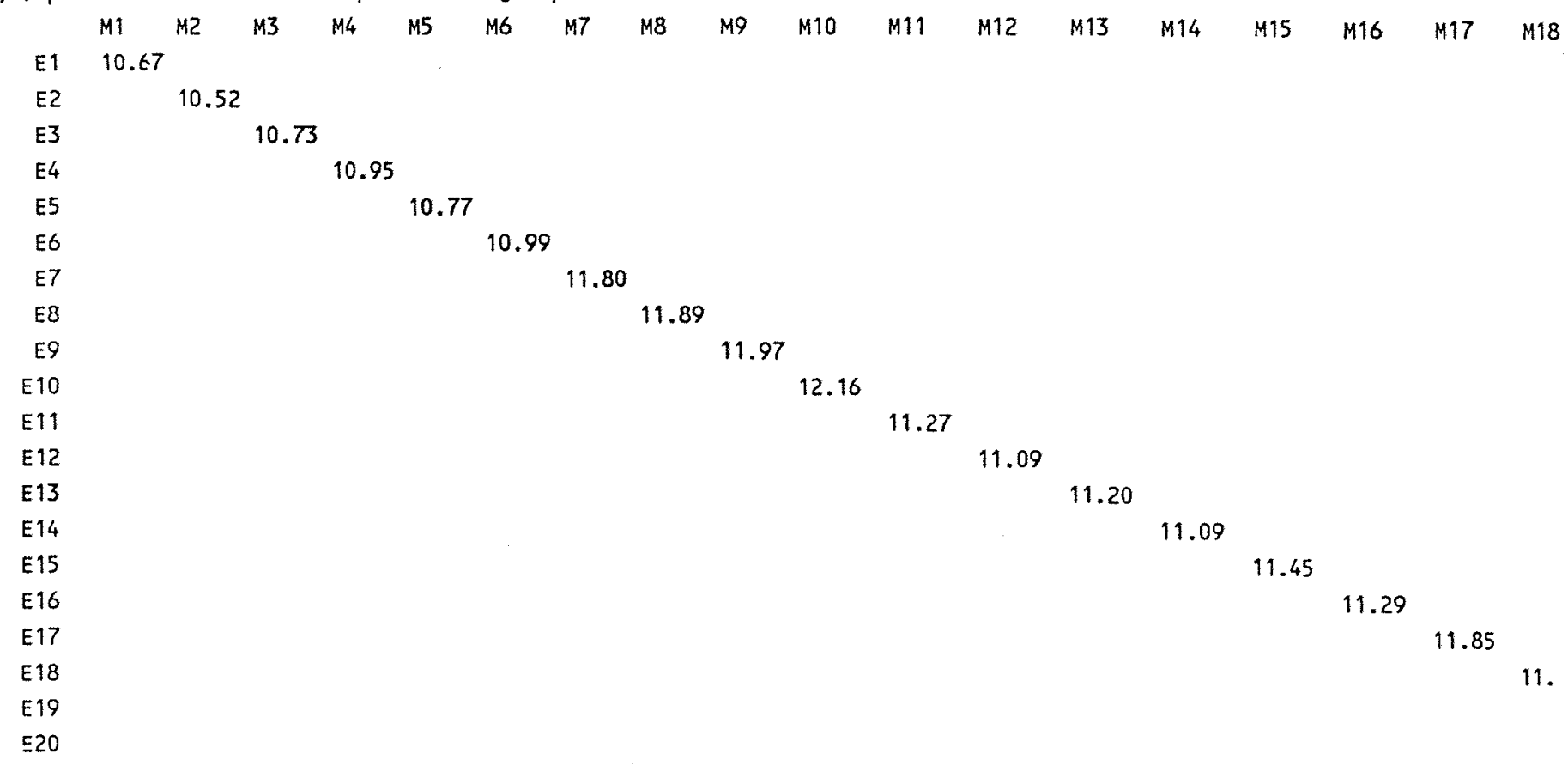

TABLE $A(I, J)$ custo de armazenagem por estrategia por mes

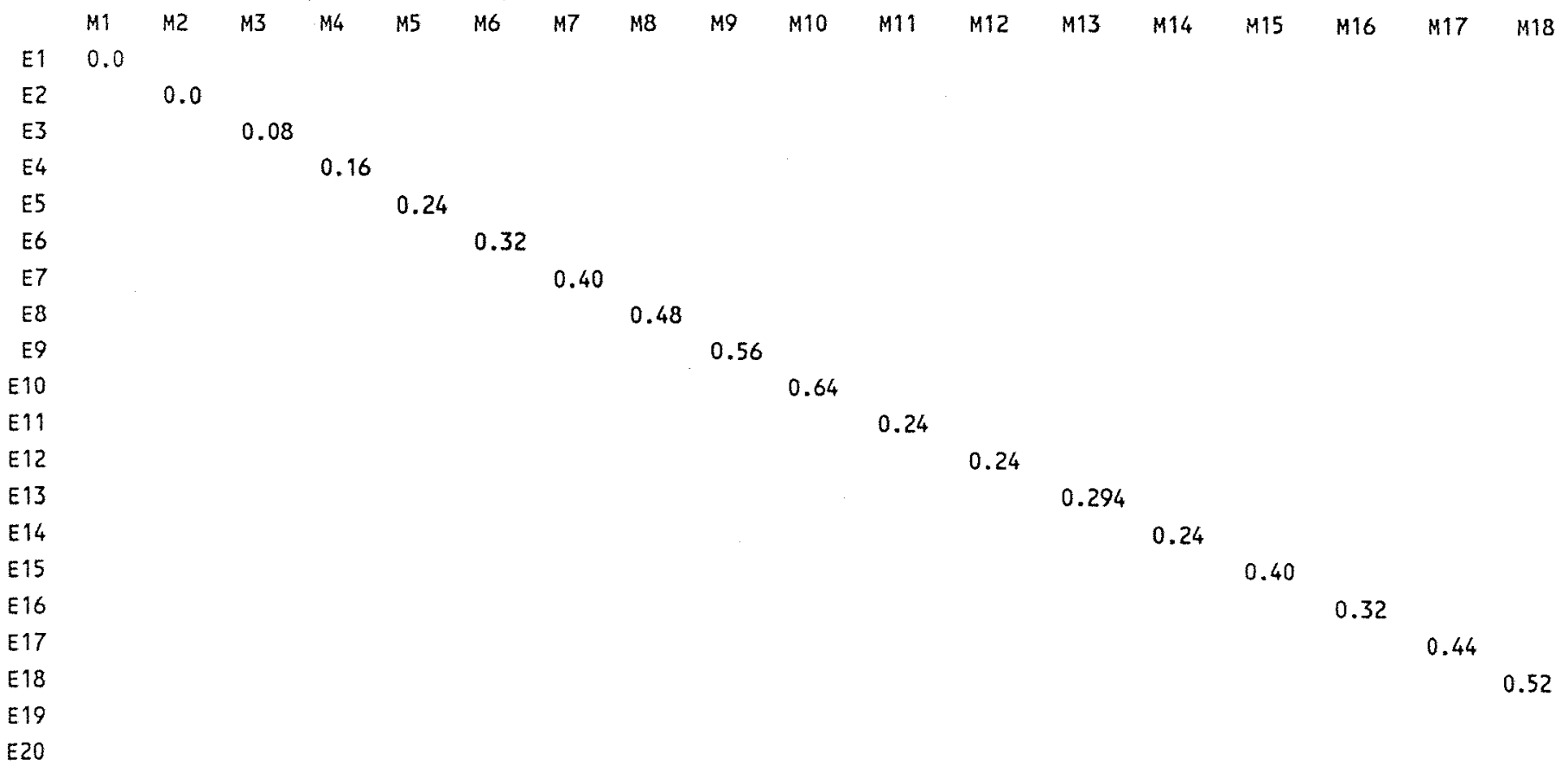


TABLE $T(1, j)$ custo de transporte por estrategia por mes

\begin{tabular}{|c|c|c|c|c|c|c|c|c|c|c|c|c|c|c|c|c|c|c|}
\hline & M1 & $M 2$ & M3 & $M 4$ & $M 5$ & MG & M7 & M8 & M9 & M10 & M11 & $M 12$ & $M 13$ & $M 14$ & M15 & M16 & M17 & $M 18$ \\
\hline E1 & 0.40 & & & & & & & & & & & & & & & & & \\
\hline E2 & & 0.40 & & & & & & & & & & & & & & & & \\
\hline E3 & & & 0.40 & & & & & & & & & & & & & & & \\
\hline E4 & & & & 0.30 & & & & & & & & & & & & & & \\
\hline$E 5$ & & & & & 0.25 & & & & & & & & & & & & & \\
\hline E6 & & & & & & 0.20 & & & & & & & & & & & & \\
\hline E7 & & & & & & & 0.10 & & & & & & & & & & & \\
\hline$E 8$ & & & & & & & & 0.05 & & & & & & & & & & \\
\hline E9 & & & & & & & & & 0.00 & & & & & & & & & \\
\hline E10 & & & & & & & & & & 0.00 & & & & & & & & \\
\hline E11 & & & & & & & & & & & 0.25 & & & & & & & \\
\hline$E 12$ & & & & & & & & & & & & 0.249 & & & & & & \\
\hline E13 & & & & & & & & & & & & & 0.216 & & & & & \\
\hline E14 & & & & & & & & & & & & & & 0.236 & & & & \\
\hline E15 & & & & & & & & & & & & & & & 0.126 & & & \\
\hline E16 & & & & & & & & & & & & & & & & 0.176 & & \\
\hline E17 & & & & & & & & & & & & & & & & & 0.076 & \\
\hline E18 & & & & & & & & & & & & & & & & & & 0.0 \\
\hline$E 19$ & & & & & & & & & & & & & & & & & & \\
\hline$E 20$ & & & & & & & & & & & & & & & & & & \\
\hline
\end{tabular}

TABLE $R(L, J)$ custo de repagamento por estrategía por mes

\begin{tabular}{|c|c|c|c|c|c|c|c|c|c|c|c|c|c|}
\hline & M4 & M2 & M3 & 144 & M5 & MG & M7 & M8 & M9 & M10 & M11 & M12 & M13 \\
\hline El & 4.9055 & & & & & & & & & & & & \\
\hline$\varepsilon 2$ & & 4.9662 & & & & & & & & & & & \\
\hline E3 & & & 5.0279 & & & & & & & & & & \\
\hline$E 4$ & & & & 5.090 & & & & & & & & & \\
\hline E5 & & & & & 5.1534 & & & & & & & & \\
\hline E6 & & & & & & 5.2173 & & & & & & & \\
\hline ET & & & & & & & 5.2821 & & & & & & \\
\hline E8 & & & & & & & & 5.3474 & & & & & \\
\hline E9 & & & & & & & & & 5.4140 & & & & \\
\hline$\varepsilon 10$ & & & & & & & & & & 5.48 & & & \\
\hline
\end{tabular}

E11 $\quad 5.1550$

E12

E13

E14

E15

E16

E17

E18

E19

E20

TABLE VAR $(I, J)$ matriz de variancia-covariancia

\begin{tabular}{|c|c|c|c|c|c|c|c|c|c|c|c|c|c|c|}
\hline & & M2 & M3 & 14 & 5 & M6 & & M8 & M9 & 10 & 111 & 112 & M13 & 114 \\
\hline E1 & & & & & .7367 & -0.3360 & 1.3830 & & & & & & & .77 \\
\hline$E 2$ & 34 & 643 & 564 & 088 & 1203 & 0617 & .0580 & & & & 969 & 3064 & 9877 & .39 \\
\hline E3 & & & & & & & & & & & & & & 1.63 \\
\hline$E 4$ & 5608 & 2088 & 9597 & 0401 & & .4275 & & & & 37 & & & 2590 & .76 \\
\hline ES & & & & & & & & & & & & & & .80 \\
\hline E6 & 60 & 0617 & .5663 & 4275 & .0315 & 124 & 780 & & & & & & 527 & 1.72 \\
\hline$E 7$ & & & & & & & & & & & & & & .32 \\
\hline$E 8$ & 69 & .0445 & & & & & & & & & & & & 2.06 \\
\hline EQ & 0.5544 & & & & & & & & & & & 863 & & 2.31 \\
\hline 10 & 0.5984 & & & & & & & & & & & & & 2.19 \\
\hline 1 & & & & & & & & & & & & & & 1.98 \\
\hline 2 & .6530 & & & & & & & & & & & 027 & & 1.92 \\
\hline 3 & & & & & & & & & & & & & & 1.80 \\
\hline 4 & .7722 & 3926 & & 7666 & .8082 & & & & & & & 208 & & 1.98 \\
\hline 5 & 0.6751 & 0541 & 3645 & & & & & & & & & & & 1.89 \\
\hline 6 & -0.3232 & 0.5310 & .8035 & 2.4429 & & & & & & & & 0725 & 302 & 2.06 \\
\hline 17 & -1.2029 & -0.0091 & & & & & & & & & & 2747 & 2.4588 & 2.19 \\
\hline 18 & -0.7841 & .2564 & 0.3916 & 1.8419 & & & & & & 3.5852 & 2.6431 & 2.1960 & 2.3499 & 2.19 \\
\hline 19 & -0.9926 & & & & & & & & & & & & 2.3767 & 2.25 \\
\hline 20 & 0.3053 & 1.2085 & 1.2815 & 2.2023 & 1.3976 & 1.5780 & 3.3149 & 2.8782 & 2.9376 & 2.8165 & 2.2970 & 1.9952 & 1.9126 & 1.96 \\
\hline
\end{tabular}


SCALAR C custo variavel

10.951

ALPHA coeficiente de aversao ao risco

10.25/;

VARIABLES $X(I, J)$ quantidade de soja vendida atraves da estrategia $i$ no mes $j$

VEN quantidade de soja vendida

2 lucro maximo;

POSITIVE VARIABLES $X$;

EQUATIONS

FOB define funcao objetivo

RESTRVND define venda de soja

VENDAEFET quantidade de soja vendida na estrategia $i$;

FOB... $Z=E=\operatorname{SUM}((I, J),(P(I, J)-(A(I, J)+T(I, J)+R(I, J)+C)) * X(I, J))-(\operatorname{SUM}((I, J), X(I, J) * X(I, J) * V A R(I, J) * A L P H A)) ;$

RESTRVND.. SUM $((I, J), X(I, J))=L=1.0$;

VENDAEFET.. VEN $=E=\operatorname{SUM}((I, J), X(I, J))$;

MOOEL SOJA /ALL/;

SOLVE SOJA USING NLP MAXIMIZING $Z$;

DISPLAY X.L, Z.L; 